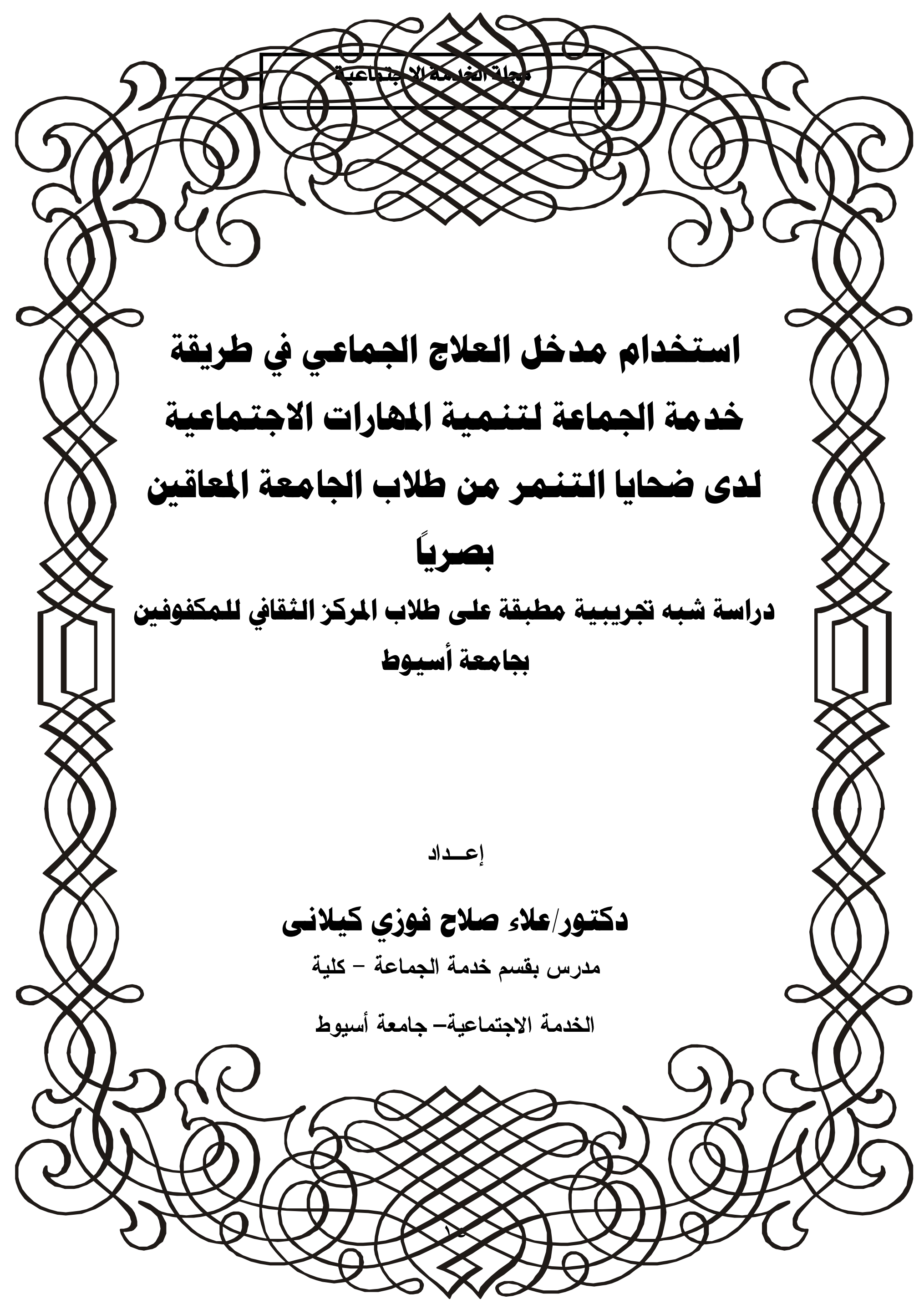


- مجلة الخدمة الاجتماعية 


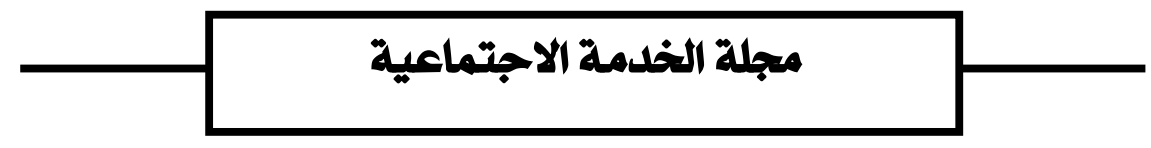

أولاً: مدخل لمشكلة الدراسة:

يمثل العنصر البشري من الثباب عماد الأمة وأملها في مستقبل فيه ثقدم ورفعة،

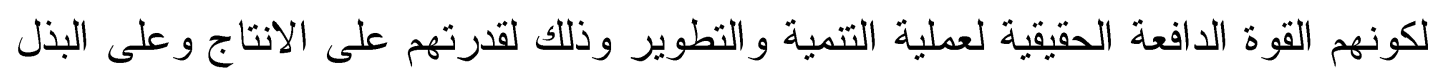

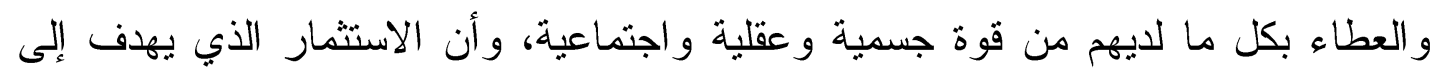

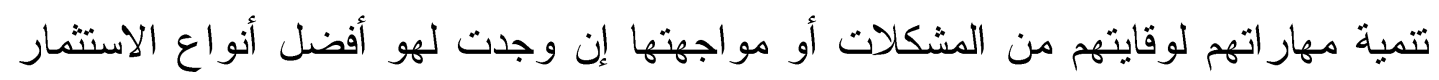
لما له من مردود كبير عليهم و على المجتمع الذي يعيشون فيه.

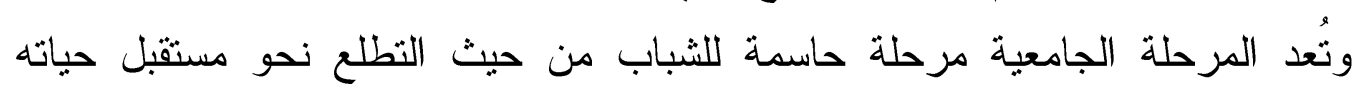
المهنية، وفيها تتحدد الأهداف والسعي إلى تحقيقها في عالم متغير منقلب اجتماعياً و اقتصادياً

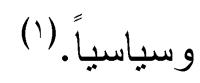

ويعتبر الطلاب بصفة عامة وطلاب الجامعات بصفة خاصة من أهم قطاعات الشباب و أهم الثروات البشرية و أثمنها ولذلك توجه إليهم الدولة مزيداً من رعايتها و اهتمامها، ويكمن

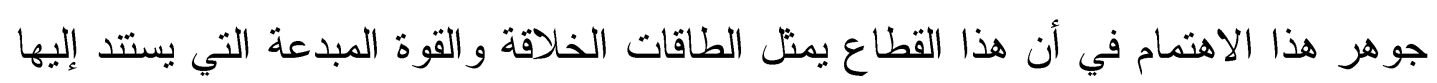

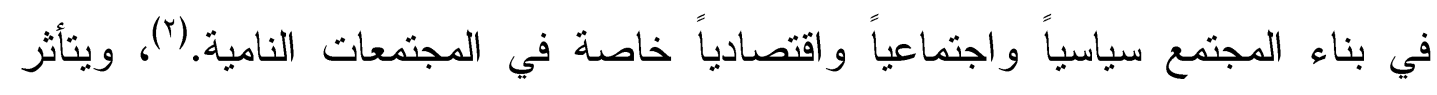

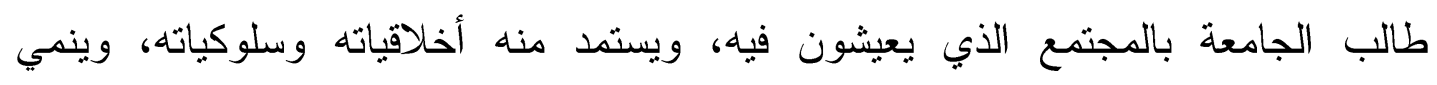

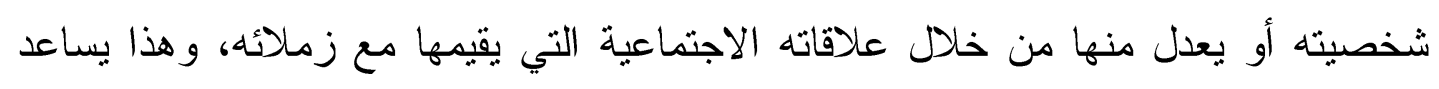

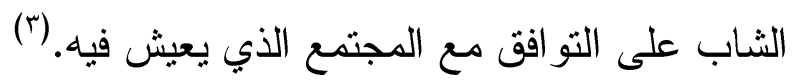

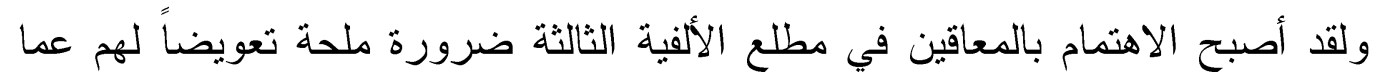

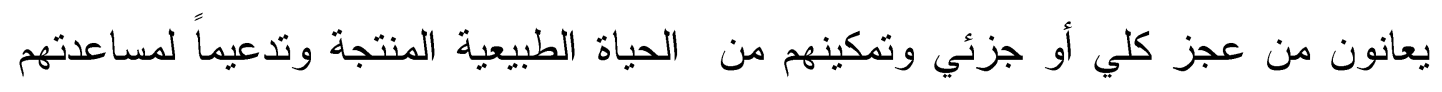

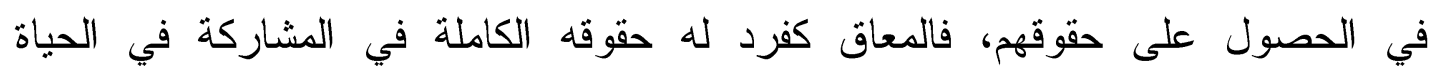

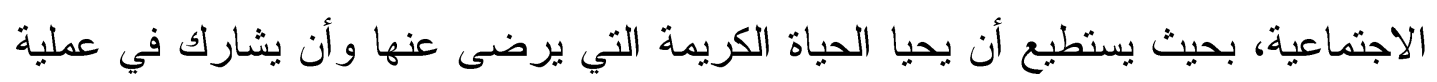

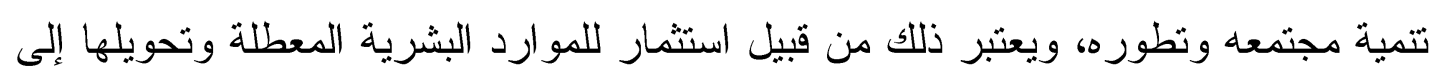

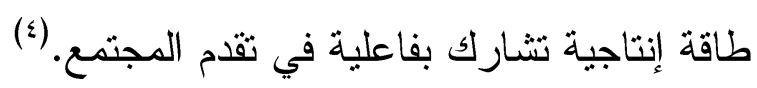

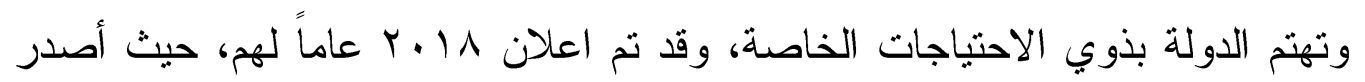

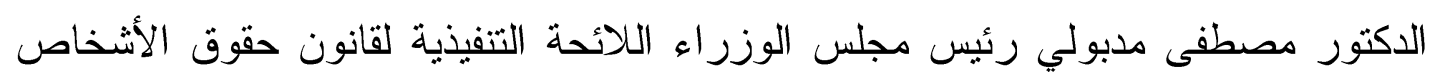

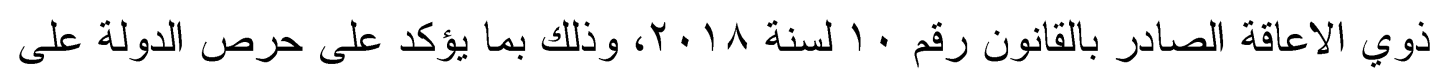
حقوق ذوي الاعاقة وتوفير سُبل الرعاية الكريمة لهم، ودمجهم في المجتمع للمشاركة

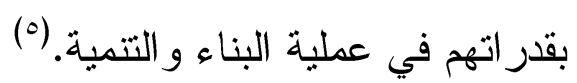
ويُعد التتمر مشكلة خطيرة وتحظى باهتمام متز ايد من كافة المؤسسات التعليمية، وقد عُرف التتمر بأنه نوع من العدوان والانتهاك المنهجي والمتكرر للسلطة، ويشمل كل من 


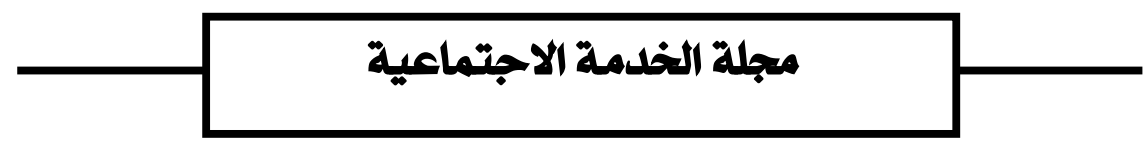

العدوان الجسدي و اللفظي والنفسي، ويمكن أن يكون بصورة مباشرة (كالضرب و الركل

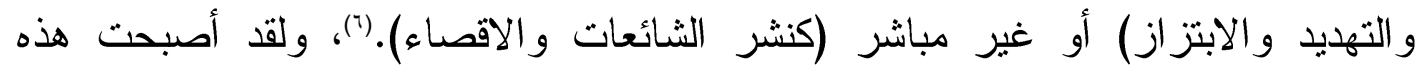
المشكلة من المشكلات المنتشرة ليس فقط بين طلاب المدارس الابتدائية والاعدادية

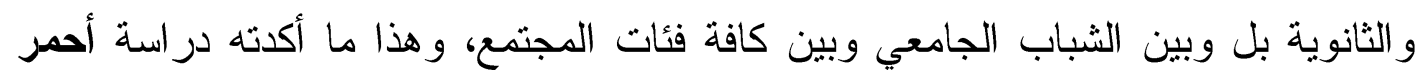

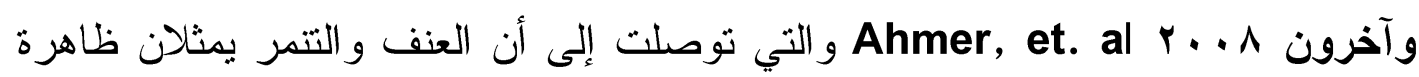

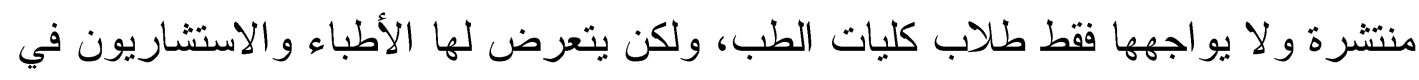

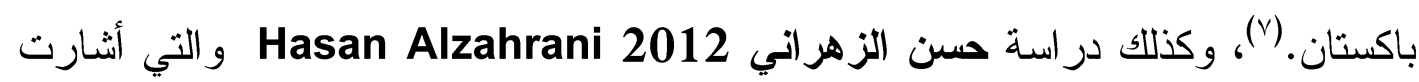
إلى انتشار ظاهرة التتمر ببعض كليات الطب بالمملكة العربية السعودية، وقد أجريت

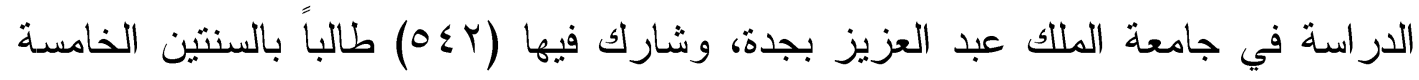

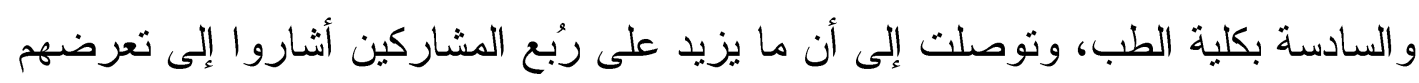

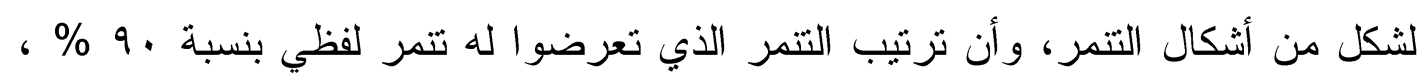

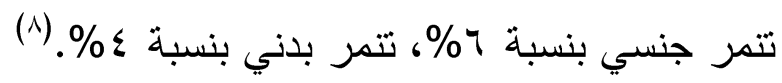

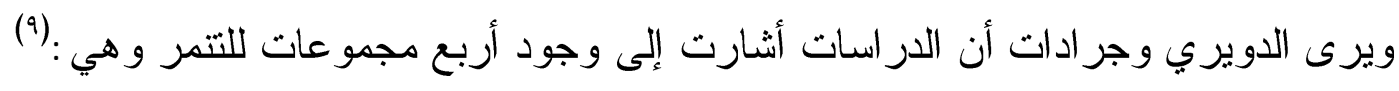
1- المتنمرون: وهم الذين يقومون بصورة منتظمة ومتكررة باستهداف مجموعة أخرى من الطلاب، ويميلون نحو العدائية و السيطرة في علاقاتهم ونقص التعاطف.

ץ-الضحايا: وهم الطلاب المستهدفون بالسلوكيات العدوانية، ويتصفون بضعف الجسم وتدن في تقدير الذات و المهار ات الاجتماعية و القلق و الخجل ويعانون من الاكتئاب و الثشعور بالوحدة و العزلة ولهم أفكار انتحارية.

r- المتنمرون - الضحايا: وهم الطلاب الذين يقومون بالتتمر في مواقف، ويقعون ضحايا

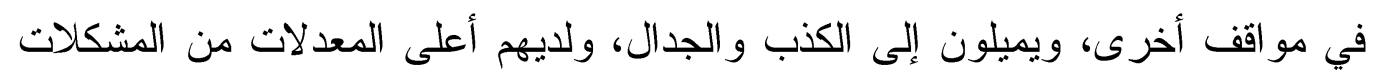

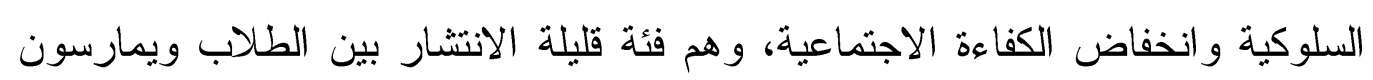

$$
\text { التتمر للانتقام وليس للحصول على الاهتمام. }
$$

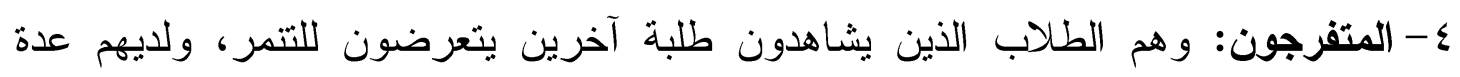

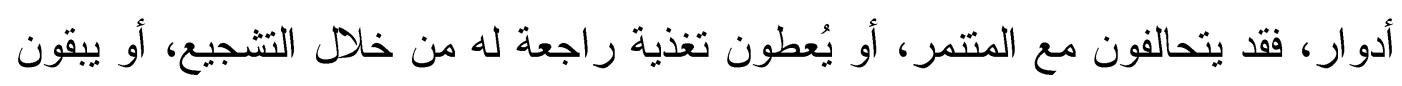

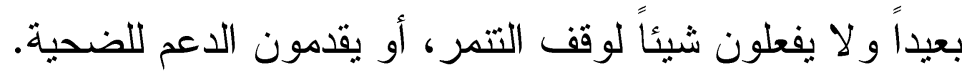

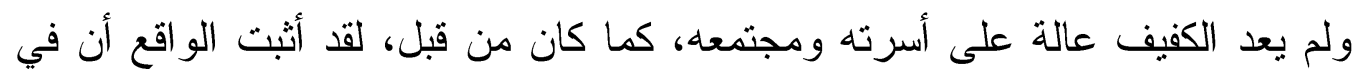

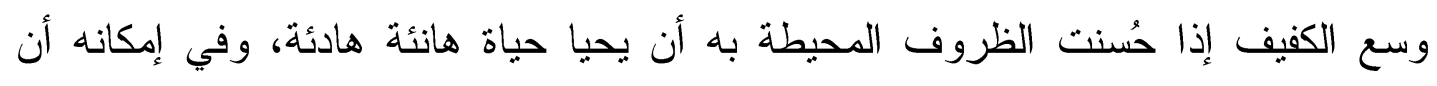

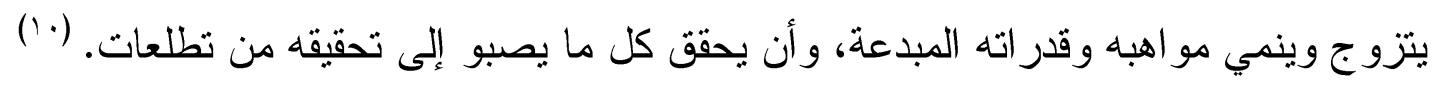


ومن واقع زيارات الباحث المتكررة للمركز الثقافي للمكفوفين بجامعة أسيوط لاحظ

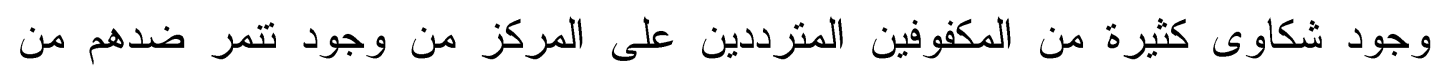
الطلاب العاديين، مما دعى الباحث إلى التفكير في إجر اء در استه الحالية علئهم.

ويعاني الطلاب المعاقين من التتمر أكثر من غيرهم، وهذا ما أكدته دراسة عمر

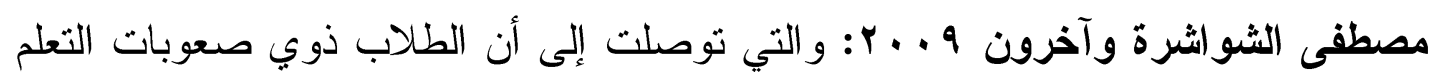

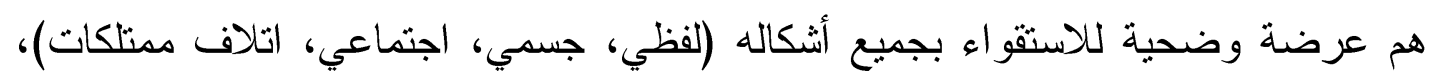

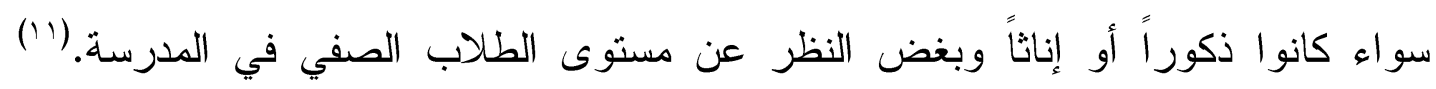

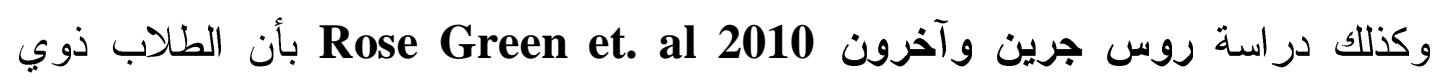

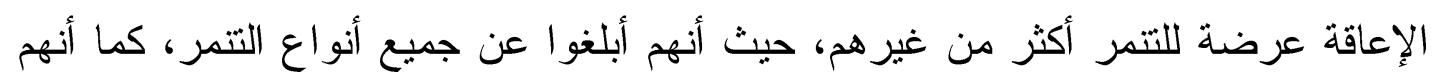

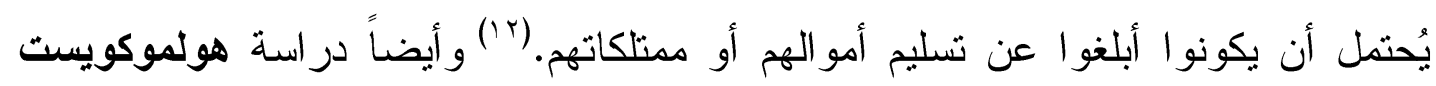
جولي Holomquist, Julie 2011 و التي أشارت إلى أن الأطفال المعاقين هم الأكثر

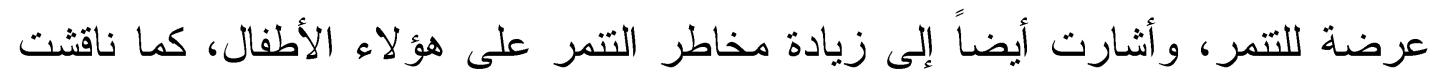

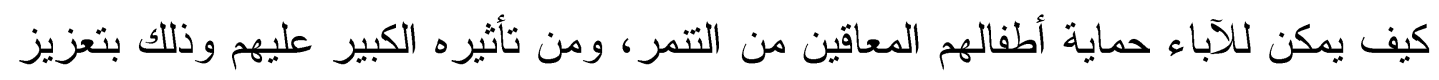

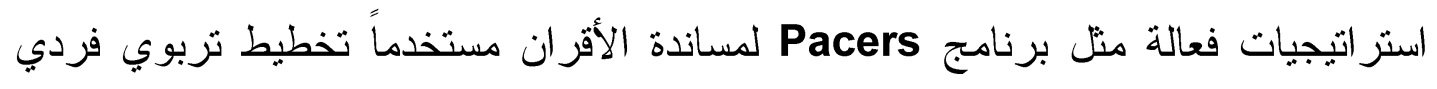
كوسيلة للعمل مع المدرسة وتعريفهم بحقوق طفلهم.(r () وكذلك دراسة مركز باسير القومي للتنمر Pacers National Bulling center 2012 الذي أكد على أن الأطفال المعاقين

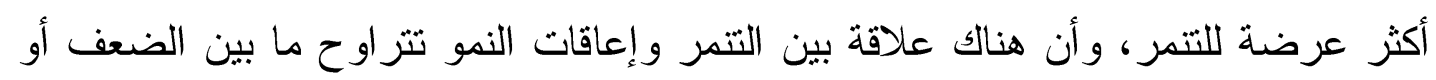

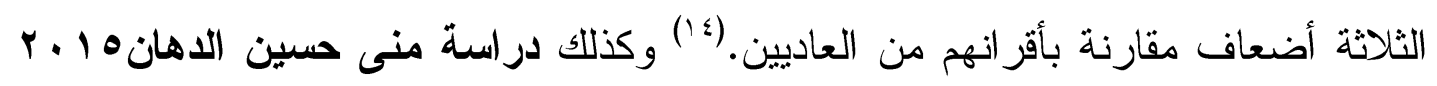

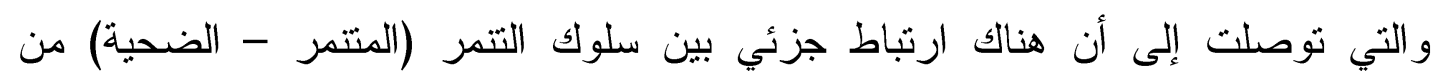

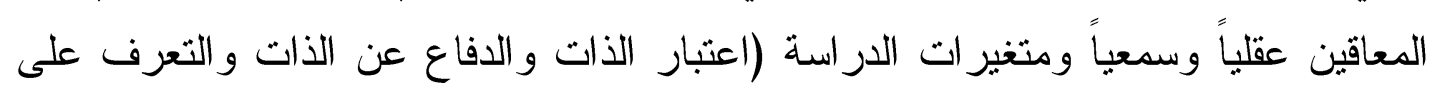
انفعالات الوجه). (10) و هناك عو امل مشتركة بين المتتمر والضحية، حيث يعاني كل من المتتمر و الضحية من تدني في تقدير الذات وكذلك انخفاض مفهوم الذات، وكذلك تدني درجات ضحايا التنمر على التى

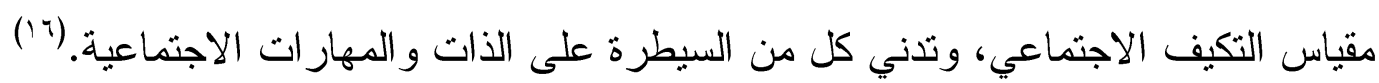
ويعاني الطلاب ضحايا التتمر من عو اقب قصيرة المدى وطويلة المدى، أما عن العو اقب

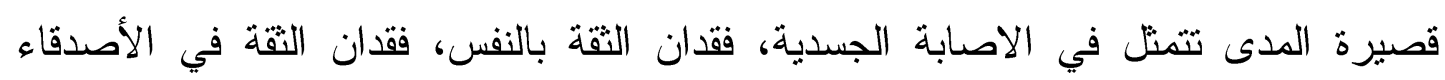

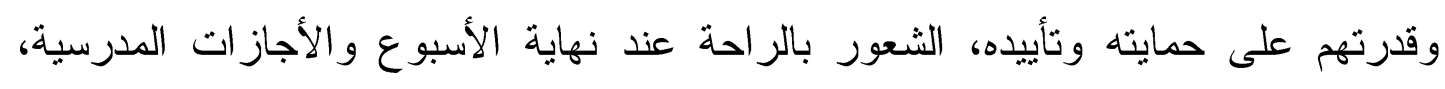

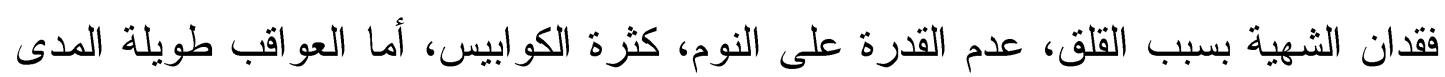




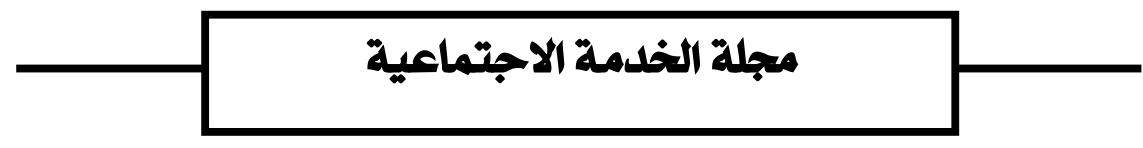

فنتمنل في التمسك بالأفكار السلبية عن النفس، الاخفاق في العمل، و التشاؤم المفرط، و القلق

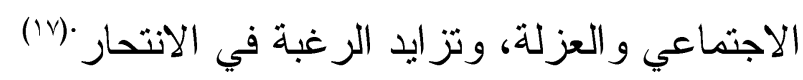

و هناك العديد من الدراسات التي تتاولت ضحايا التتمر من حيث سماتهم الشخصية وآثار التتمر عليهم و التي منها الدراسات التالية:

دراسة كرانهام، كارول Cranham \&Carroll 2003 و التي أثارت إلى أن ضحايا

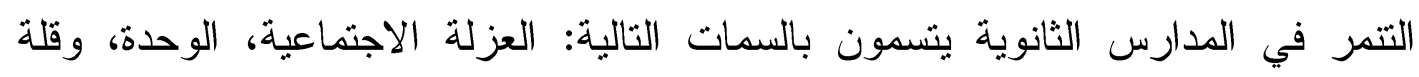

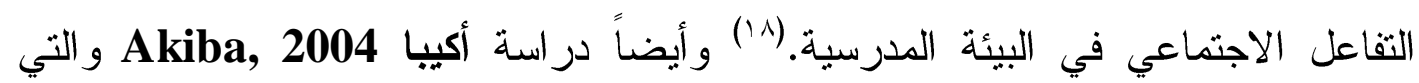

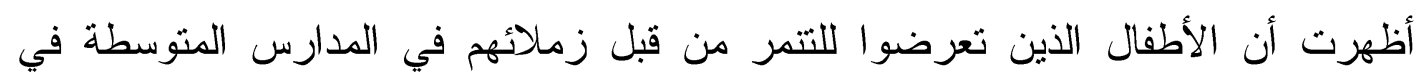

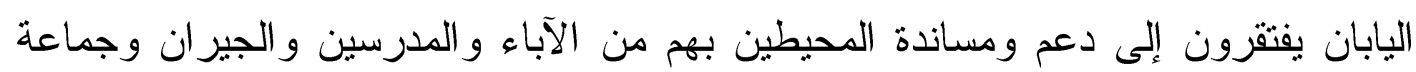

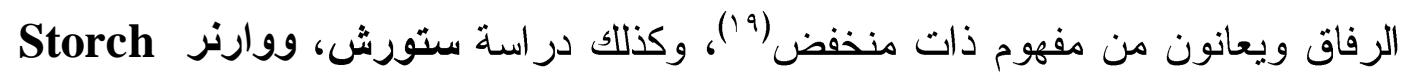
\&Warner 2004

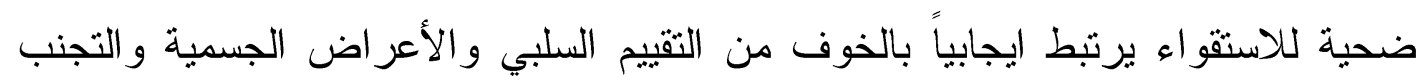

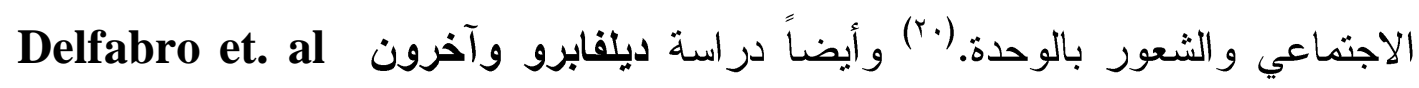

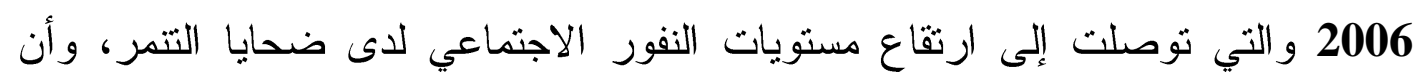

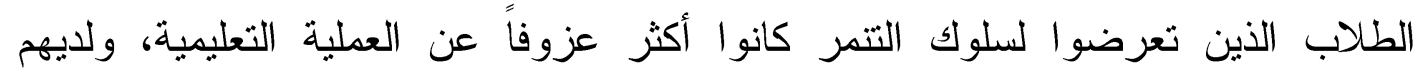

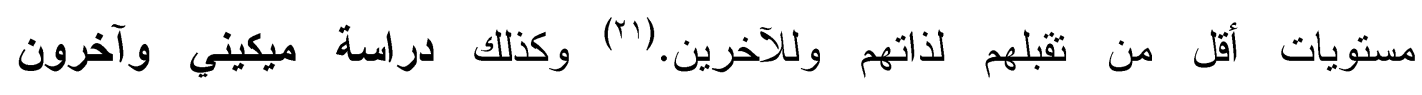
Mckenney, et al 2006

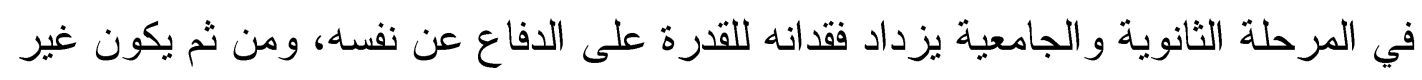

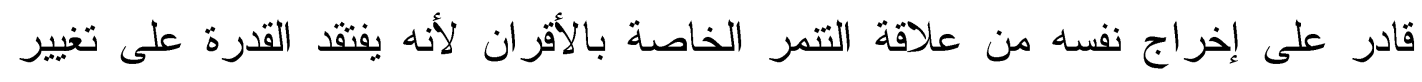

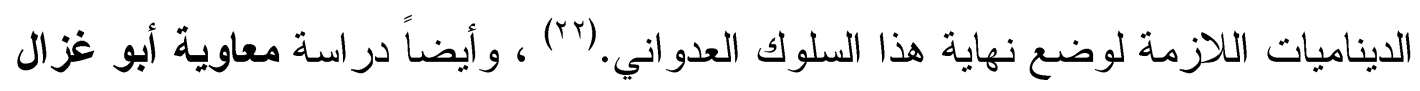

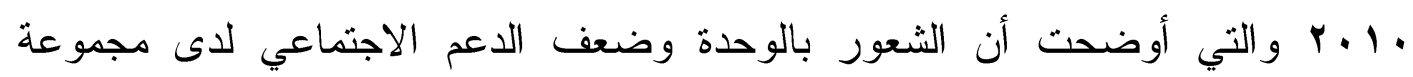

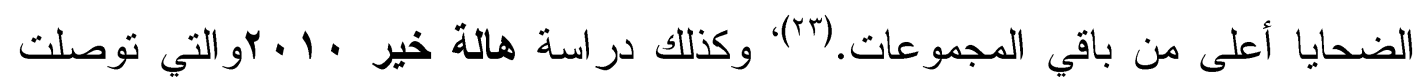

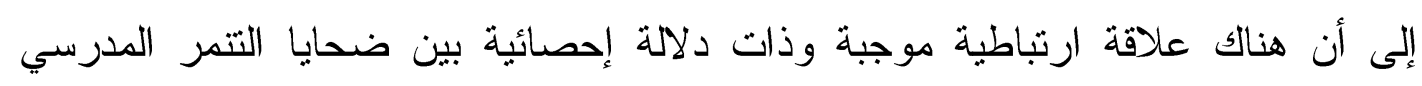

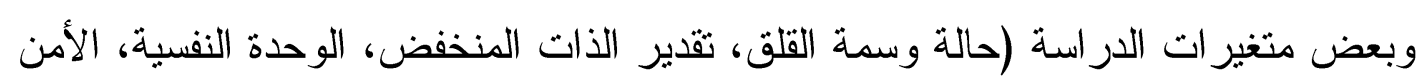

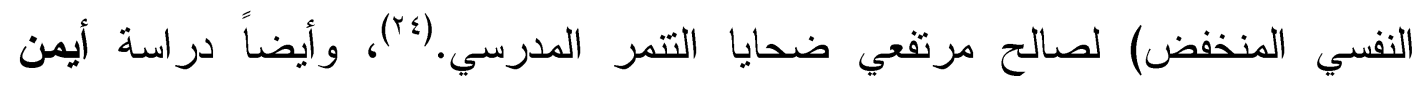

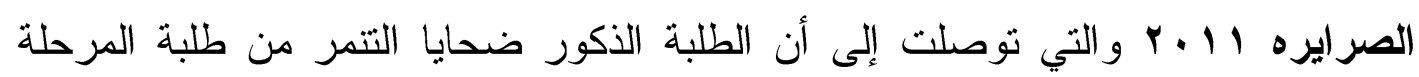

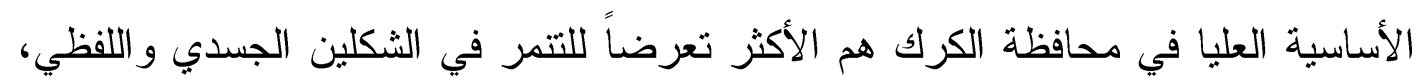

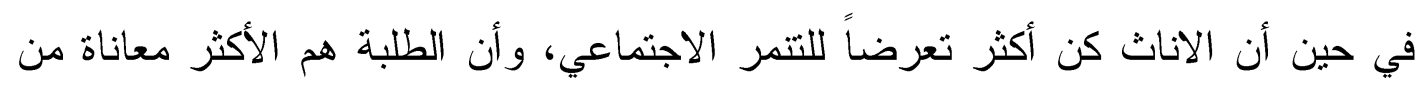

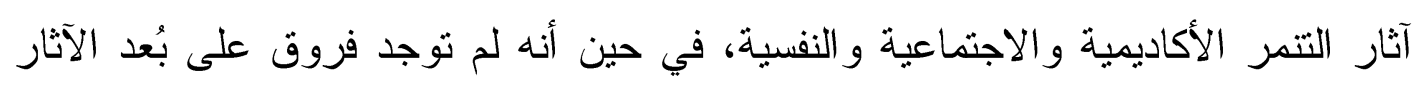


الجسمية. (ro) وكذلك دراسة سيد البهاص r ب ب ب و التي نوصلت إلى أن هناك خصائص

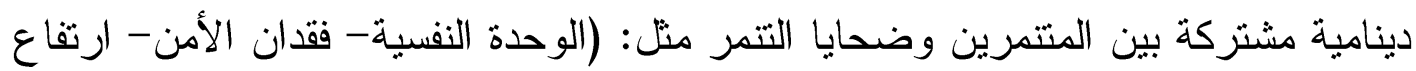

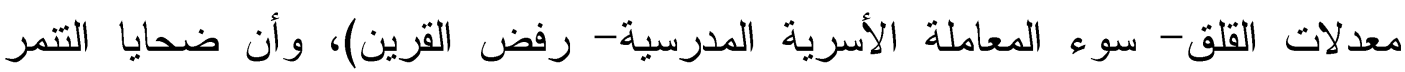

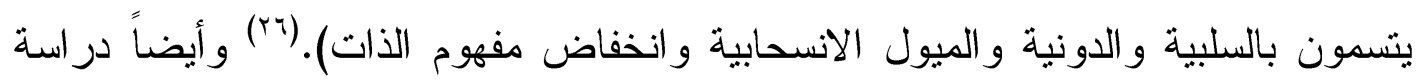
برانك وآخرون Brank et al. 2012 التي أوضحت أن ضحايا التتمر ضعفاء وخجولون مالون وقلقون، وأن آدائهم المدرسي ضعيف، وأنهم يتجنبون حضور الفصول الدراسية بغرض

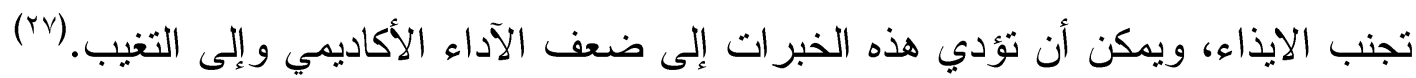
وكذلك دراسة تريث ودنكن Tritt\& Duncan 2015 والتي أنثارت نتائجها إلى وجود الألى فروق دالة احصائياً في الثعور بالوحدة وتقدير الذات بين الضحايا وغير المشاركين وبين

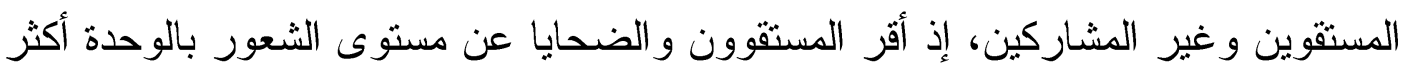

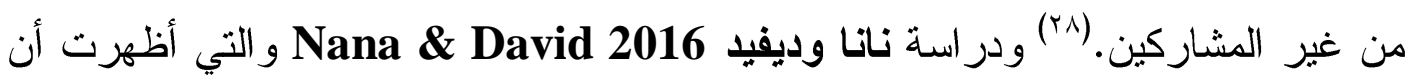
الضحايا من الذكور والاناث يفتقرون إلى احترام الذات، العصبية، انخفاض مستويات

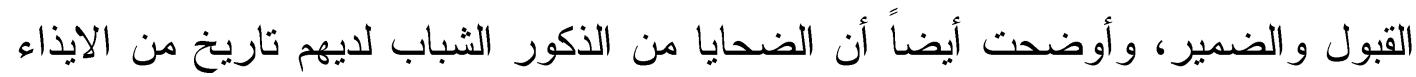

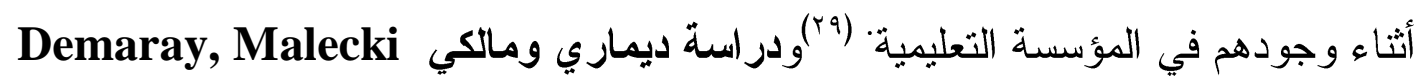

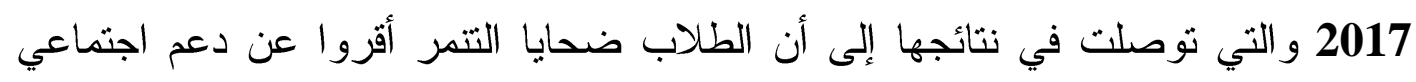

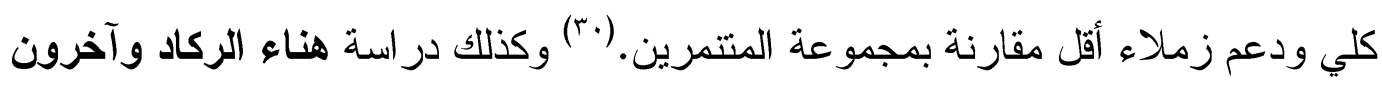
Hana al-Raqqad et. al 2017

من ضعف التحصيل الدراسي. ("r) و هناك بعض الدراسات التي أوضحت أن ضحايا التتمر يعانون من ضعف المهارات الاجتماعية و التي منها: دراسة إليوت Elliott, 1991 والتي توصلت إلى أن ضحايا التتمر غير مهرة اجتماعياً، حيث إنهم ينقصهم الصفات التي تسهل حياتهم الاجتماعية كل يوم والتي منها التفاعلات

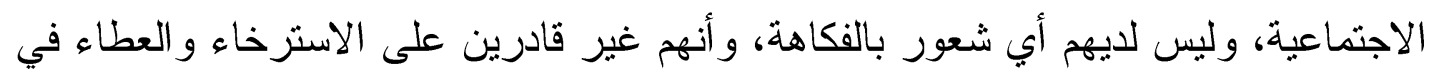

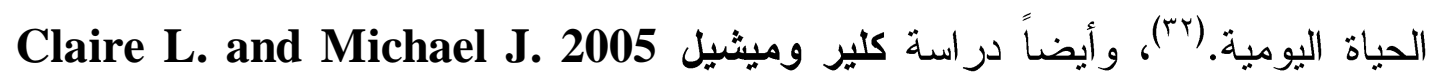

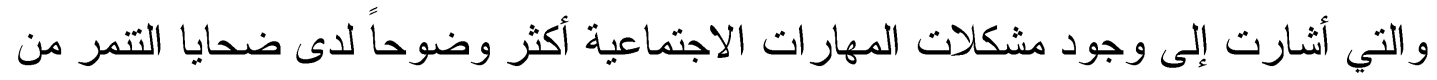

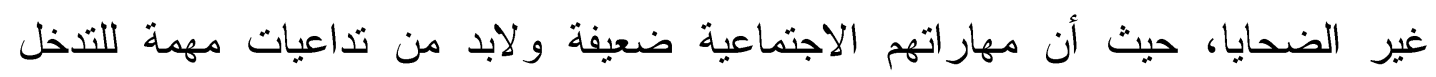

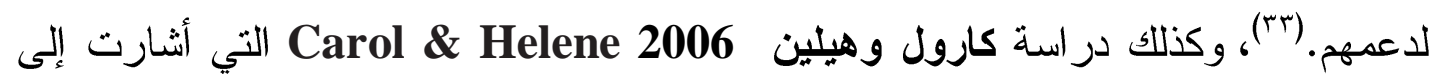
أن ضحايا التتمر يعانون من الوحدة النفسية وسوء النوافق النفسي والاجتماعي وندرة

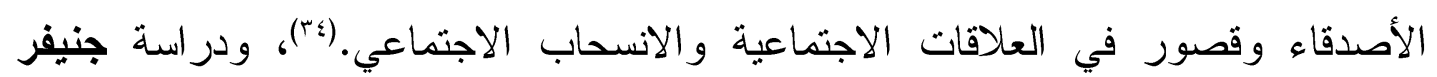




\section{مجلة الخدمة الاجتماعيةم}

ونج 2009 Jennifer S. Wong التي أكدت على أن الضحايا لديهر نقص في المهار ات الاجتماعية والشخصية، فهم يعانون من العزلة الاجتماعية وهم أقل شهرة من الآخرين،

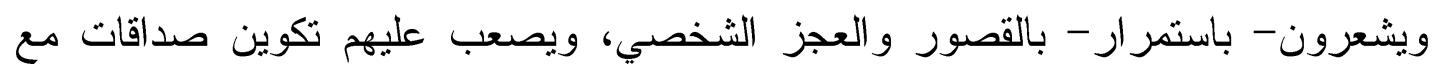
الأقران، ويقومون بأفعال تدمير للذات، ويفتقرون إلى التواصل بالفول الاجتماعي أثناء الأحداث

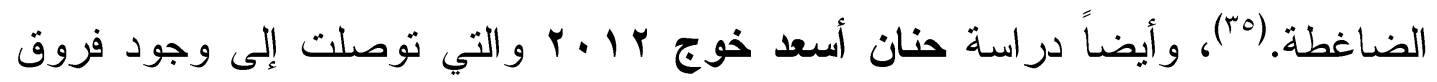

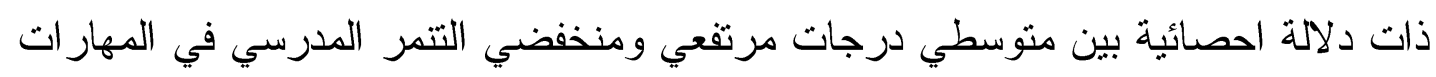
(एT)

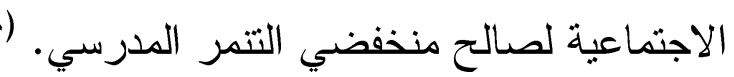

وتعد المهارات الاجتماعية من المحددات الرئيسية لنجاح الفرد أو فثله في المواقف

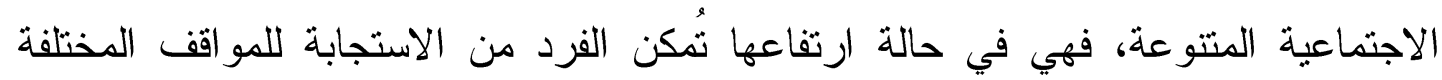

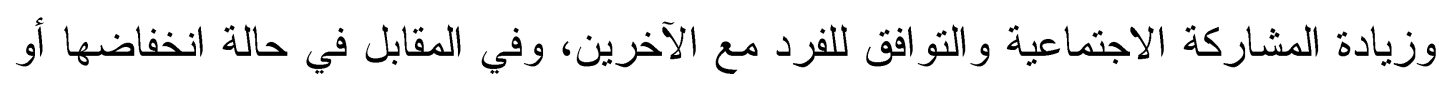

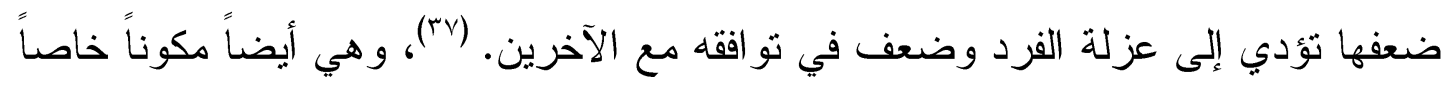

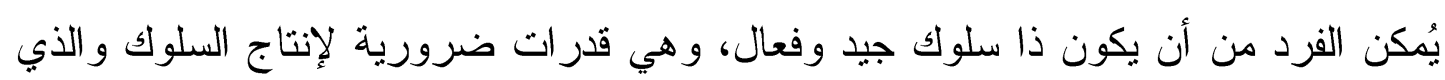

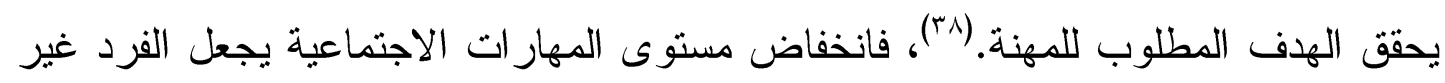

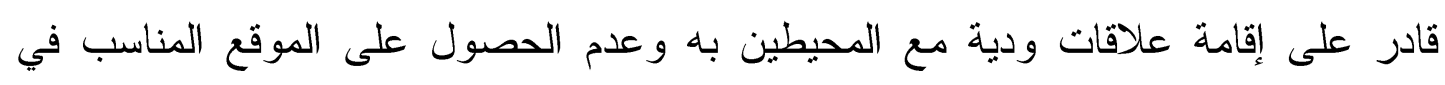

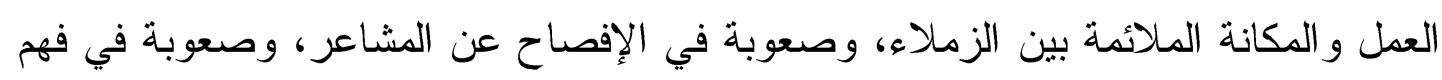

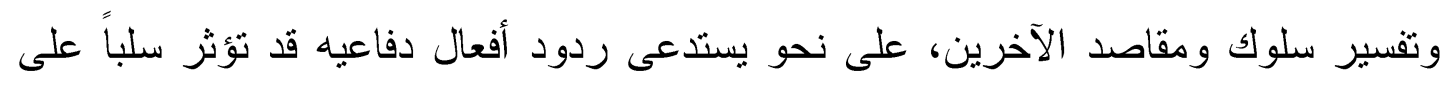

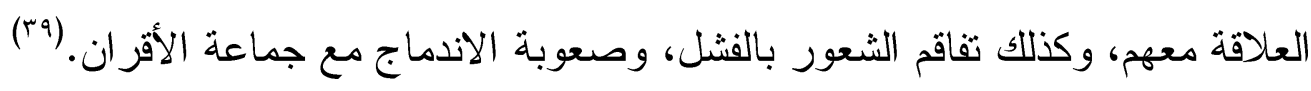
ولقد قام الباحث بإجراء دراسة ثقدير موقف للتعرف على المهارات الاجنماعية التي

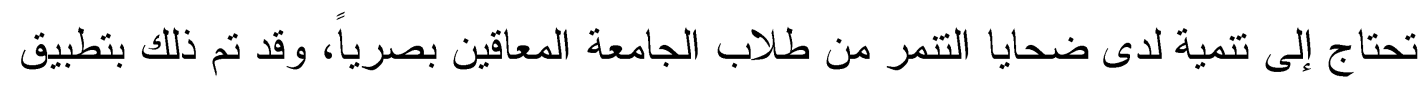

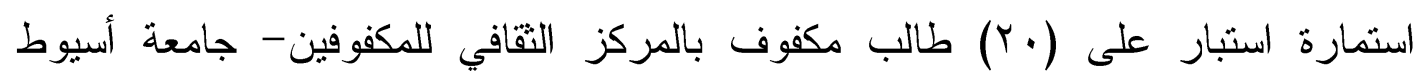

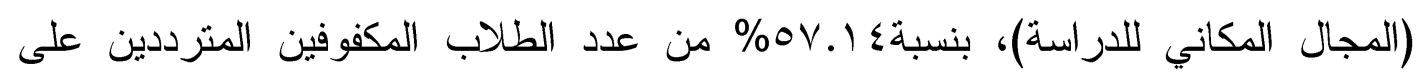

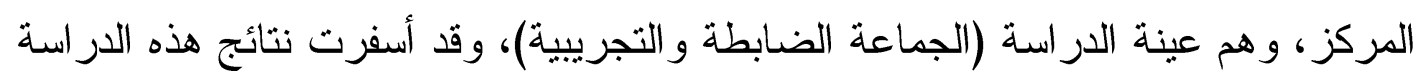

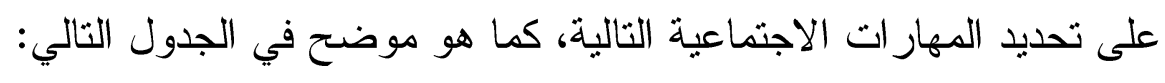




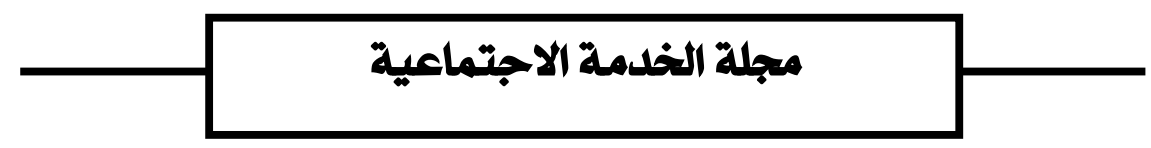

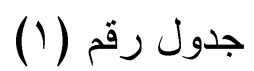

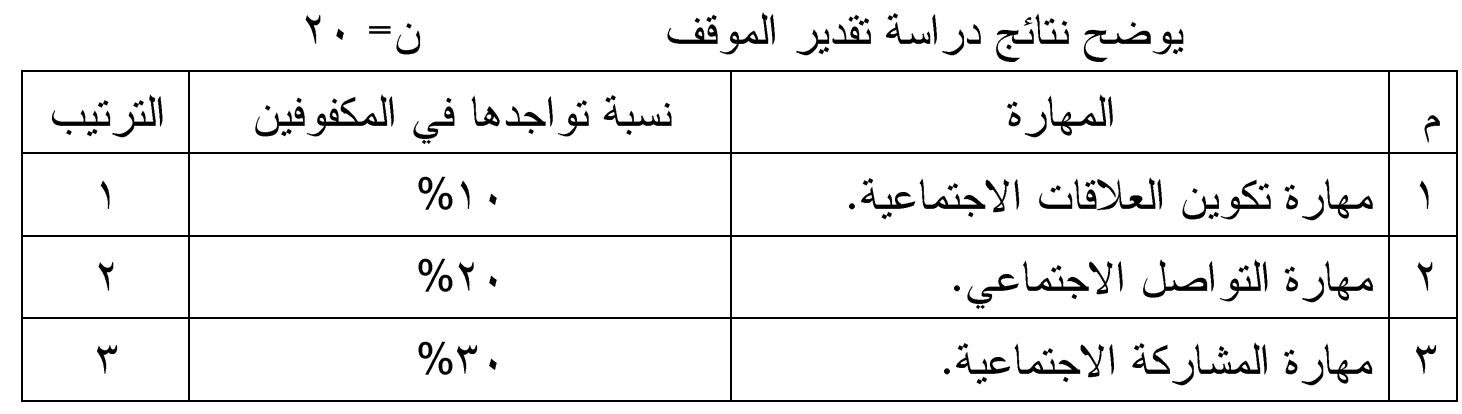

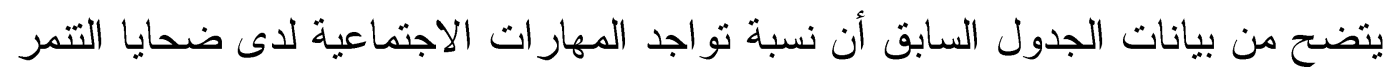

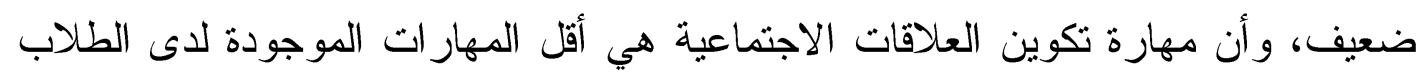

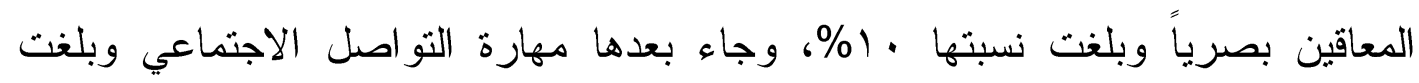

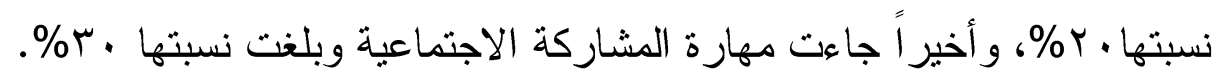

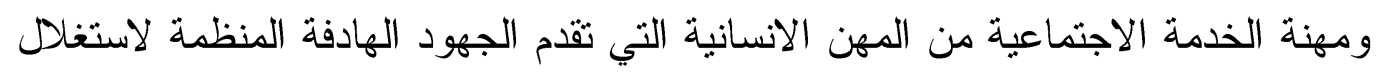

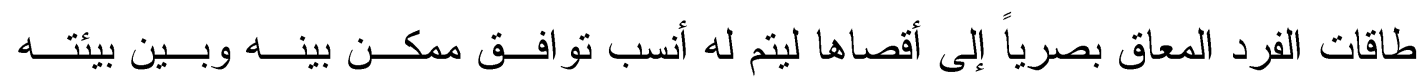

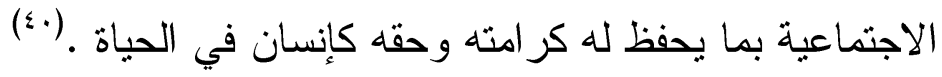

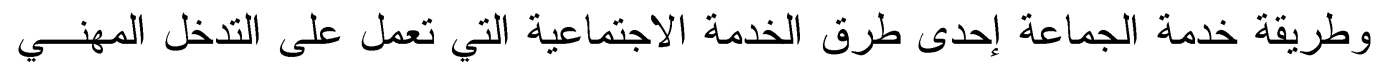

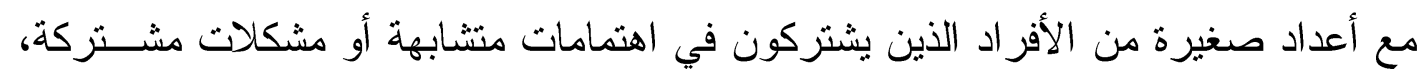

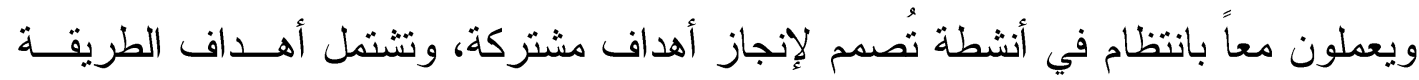

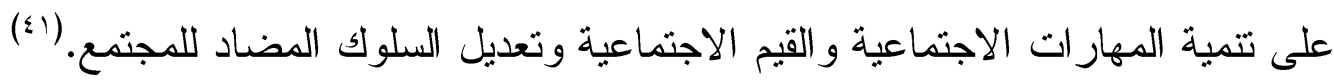

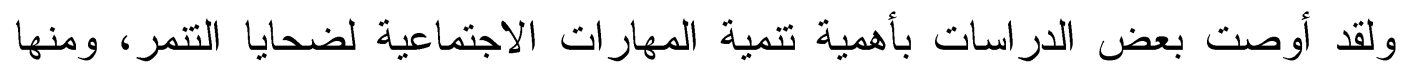
دراسة شوارتز Schwartz 2000 التي توصلت إلى أن ضحايا التتمر ينبغي تعليمهر

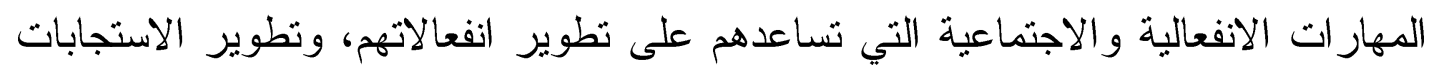

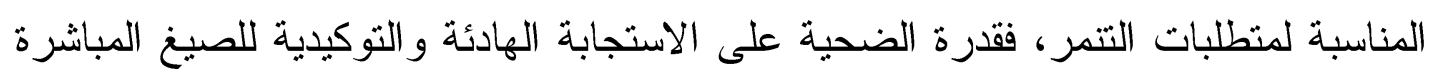

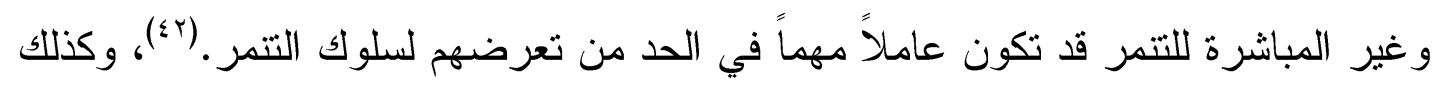

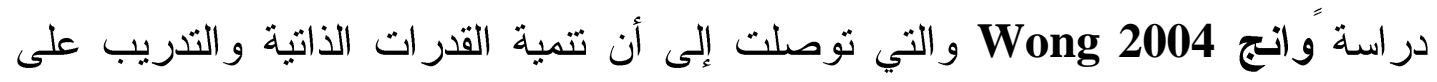
المهار ات الاجتماعية والعلاقات الجيدة مع الآباء و المعلمين استر اتيجية أكثر فاعلية في الحد فئه

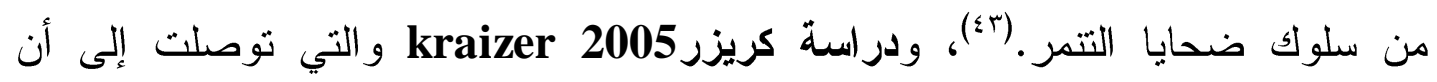

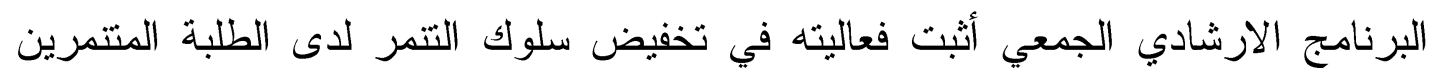

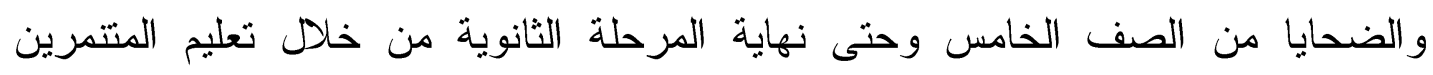

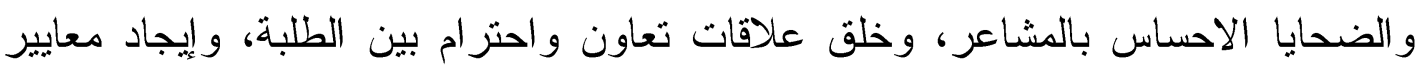

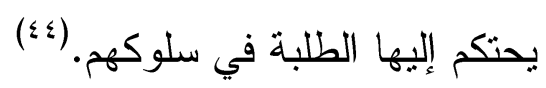




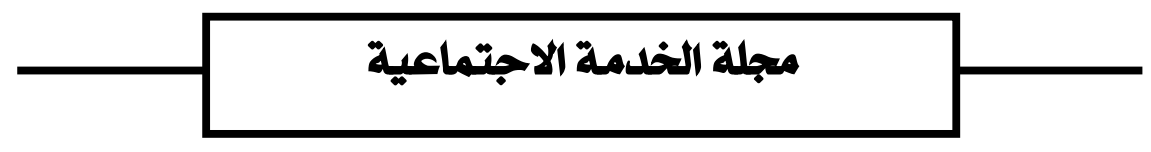

وتذخر طريقة العمل مع الجماعات بالعديد من المداخل و النماذج و النظريات التي تمكنها من الاسهام بدور فعال في وقاية وعلاج وتتمية مهار ات أعضاء جماعة المكفوفين من شباب الجامعة، وخاصة مدخل العلاج الجماعي الذي يعتمد على العديد من الاستراتيجيات و التكنيكات المهنية التي يمكن أن تُفيد في زيادة المهار ات الاجتماعية لديهم، ويُستخدم العلاج الجماعي الجماعة باعتباره تتظيماً اجنماعياً يضم مجموعة من الناس ذوي الاهنمامات و الأهداف المشتركة، حيث يتحدثون ويتفاعلون معاً، ويشعرون بالانتماء للجماعة كوحدة

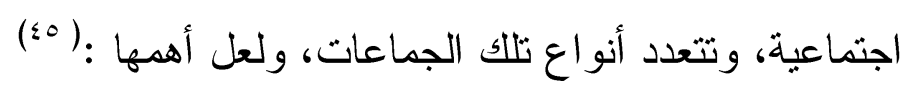
ا- جماعات الاعم الأتي: وتقوم على خلق نوع من الدعم الاجتماعي و النفسي لأعضائها، وتوفر لهم الحماية من الضغوط والتوترات النفسية. r - جماعات الارشاد والنمو والتعليم: وهذه الجماعات مهمتها تشجيع وتدعيم النمو لأعضائها من خلال مساعدتهم على التبصر و الفهم الذاتي. ب- الجماعات العلاجية: ونساعد هذه الجماعات أعضاءها على تحقيق هدفاً محداً، ويتضمن تغيير أنماط سلوكهم.

ويُركز الباحث في در استه الحالية على النوع الثاني من جماعات العلاج الجماعي وهي جماعة الارشاد و النمو و التعليم و التي تهدف إلى تتمية القدرات و المهار ات لأعضائها.

و هنالك بعض الدراسات التي تتاولت العلاج الجماعي ومنها دراسة عادل محمود مصطفى צ . . r و التي أكدت على أن استخدام مدخل العلاج الجماعي في برنامج التدخل المهني لطريقة العمل مع الجماعات قد ساعد الأطفال المكفوفين في تحقيق التوافق الاجتماعي من حيث بناء القدرات الذاتية وتتمية المهارات الحياتية والدمج الاجتماعي

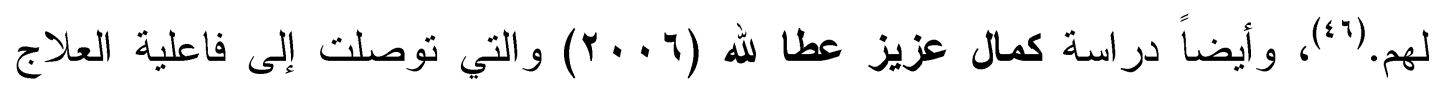
الجماعي من منظور طريقة خدمة الجماعة في تتمية تقدير الذات لدى الفتيات القاصرات

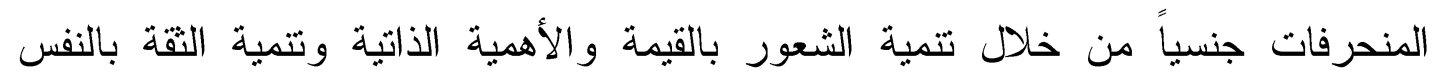

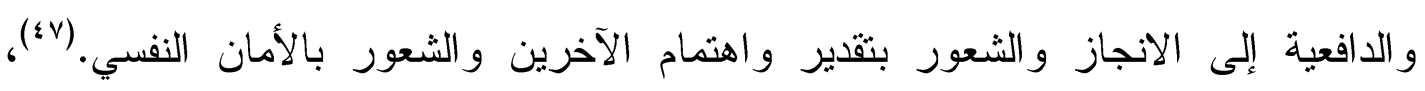
ودر اسة يسري سعيد حسانين و ج. . . والتي توصلت إلى اختبار تأثثر مدخل العلاج الجماعي في طريقة العمل مع الجماعات في ثتمية قدرات الثباب الجامعي على تحمل المسئولية و المشاركة الاجتماعية وثقدير الذات.(^ء) وكذلك در اسة أحمد شفيق حسن مكاوي ه • r و التي توصلت إلى اختبار تأثثر مدخل العلاج الجماعي في الخدمة الاجتماعية في تحقيق الدمج الاجتماعي للأطفال المعاقين سمعياً من خلال اختبار نأثيره في زيادة التفاعل 


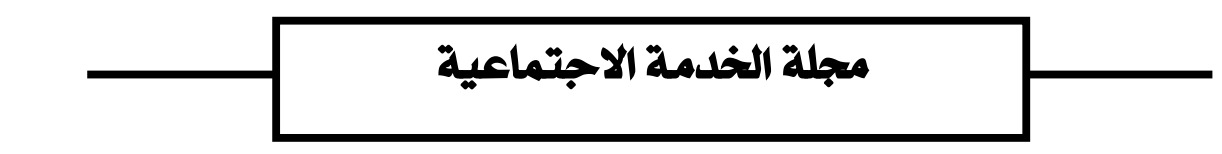

الجماعي و المشاركة في ممارسة الأنشطة وتقدير الذات.(9؛)، وأيضاً دراسة عيشه شيخ Ayesha Shaikh 2018

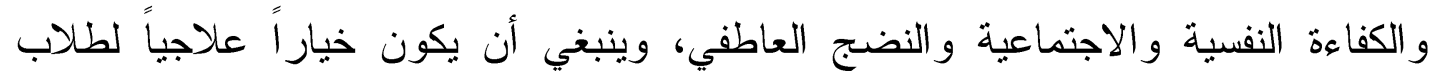
الجامعات الذين يعانون من اضطر اب فرط الحركة ونقص الانتباه.(.) أوجه التشابه والاختلاف بين الار اسة الحالية والار اسـات السابقة:

تثفق الدراسة الحالية مع الدراسات السابقة في أن هناك تتمر بين الشباب الجامعي وكذلك هناك تتمر ضد المعاقين بكل أنو اع اعاقاتهم، وأن هناك بعض السمات و الخصائص التي تميز ضحايا التتمر وكذلك الآثار السلبية للتتمر عليهح والتي تتمنل في الآثار الجسدية و النفسية و الاجتماعية و التعليمية و الأكاديمية، وأن ضحايا التتمر يعانون من ضعف المهار ات الاجتماعية، وأن العلاج الجماعي له تأثير كبير في تتمية المهار ات الاجتماعية و الحياتية. وتختلف الدراسة الحالية عن الدراسات السابقة في فئة ضحايا التتمر و المرحلة العمرية لهم، حيث تتاولت الدراسة الحالية ضحايا التتمر من فئة الشباب (مرحلة التعليم الجامعي)، ولكن معظم الدراسات السابقة تتاولت ضحايا التتمر في مرحلة الطفولة و المراهقة (المرحلة الابتدائية و الاعدادية و الثانوية)، وكذلك تختلف الدراسة الحالية عن الدراسات السابقة في استخدامها للعلاج الجماعي كأحد المداخل العلاجية لطريقة خدمة الجماعة في تتمية المهار ات الاجتماعية لضحايا التتمر -

وقد استفاد الباحث من الدراسات السابقة في صياغة مشكلة الدراسة و أهدافها وفروضها وكذلك الاجر اءات المنهجية لها من نوع الدراسة ومنهجها و أدو اتها ومجالاتها.

وبعد عرض ما سبق من اطار نظري ودر اسات سابقة عن ضحايا التتمر وسماتهم و آثار التثر عليهح و أهمية اكسابهم المهار ات الاجتماعية وأهمية العلاج الجماعي في طريقة العمل مع الجماعات في التخفيف من المشكلات وتحقيق الدعم الذاتي وتتمية المهار ات لأعضائها، ولذلك يمكن صياغة مشكلة الدر اسة في التساؤل الرئيس التالي: 


\section{مجلة الخلمة الاجتماعيةً}

هل يؤدي استخدام مدخل العلاج الجماعي في طريقة خدمة الجماعة إلى تنمية المهارات الاجتماعية لاى ضحايا التنمر من طلاب الجامعة المعاقين بصرياً؟ ثانياً: أهمية الدر اسة: 1- اهتمام الدولة بفئة المعاقين بصرياً ورعايتهم من خلال انشاء المؤسسات الخاصة بهم

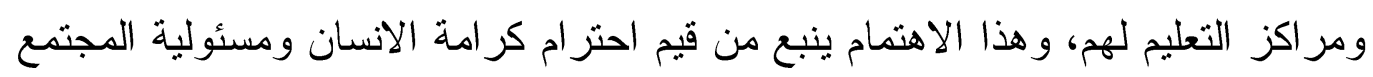
عن رعاية أبنائه سواء أكانو ا أصحاء أم معاقين.

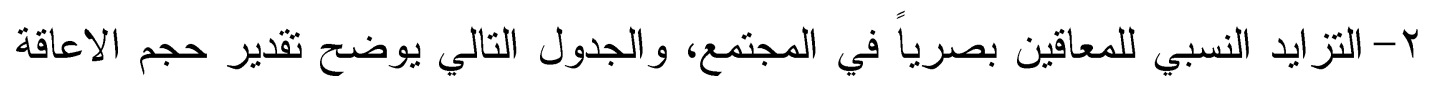

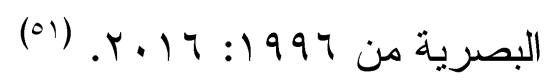

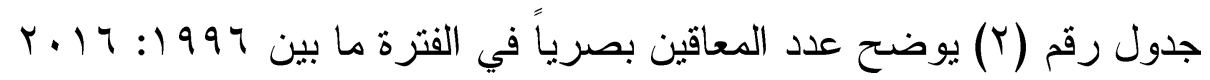

\begin{tabular}{|c|c|c|c|c|}
\hline r.17 & r.ll & r..r & r.. & 1997 \\
\hline rIrIVO & 19V0ro & rAr.91 & 1791.0 & 10101. \\
\hline
\end{tabular}

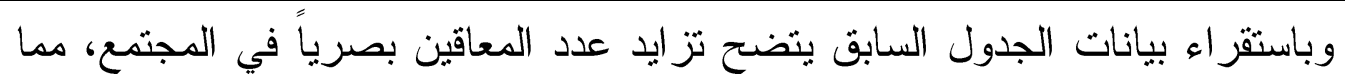

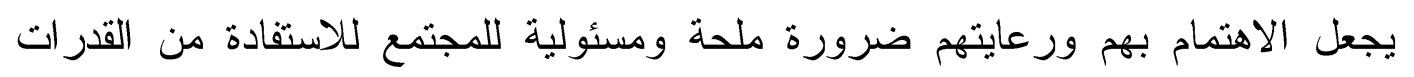
الموجودة لديهم لإتاحة الفرص لهم للعيش بسلام و المساهمة في تنمية مجتمعهم.

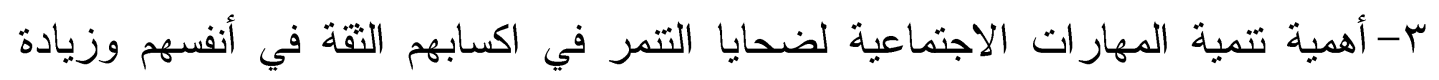

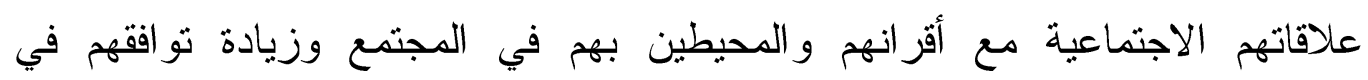
المجنمع. ع- أهمية الدور الذي يمكن أن يقوم به مدخل العلاج الجماعي في طريقة العمل مع الجع

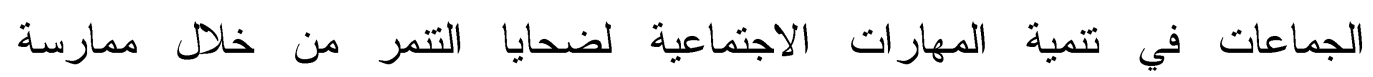

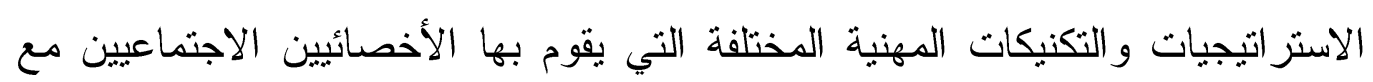
المكفو فين. 0-قلة الدراسات - في حدود علم الباحث- التي تناولت قضية التتمر بين طلاب الجامعة

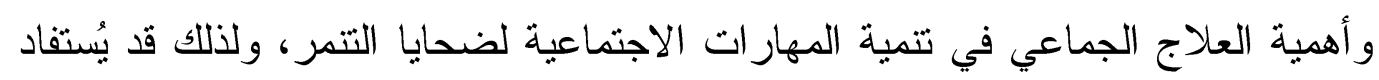
من معطيات هذه الدراسة في الوصول لبعض الخبرات الميدانية التي قد تُسهم في إثراء

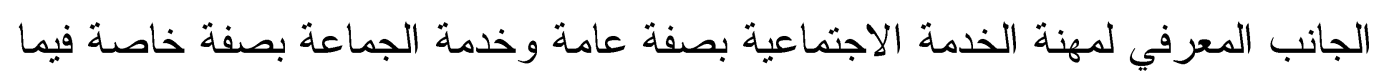

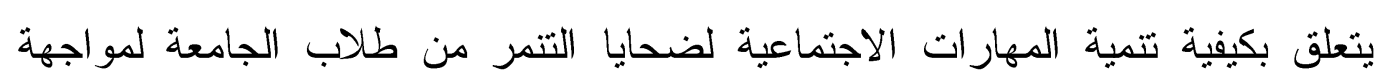
مشكلة التنمر . بكرن. 


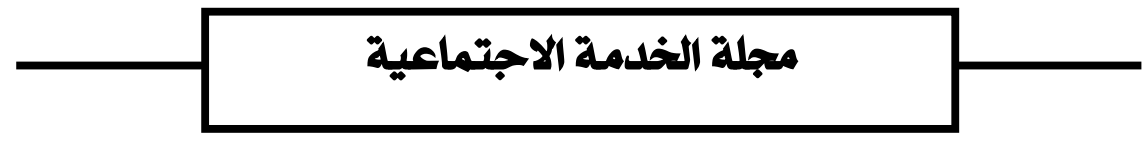

ثالثاً: أهداف الار اسة: تتطلق الدراسة من هدف رئيس وهو : اختبار استخدام مدخل العلاج الجماعي في طريقة خدمة الجماعة لتمية المهارات الاجنماعية لدى ضحايا التتمر من طلاب الجامعة المعاقين بصرياً.

ويتحقق هذا الهُف من خلال تحقيق الأهداف الفرعية التالية:

ا- - اختبار استخدام مدخل العلاج الجماعي في طريقة خدمة الجماعة لتنمية مهارة تكوين العلاقات الاجتماعية لدى ضحايا التتمر من طلاب الجامعة المعاقين بصرياً. ץ- اختبار استخدام مدخل العلاج الجماعي في طريقة خدمة الجماعة لتتمية مهارة التواصل الاجتماعي لدى ضحايا التنمر من طلاب الجامعة المعاقين بصرياً. r- اختبار استخدام مدخل العلاج الجماعي في طريقة خدمة الجماعة لتتمية مهارة المشاركة الاجتماعية لدى ضحايا التتمر من طلاب الجامعة المعاقين بصرياً.

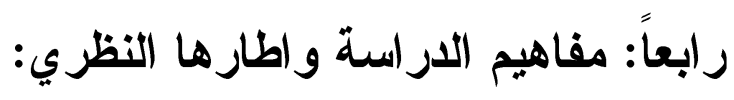
تعثمد الار اسة الحالية على مجموعة من المفاهيم تثمثل في:

$$
\text { r - مفهوم المهار ات الاجتماعية. }
$$

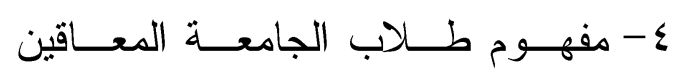

$$
\begin{aligned}
& \text { 1- مفهوم العلاج الجماعي. } \\
& \text { r - مفهوم ضحايا التنمر . } \\
& \text { بصريًا. }
\end{aligned}
$$

0- العلاج الجماعي وتتمية المهار ات الاجتماعية لضحايا التتمر من طلاب الجامعة المعاقين بصريًا.

\section{وسوف نقوم بتوضيح ذلك كالتالي: \\ ا-مفهوم العلاج الجماعي:}

يُعرف العلاج الجماعي بأنه اجتماع جماعة من المرضى بالمعالج الذي يُدير مناقثاتهم

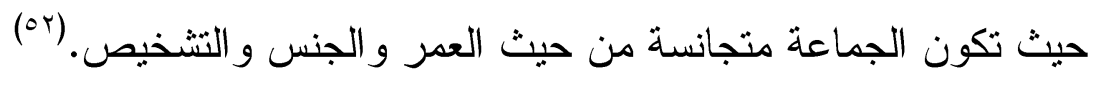

و هو أيضاً علاج عدد من المرضى الذين تنشابه مشكلاتهم و اضطر اباتهم معاً في جماعات صغيرة، حيث يُسثمر أثز الجماعة في سلوك الأفراد، أي بين ما يقوم به أعضاء الجماعة من تفاعل وتأثير متبادل بين بعضهم البعض وبينهم وبين المعالج مما يؤدي إلى تغيير سلوكهم المضطرب وتعديل نظرتهم في الحياة.(r) 


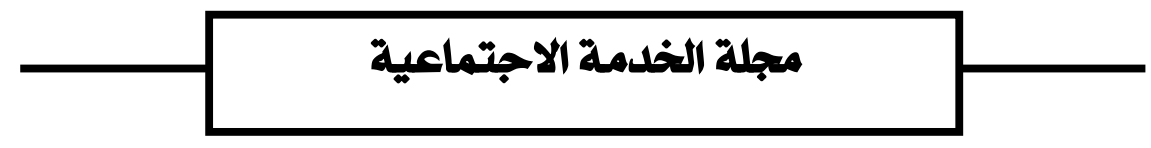

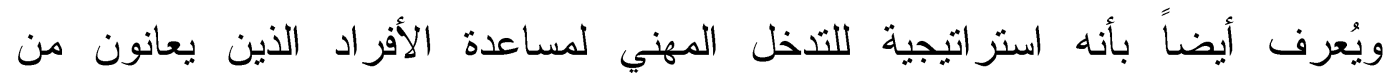

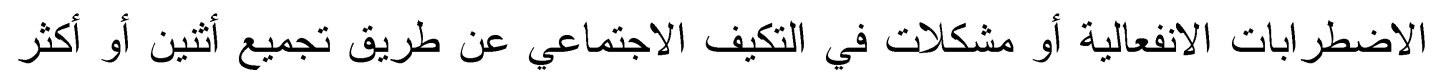

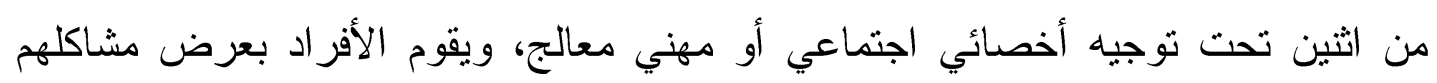

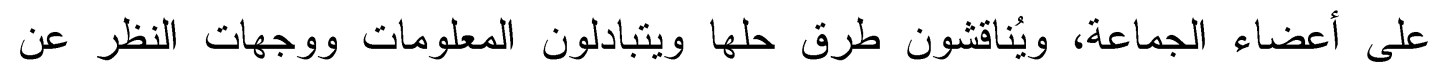

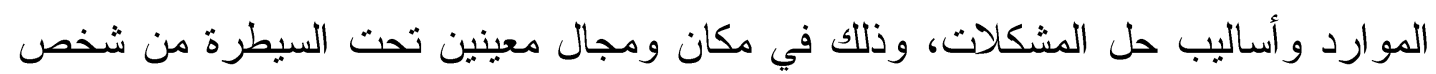

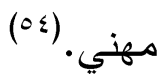
و هو كذلك علاج يستخدم الجماعة كعامل مساعد في التغيير، ويُولي اهتماماً دقيقاً للقوى الأولية الثلاث التي تعمل في جميع الأوقات في العلاج الجماعي وهي الديناميات الفردية و الثخصية و الجماعية كديناميكيات متكاملة. (00)

كما يُعرف أيضاً بأنه اجتماع جماعة من المرضى بالمعالج الذي يُريد مناقشتهم،

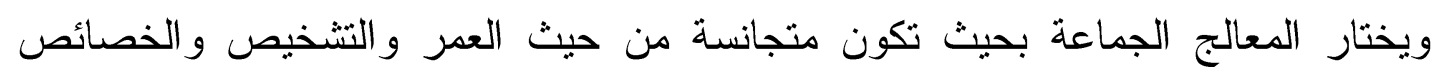

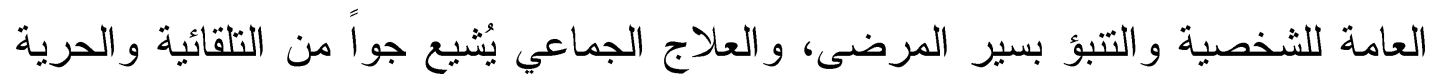

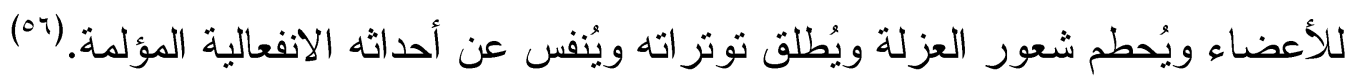
كما يُعرف بأنه أحد الدداخل العلاجية التي ينم استخدامها مع الأعضاء لمساعدنهم على حل مشكلاتهم الشخصية والاجتماعية من خلال الجماعة كوسط للعلاج وما توفره العمليات الجماعية للجماعة من فرص لتتمية الأداء الاجتماعي. (ov) ويمكن من جانبنا نعريف العلاج الجماعي على أنه أحد المداخل العلاجية لطريقة العمل

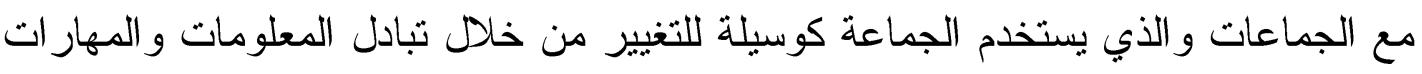

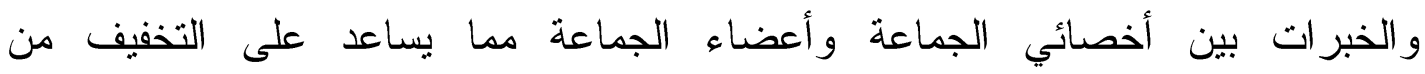
الاضطر ابات النفسية والانفعالية التي يعانون منها وكذلك تتمية مهار اتهم.

وبعد عرض ما سبق من تعريفات يمكن وضع المفهوم الاجر ائي للعلاج الجماعي على أنه: أ- مدخل علاجي من مداخل طريقة العمل مع الجماعات يعتمد على مجموعة من الاجر اءات.

ب- يتضمن مجمو عة من الخطوات المهنية و الاستر اتيجيات و التكنيكات المهنية.

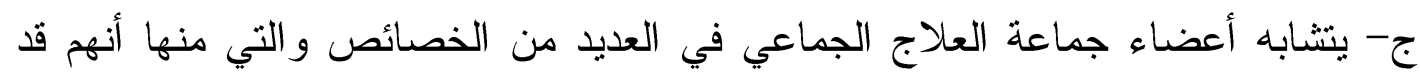
تعرضو اللتنمر وكذلك يعانون من نقص المهار ات الاجنماعية. 


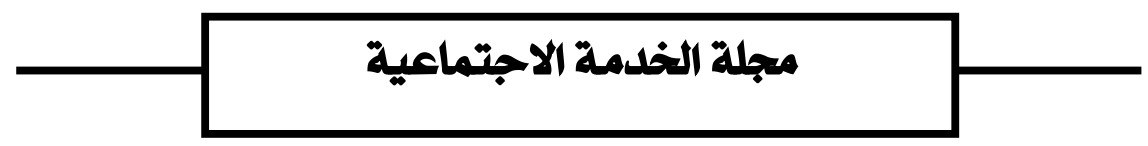

د- يستخدمه أخصائي الجماعة (الباحث) لتبادل المعلومات و المهارات بينه وبين أعضاء

الجماعة وذلك لتتمية المهار ات الاجتماعية لضحايا التتمر من الطلاب المعاقين بصرياً.

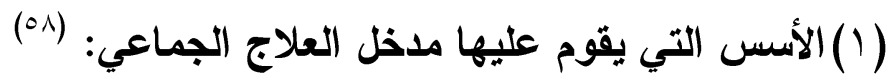

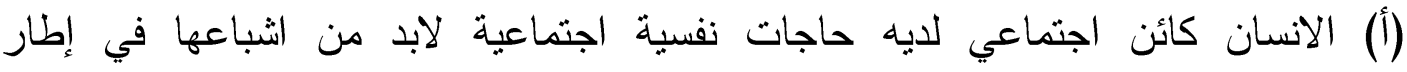

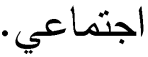

(ب) يتحكم في سلوك الفرد المعايير الاجتماعية التي تحدد الأدوار الاجتماعية التي يقوم بها

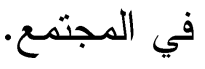

(ج) تحقيق التوافق الثخصي والثوافق الاجنماعي بما يحقق سعادة الفرد في تفاعله الاجنماعي.

(د) يُؤثر التفاعل الاجتماعي بين أعضاء الجماعة في الجماعة العلاجية فيجعل كل منهم

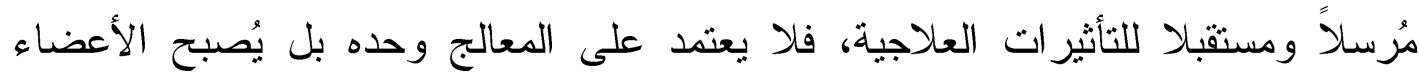

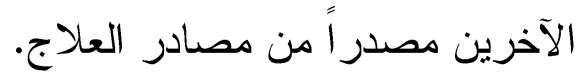

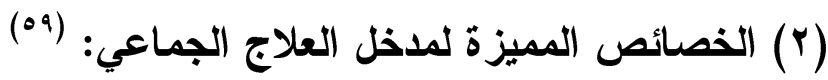

$$
\text { (أ) يُمكن تحديد أهداف العلاج التعاوني بدقة. }
$$

(ب) ائُكن من خلاله صياغة إجر اء علاجي محدد مناسب لمشكلة معينة.

(ج)يُمن من خلاله وضع تقييم موضوعي لنتائج العلاج، حيث يميل المعالجون إلى استخدام

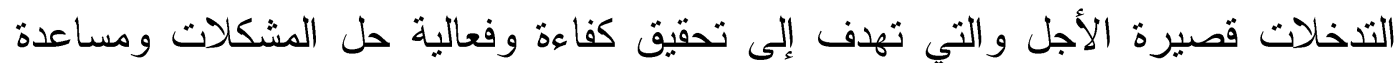
الأعضاء على تتمية مهار ات جديدة.

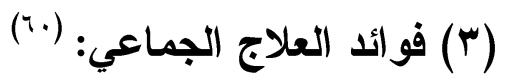

$$
\text { (ب) يساعد العلاج الجماعي على إدر الك أنك لست وحدك. }
$$

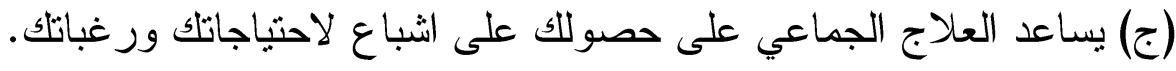

(د) يساعد العلاج الجماعي في التواصل مع الآخرين بطريقة صحية وسليمة.

$$
\text { (ه) يوفر العلاج الجماعي شبكة أمان. }
$$$$
\text { ( ) مجالات استخدام العلاج الجماعي: }
$$

يُعد العلاج الجماعي ضروري بالنسبة لحالات معينة من الاضطر ابات نورد نماذج منها

فيما يلي: (11)

(أ)الثخصيات الانسحابية. (ب) النماذج العدوانية. (ج) الثخصيات غير الناضجة. 


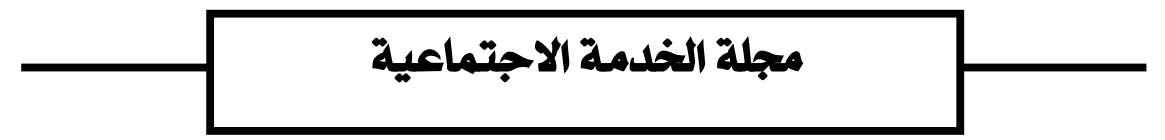

$$
\begin{aligned}
& \text { (د)الشخصيات الذين يدعون مهار ات وهمية. (0) الأشخاص الــذين يعـانون مخــاوف } \\
& \text { شاذة. }
\end{aligned}
$$

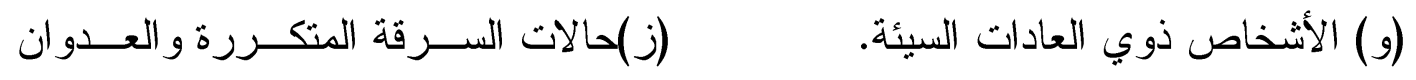

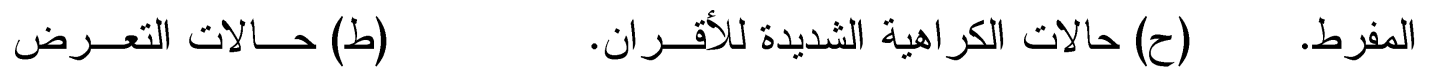

$$
\begin{aligned}
& \text { لمو اقف صادمة. } \\
& \text { (ي)الأشخاص الذين يبدون اتجاهات سوسيوباتية (عدم الوعي أو الشعور بالآخرين). } \\
& \text { : (0) شروط تطبيق العلاج الجماعي (ل) } \\
& \text { هنالك شرطين يجب أن تتحقق لتطبيق العلاج الجماعي هي: (rآ) } \\
& \text { الثرط الأول: شروط تتعلق بتثكيل الجماعة العلاجية: } \\
& \text { (أ) حجم أعضاء الجماعة ويفضل أن لا يقل عن ثلاثة و لا يزيد عن } 10 \text { عضواً. } \\
& \text { (ب) يفضل أن يكون عمر الأفر اد (أعضاء الجماعة) منقارباً. } \\
& \text { (ج) التقارب في المستوى العقلي والثقافي والاجتماعي و الاقتصادي. } \\
& \text { (د) التقارب و التجانس في نوعية المشكلات التي يعانيها أعضاء الجماعة. } \\
& \text { الثرط الثاني: اختيار الاستراتيجية أو الطريقة العلاجية المناسبة: } \\
& \text { هناك عدة استر اتيجيات أو طرق علاجية تستخدم في مجال العلاج الجماعي منها: } \\
& \text { (ب) لعب الأدوار . } \\
& \text { (أ) العلاج باللعب. } \\
& \text { و المعسكر ات. }
\end{aligned}
$$

(7) أدوار أخصائي الجماعة في إطار ممارسة مدخل العلاج الجماعي: (זٓ) (أ) مساعدة الجماعة على تحمل المسئولية الاجتماعية التي تثقق وقدر اتهم المتاحة. (ب)مساعدة الجماعة على تتمية المهار ات لدى أعضائها.

(ج)مساعدة الجماعة على تحديد احتياجاتها و السعي إلى اشباعها بالطريقة الكافية. (د) مساعدة أعضاء الجماعة في اتخاذ القرارات المرثبطة بالأنشطة و البرامج المقدمة. (ه) مساعدة الجماعة على تتمية الأداء الاجتماعي لدى أعضائها. (و) مساعدة الجماعة على إدر الك وتحديد المشكلات التي تعوق تتمية قدر ات أعضائها. (ز) مساعدة أعضاء الجماعة على تحديد أهدافهم و امكانية تحقيقها. (ح) مساعدة الجماعة على البقاء كوحدة واحدة ولفترة كافية لتحقيق أهدافها. 


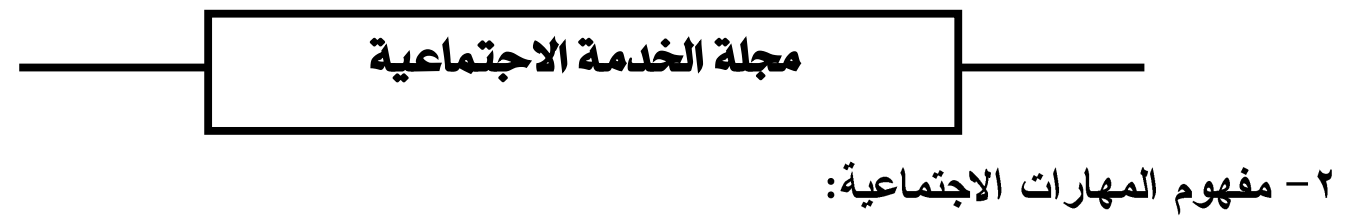

تُعرف المهارة لغوياً بأنها مشتقة من الفعل "مهر" الثئ، وبه مهارة أي أحكمه صار بـه

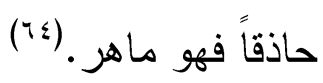

تُعرف المهارة اصطلاحاً بأنها عبارة عن قدرات محددة ناتجة عن المعرفة و المعلومات،

الممارسة، الاستعداد الطبيعي.(70)

أما المهارة الاجتماعية فتعرف على أنها القدرة على تبادل الفكر، و العمل مع الآخرين لتحقيق أهداف اجتماعية معينة، كالتحدث إلى الناس بأسلوب مفهوم و الكتابة إليهم بتعبير صادق و القدرة على الاتصال بهم و التأثير فيهم. (T)

وتعرف أيضًاً على أنها" القدرة على قراءة وفهم كل من السلوك الاجتماعي، ومهارة المشاركة الاجتماعية، مثل التعبير اللفظي والانفعالي، والقدرة على لعب الدور الاجتماعي بكفاءة. " (TV)

وفي ضوء عرض التعريفات السابقة وتمشياً مع الدراسة الحالية يمكن عرض المفهوم الاجر ائي للمهار ات الاجتماعية على أنها:

أ- قدر ات كامنة لدى ضحايا التتمر من طلاب الجامعة المعاقين بصرياً. ب- يمكن تتميتها لهؤلاء الطلاب من خلال استر اتيجيات وتكنيكات مدخل العلاج الجماعي في طريقة خدمة الجماعة. ج- الهذف من تتميتها لهؤلاء الطلاب هو تمكينهم من مواجهة التتمر الذي يتعرضون له في المجتمع الجامعي. (1) مفهوم المهارة في تكوين العلاقات الاجتماعية: الأصل اللغوي لكلمة العلاقة مشتق من (علق) و العلاقة بفتح العين تعنى علاقة الارتبــاط و التعلق بشيء ما، و العلاقة بكسر العين تشير إلى علاقة القوس و السوط. (^^)

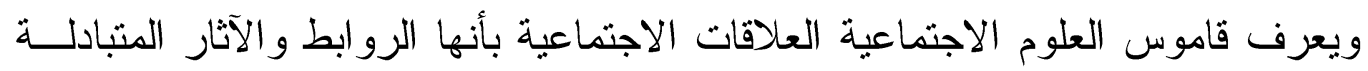
بين الأفر اد في المجتمع والتي تنشأ عن طبيعة اجتماعهم وتبادل مشاعر هم و أحاسيسهم فـي المجتمع، وهذه العلاقات إما تكون بناءة أو هدامة مباشرة أو غير مباشرة. (99)

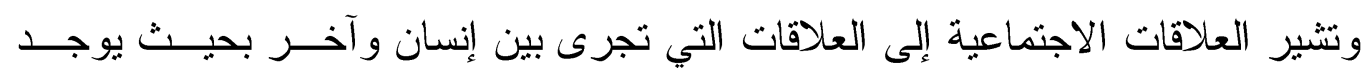

بينهما تفاعل و استجابة، و هذه العلاقات هي الأساس الأول لجميع العمليات الاجتماعية.(•) 


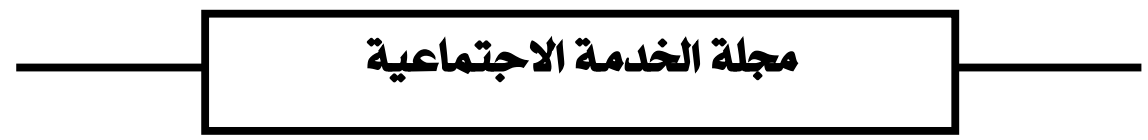

كما تعرف أيضا بأنها نسق معين ثابت يشمل طرفين (سواء كانــا فــردين أو جمـــاعتين)

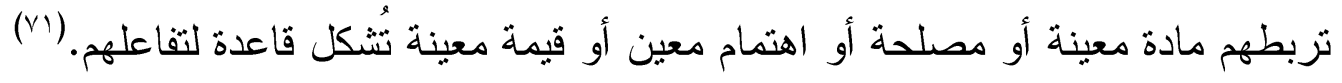

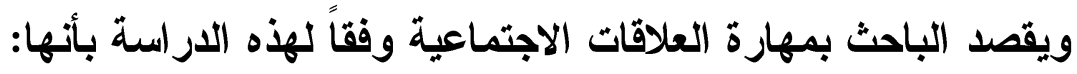

$$
\text { (ب) القدرة القدرة على تكوين علاقات اجتماعية مع الزملاء. }
$$

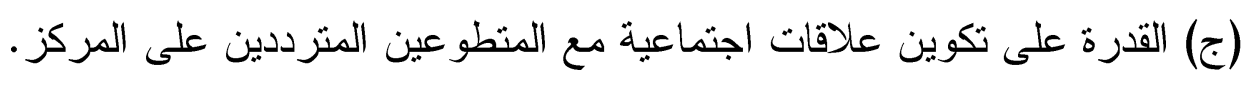

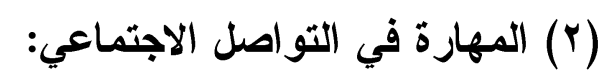

الاتصال عبارة عن العمليات البسيطة التي يتبادل الأشخاص بواعية اسطتها المشاعر ويبنــون

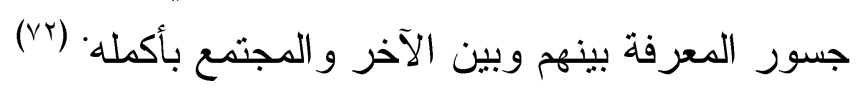

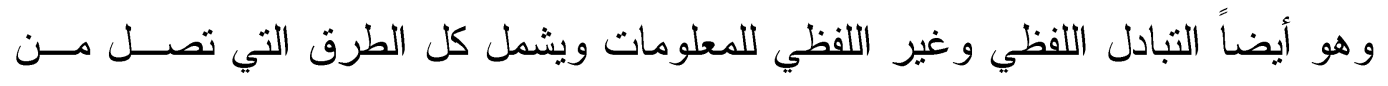

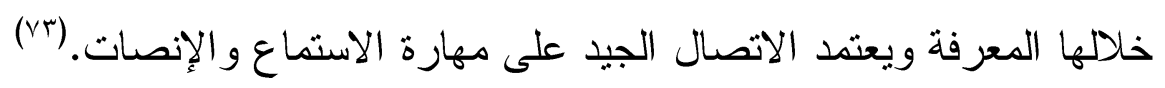

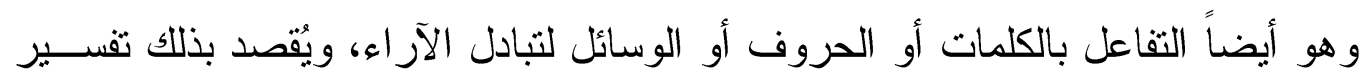

الكلمات و المعلومات ثم ثتاقلها. (Y乏) ويقصد بمهارة التو اصل الاجتماعي وفقاً لهذه الار اسة بأنها:

$$
\begin{aligned}
& \text { (أ) القدرة على التعبير عن المشاعر . } \\
& \text { (ب) القدرة على الحوار . } \\
& \text { (ج) القدرة على الاقناع. }
\end{aligned}
$$

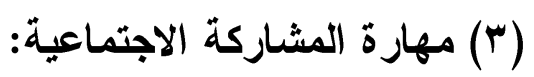

يُعرف معجم العلوم الاجتماعية المشاركة على أنها: تفاعل الفرد عقلياً وانفعالياً في

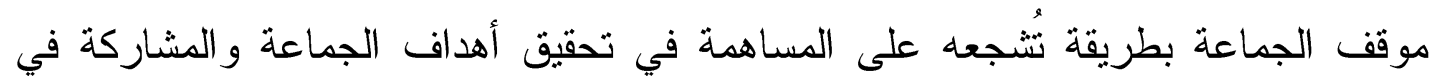
تحمل المسئولية.

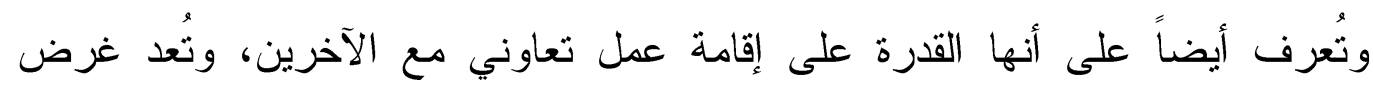

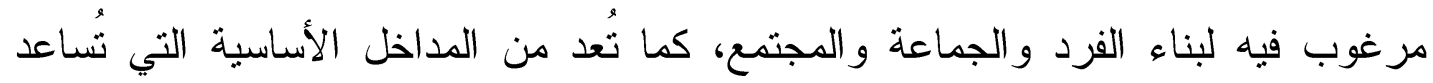
الجماعات والمجتمعات في تحقيق الاشباع المناسب لاحتياجاتهم وتتمية المسئولية الاجتماعية

ويقصد بمهارة المشاركة الاجتماعية وفقاً لهذه الار اسة بأنها:

(أ) القدرة على مشاركة الزملاء في المناقشات الجماعية.

(ب) القدرة على مشاركة الزملاء في الأنشطة الجامعية. 


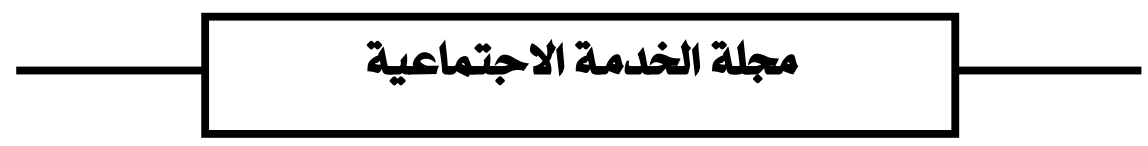

$$
\begin{aligned}
& \text { (ج) القدرة على مشاركة الزملاء في المو اقف الحياتية. } \\
& \text { (1) خصائص المهارات الاجتماعية: }
\end{aligned}
$$

هناك عدة خصائص أساسية مميزه لمفهوم المهارات الاجتماعية أهمها ما يلي: (VV)

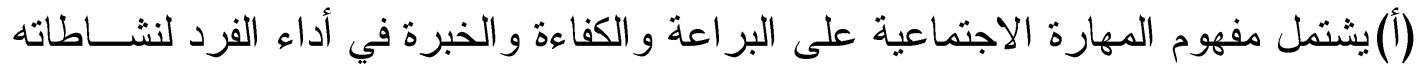
الاجتماعية، ومختلف أثنكال تفاعلاته مع الآخرين.

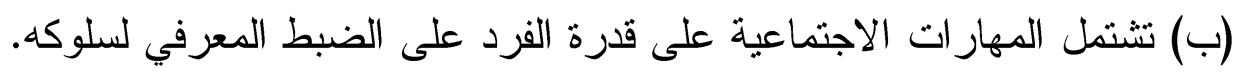

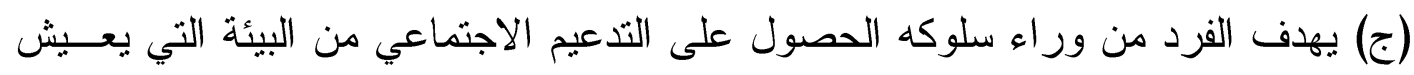
فيها بالشكل الذي يحقق له التو افق النفسي و الاجتماعي. (د) تتحدد المهارات الاجتماعية في ضوء جو انب معينة من سلوك الفرد، وخصاله، وفي إطار الملائمة للموقف الاجتماعي.

(r) أهمية تنمية المهارات الاجتماعية لضحايا التنمر من الطلاب المكفوفين:

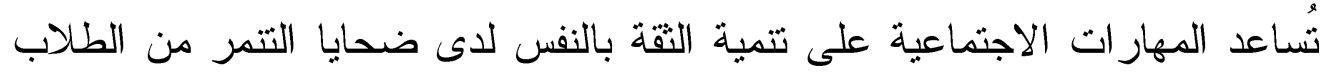

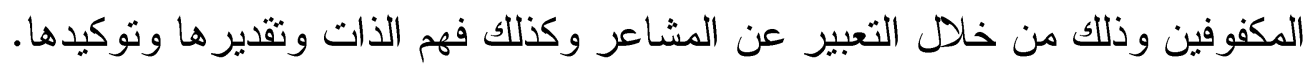

(ب) تُساعد على تجنب العلاقات السلبية وزيادة العلاقات الايجابية للمكفوف مع الرفاق.

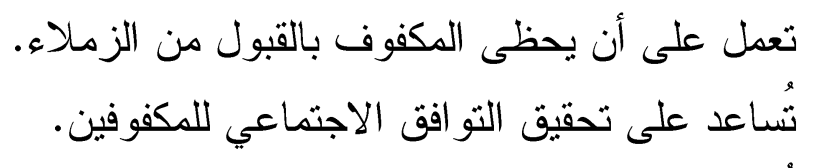
تؤدي إلى تحقيق السعادة و التقليل من مشاعر الاحباط و التعاسة.

\section{r- مفهوم ضحايا التنمر :}

يُعرف التتمر لغةً: يُقال للارجل السيئ الخلق قد نمّر وتتمّر ونمّر وجهه، أي غيّره

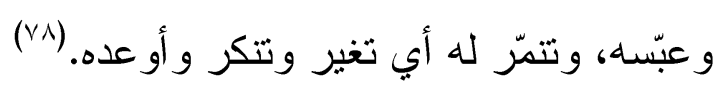

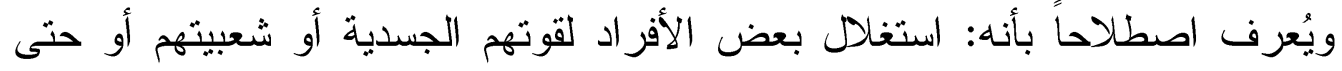

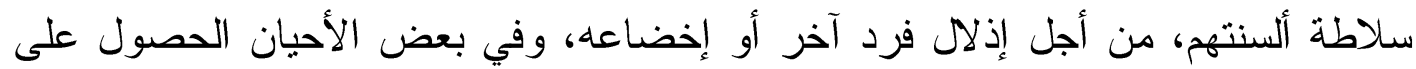
ما يريدونه هنه. (19a) بينما يُعرف ضحايا التتمر على أنهم هم الطلاب الذين يتعرضون للإساءة والضرر من

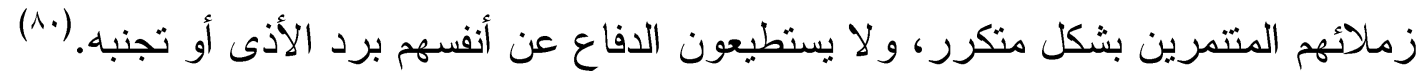

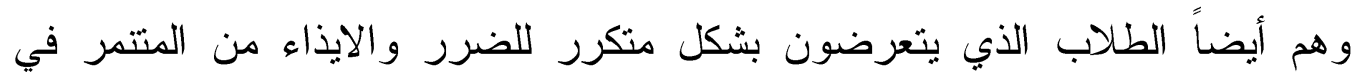

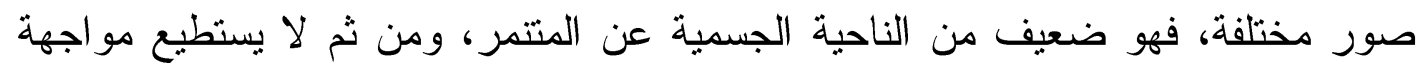
سلوك الايذاء الذي يتعرض لله من جانب المتنمر، فضلاً عن خصائصه النفسية

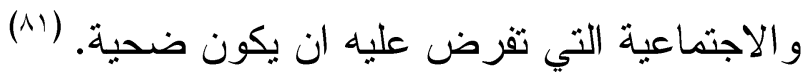




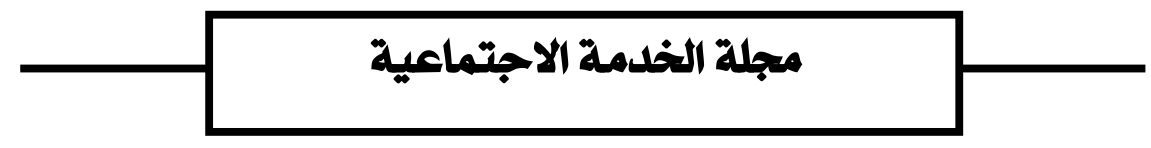

ومن جانبنا يمكن تعريف ضحايا التتمر بأنهم: هؤلاء الطلاب الذين يعانون من الايذاء

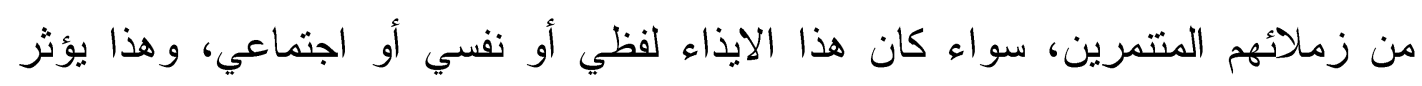

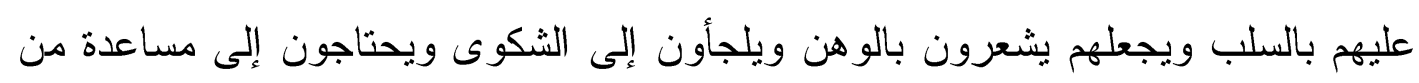

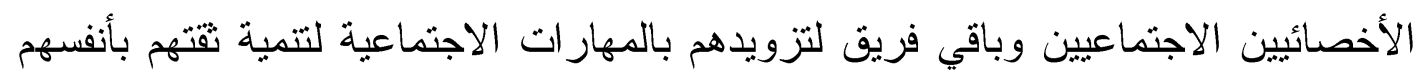

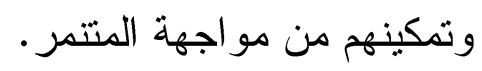

وبعد عرض ما سبق يمكن وضع المفهوم الاجرائي لضحايا التنمر: أ- الطلاب المكفوفين المستفيدين من المركز الثقافي للمكفوفين بجامعة أسيوط. ب- الذين يدرسون في كلية الآداب أقسام (اللغة العربية والدراسات الاسلامية والفلسفة لإنة و التاريخ).

ج- تتر اوح أعمار هم ما بين 9 أ: أقل من سب سنة. د- لا يعانون من أي إعاقة أخرى غير كف أفمار البصر . ه- من حصلو ا على درجات منخفضة على مقياس المهار ات الاتهر الاجنماعية.

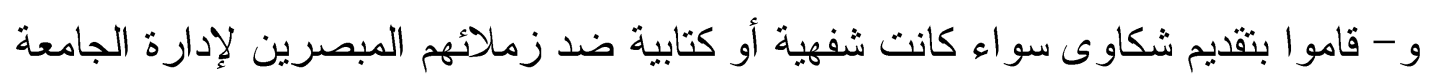

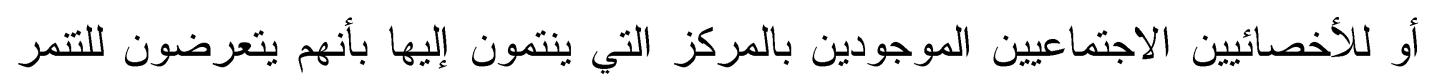

$$
\text { و الايذاء اللفظي و النفسي و الاجتماعي من الآخرين. }
$$

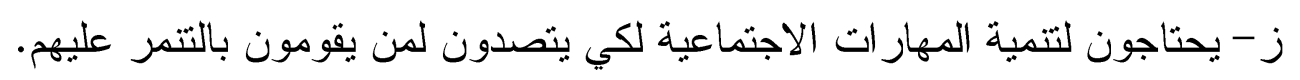
(1) (1)

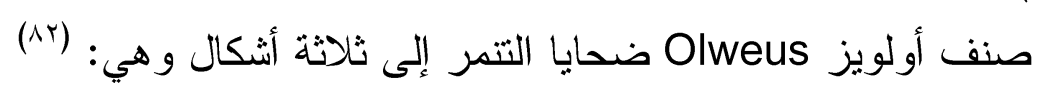
(أ)/الضحية السلبي: وهو من أكثر أثكال الضحايا انتشاراً، وهو شخص ضعيف البنية، لديه القليل من الأصدقاء أو ليس لديه اصدقاء، ويُّلقي حماية زائدة من الأسرة.

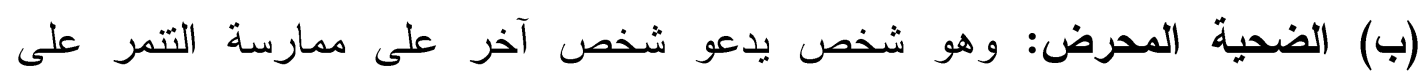

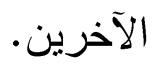
(ج)(الضحية المتنمر : الذين يدفعه للتتمر كونه كان ضحية للتنمر من قبل.

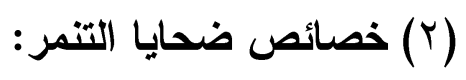
هناك بعض الخصائص التي تميز ضحايا التتمر كالتالي: (أ) قابلية السقوط (فالضحية سريع الانخداع، و لا يستطيع أن يدافع عن نفسه، وله خصائص نفسية وجسدية تجعله عرضه لأن يكون ضحية). 


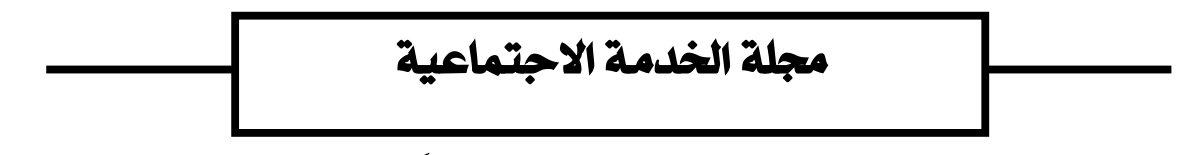

(ب) غياب الدعم (فالضحية يشعر بالعزلة والضعف، وأحياناً لا يذكر الضحايا الأشخاص الأين يتمرون بهم خوفاً من انتقامهم).

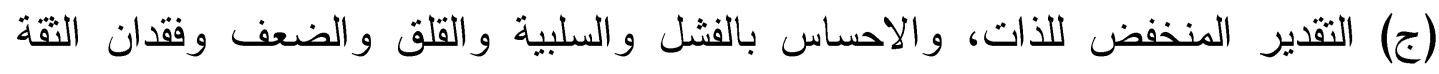

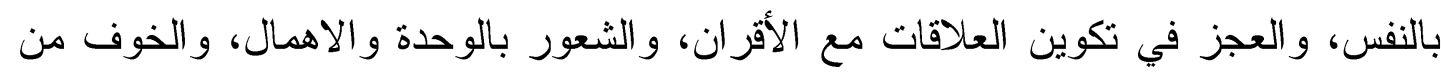

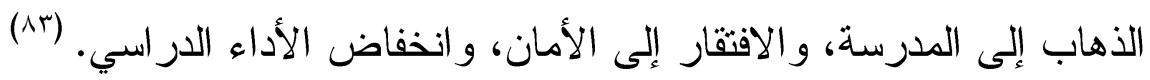

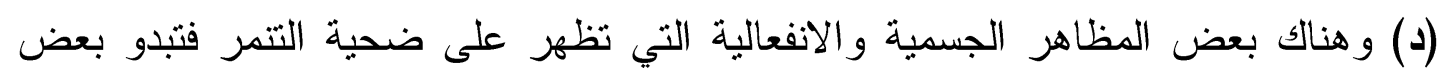

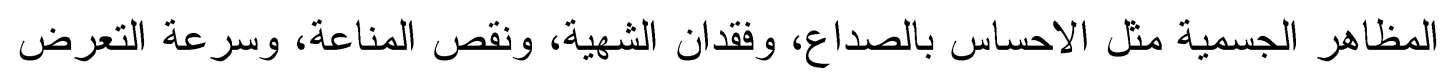

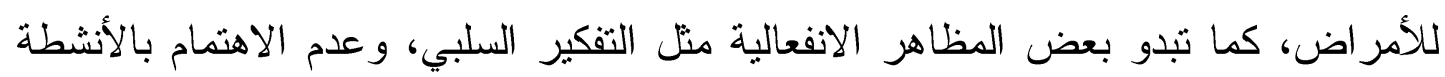

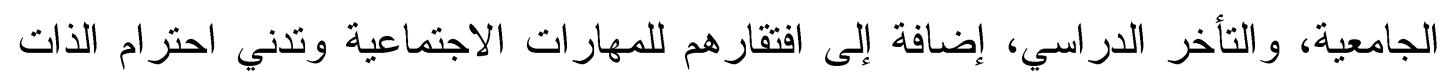

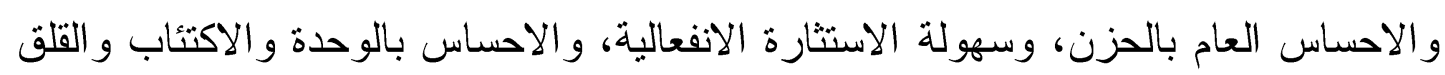

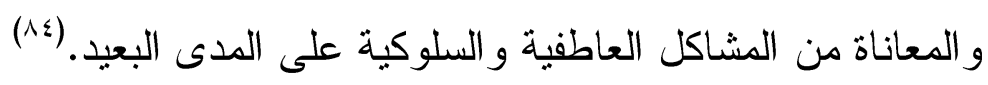
ع - مفهوم المعاقين بصرياً:

يُعرف المعاق بصرياً من وجهة النظر الطبية بأنه الفرد الذي يقفا المقدرة على الرؤية العزية

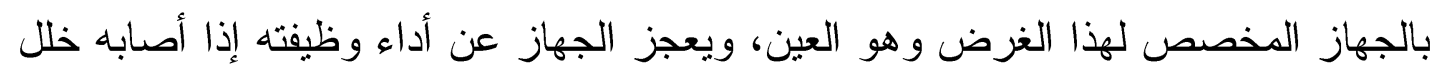

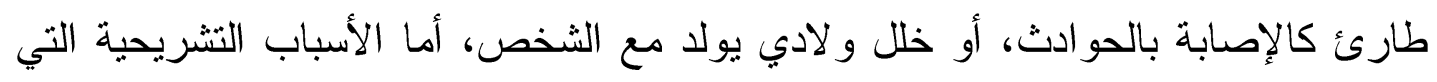

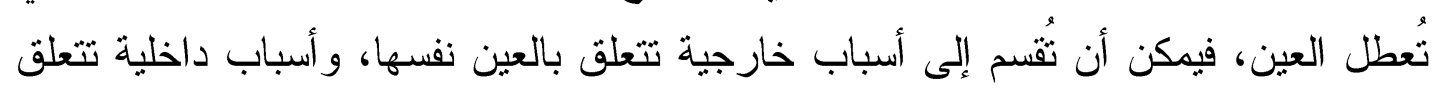
بالعصب البصري الموصل بالمر اكز العصبية. (10) العبان

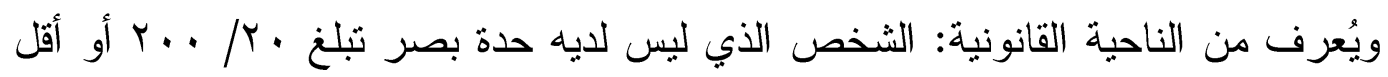

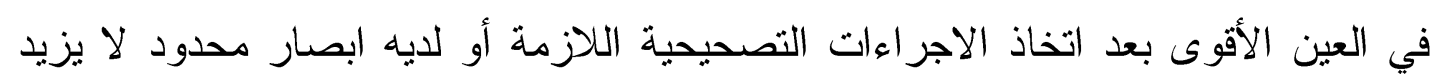

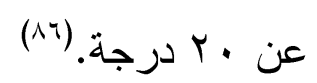

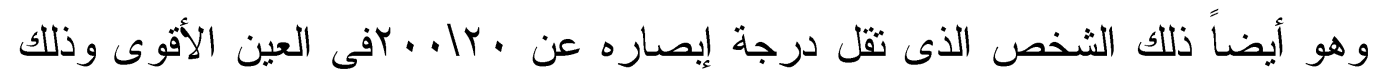
بعد استخدام النظارة لان مثل هذا الثخص لا لا يمكنه الاستفادة من الخبرة التعليمية التي تقدم

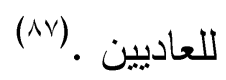

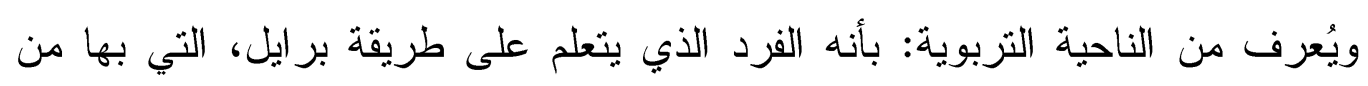

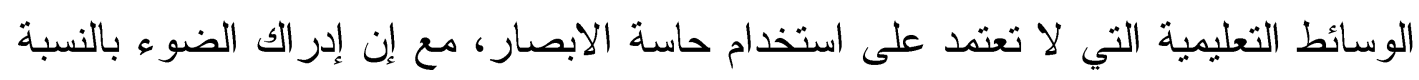

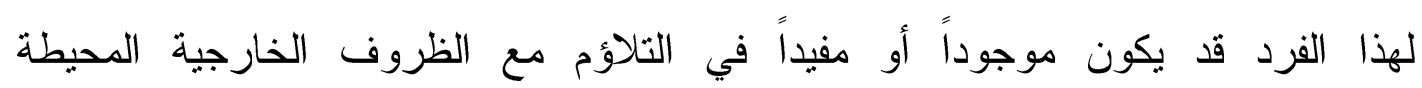
و والحركة. (^) 


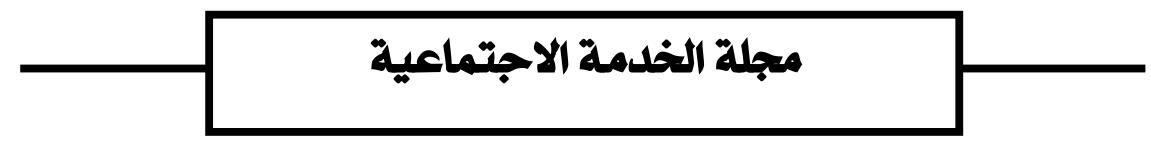

ويُعرف من المنظور الاجنماعي بأنه الفرد الذي لا يستطيع أن يجد طريقه دون قيادة

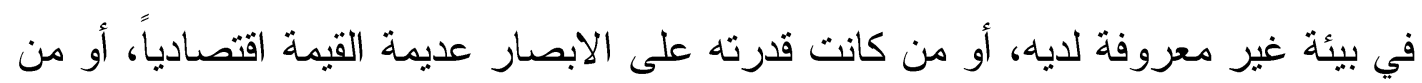

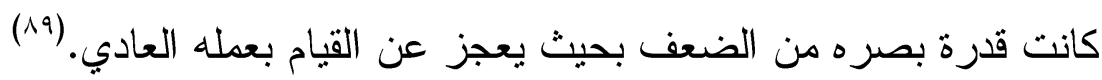
(1) (1) سمات المعاقين بصرياً:

(أ) السمات النفسية: إن الإعاقة البصرية تفرض على الثخص أن يعيش في عالمين عـالم

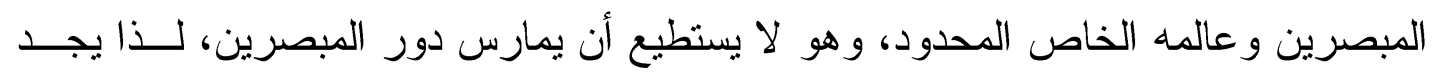

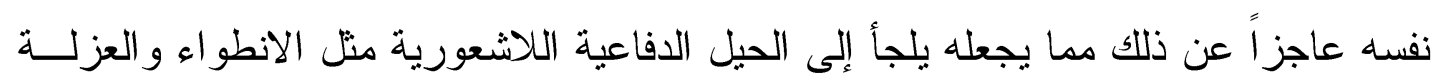

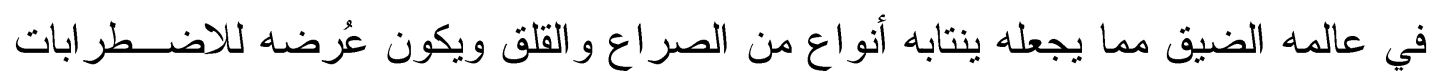

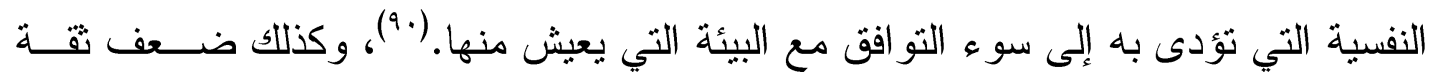
الكفيف بنفسه و عدم تقديره لذاته و الحساسية الز ائدة و الميول الانسحابية.

(ب) السمات الاجتماعية: الإعاقة البصرية غالباً ما تمنع الثخص من المشاركة في الأنشطة

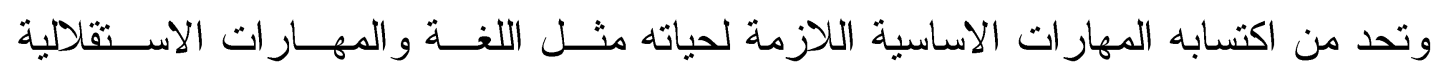

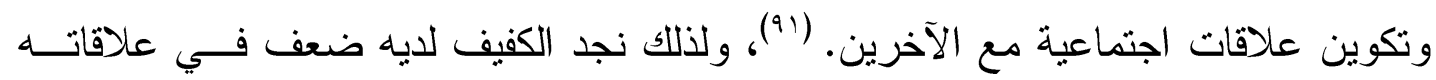
الاجتماعية وضعف التو اصل مع الآخرين وكذلك ضعف فئ في المشاركة الاجتماعية بالمقارنة بالمبصرين.

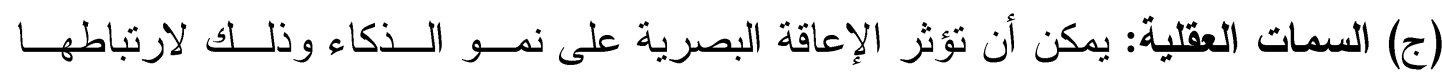
بجوانب القصور منل معدل نمو الخبرات وعلاقة المعاق بصرياً بيئنّه وقدرته على الإعة السيطرة

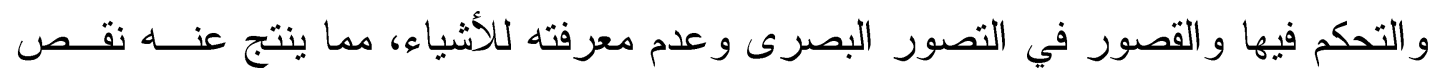

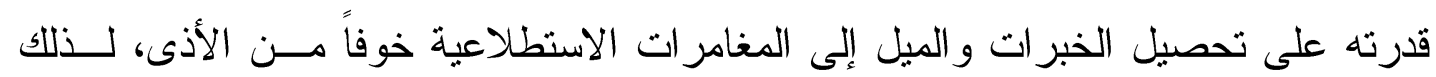

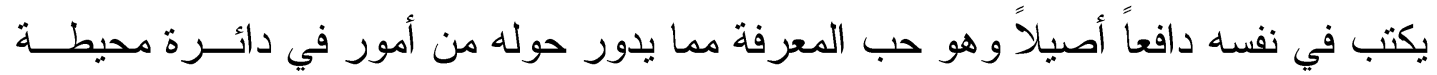

الني يعيش فيها. (9r)

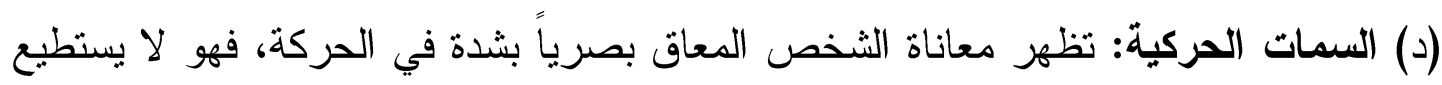

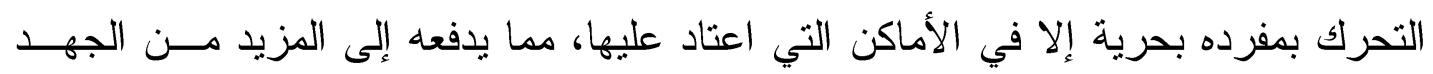

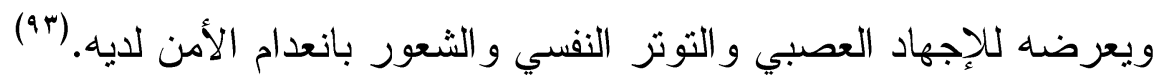

ه- العلاج الجماعي وتنمية المهارات الاجتماعية لضحايا التنــر مـن طـلاب الجامعـة

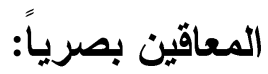

تدخل المهارات الاجتماعية في كل مظهر من مظاهر حياة الفرد، وتُؤثر في تكيفه وسعادته في مراحل حياته، وبالنسبة للمعاق بصرياً نجد أن قدرته على تكوين علاقات 


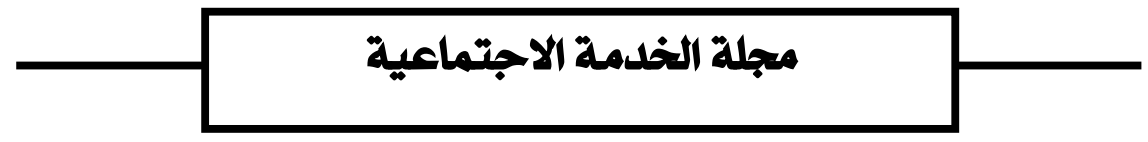

اجتماعية تحدد شعبيته بين أقرانه ومعلميه و الر اشدين المهمين في حياته، بالإضافة إلى أن

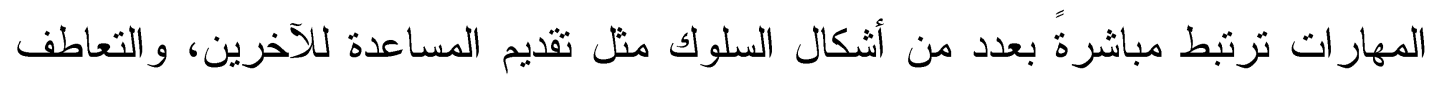

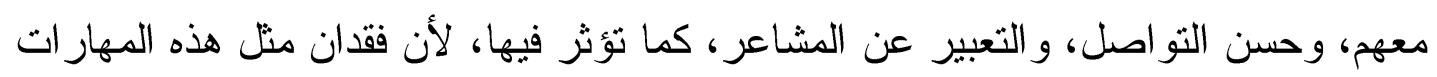

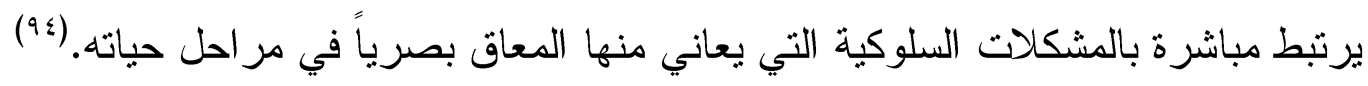
ويُركز مدخل العلاج الجماعي على العديد من الأبعاد المرتبطة بتتمية الوعي وزيادة

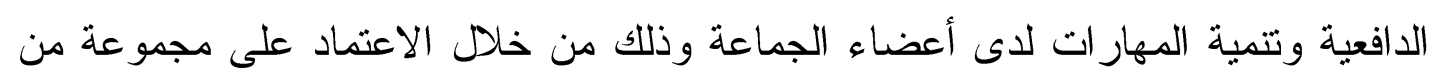

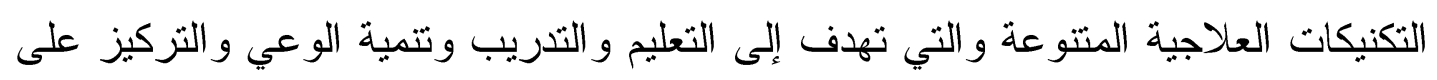

الآداء الاجتماعي لأعضاء الجماعة وتقويم الأنشطة التي يقومون بتتفيذها. (90)

أ- العلاج الجماعي وتنمية مهارة تكوين العلاقات الاجتماعية لضحايا التنمـر مـن طـلاب

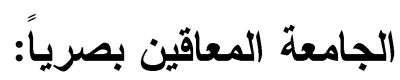

يُعد تكوين العلاقات الاجتماعية بؤرة اهتمام طريقة خدمة الجماعة، حيث يُنظر للجماعة

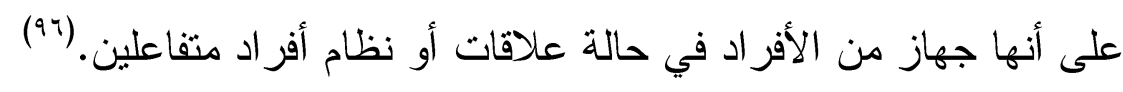
و العلاقات الاجتماعية بين الأفر اد لا تقتصر فقط على الود و الصداقة و التعاون بل تتيح

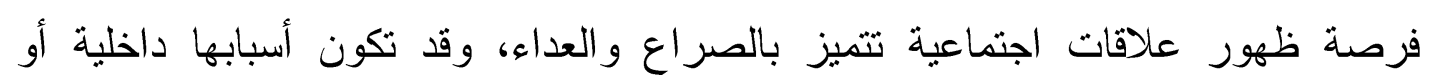
خارجية، سيكولوجية أو اجتماعية. (av)

وقد قام الباحث باستخدام استر اتيجيات وتكنيكات العلاج الجماعي في تنمية مهارة تكوين

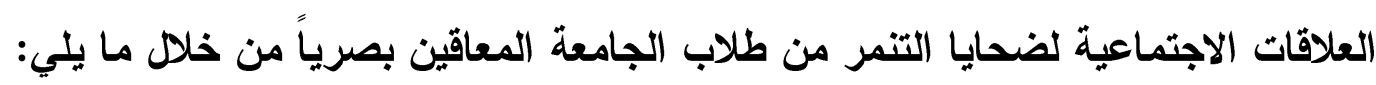
(1)حرص الباحث على الاهتمام بتكوين العلاقات الاجنماعية بينه وبين الطالب المعاق

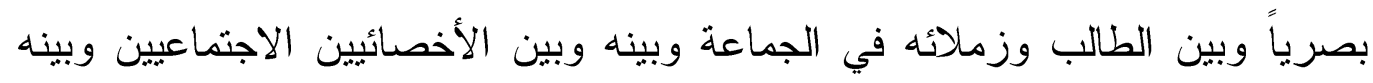
وبين المنظوعين في المركز.

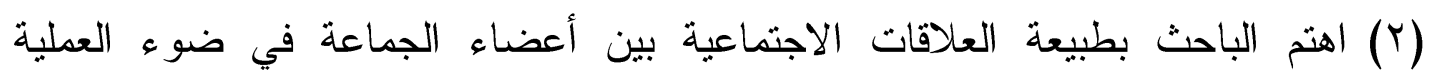

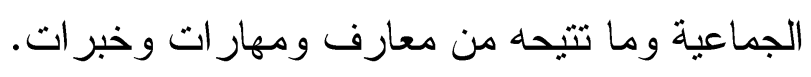

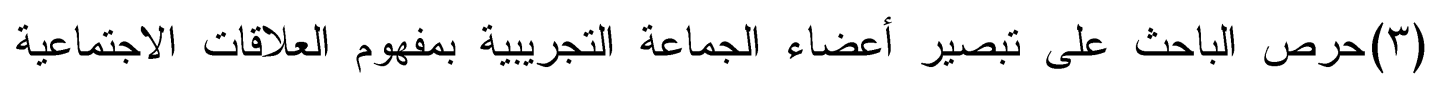

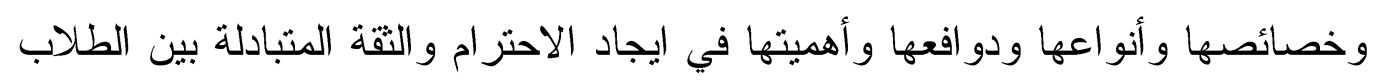

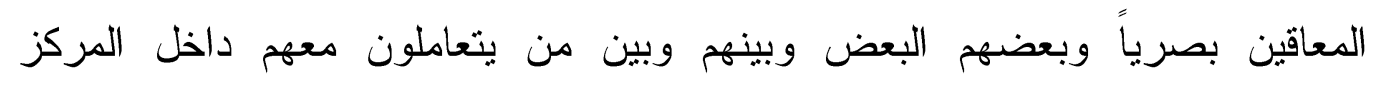
وخارجه.

(ع)حرص الباحث على ايجاد وابتكار الأنشطة التي تزيد من العلاقات الاجتماعية بين الطلاب وبعضهم البعض. 


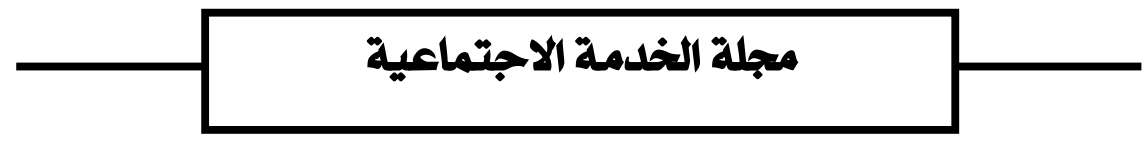

ب-العلاج الجماعي وتنمية مهارة التواصل الاجتماعي لضحايا التنمر من طلاب الجامعـة

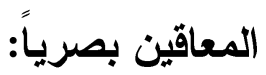

يلعب التو اصل دوراً أساسياً في حياة الفرد يبدأ باشباع حاجاته الأساسية وينتهي بتقـــيره

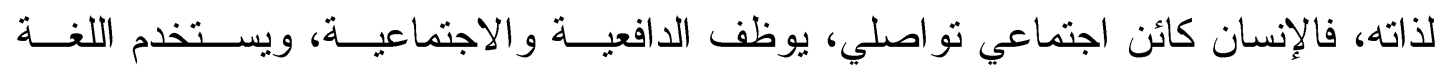

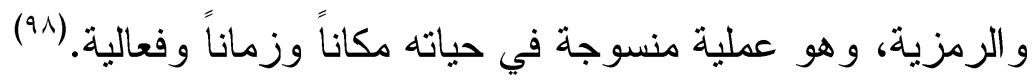

وقد أثبتت بعض الدراسات أن الثخص الكفيف يعاني من مشكلة النواصل اللفظي، وقد

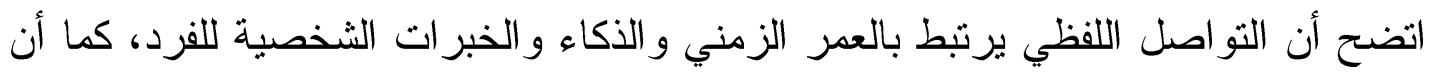

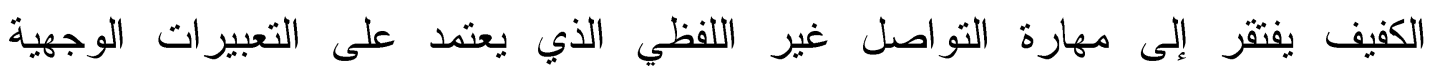

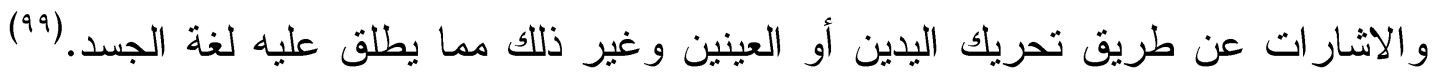

ويُعد غياب حاسة الابصار من الأسباب التي تؤدي إلى صعوبة نسبية في الاتصال

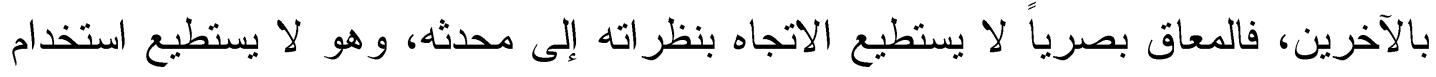

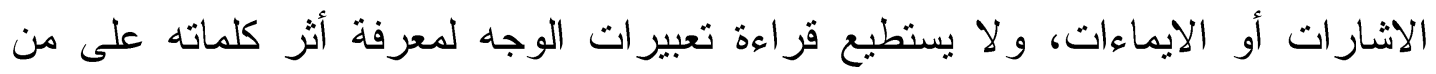

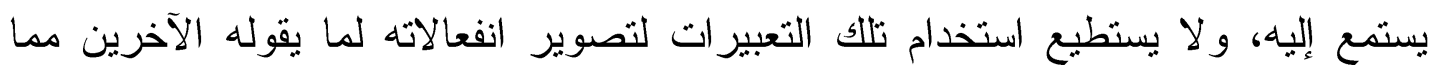

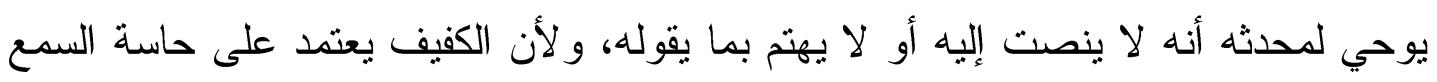
وحدها في الاتصال بالآخرين، و لأنه لا يستطيع ادر الك أفعال الآخرين بما يقوله لهانه، فإنه يحتاج

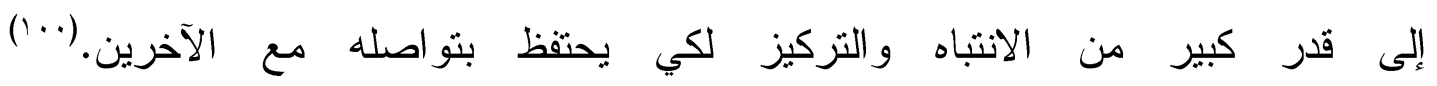

وقد قام الباحث باستخدام استر اتيجيات وتكنيكات مدخل العلاج الجماعي في تنمية مهارة التواصل الاجتماعي لضحايا التنمر من طلاب الجامعة المعاقين بصرياً فيما يلي: (1) حرص الباحث على تبصير أعضاء الجماعة بأهمية مهارة التواصل الاجتماعي في تقوية شخصية الطالب ضحية التتمر من خلال الاتقان في فن الحديث وترتيب الأفكار

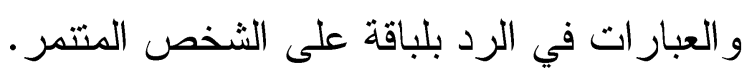

(Y) حرص الباحث على تدريب أعضاء الجماعة على الانصات الفعال للخبر اءو الزملاء أثثاء ممارسة أوجه نشاط البرنامج.

(r) حرص الباحث على تدريب أعضاء الجماعة على استخدام وسائل التو اصل اللفظي وغير اللفظي في رفض أي تتمر أو مضايقة من الآخرين. 


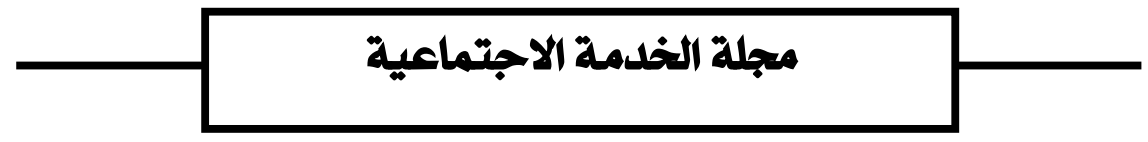

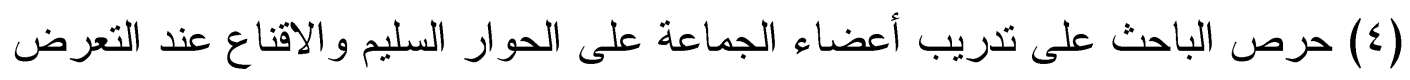
للتتمر و التعامل مع المتتمر بالأخلاق الحميدة و عدم اتباع نفس أسلوبه.

ج- استخدام العلاج الجماعي وتنمية مهارة المشاركة الاجتماعية لضحايا التنمر من طلاب

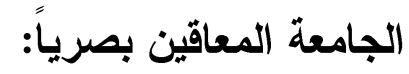

تستتد طريقة خدمة الجماعة من خلال مدخل العلاج الجماعي إلى المسلمات التالية لتتمية مهارة المشاركة الاجتماعية:

(1) ينضم الأعضاء إلى الجماعة العلاجية رغبة منهم في الشباع حاجاتهم وتتميـــة مهــار اتهم الاجتماعية.

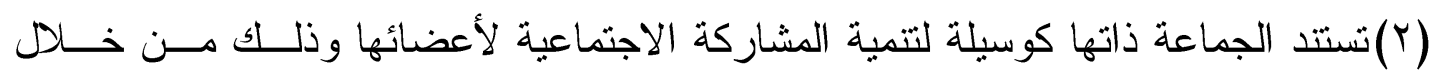
اشتر اكهم في تصميم وتتفيذ وتقويم الأنشطة المختلفة خلال فترة التذخل المهني. (r) تستخدم الجماعة من خلال الخبرة الجماعية اكساب أعضاء الجماعة المشاركة. وقد قام الباحث باستخدام استراتيجيات وتكنيكات مدخل العلاج الجماعي في تنمية مهارة

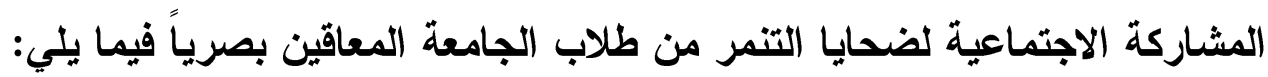
(أ) حرص الباحث على بناء الثقة في طلاب الجامعة المعاقين بصرياً واستثارتهم للمشاركة. (ب) اتاحة الفرصة لطلاب الجامعة المعاقين بصرياً للمشاركة في البرامج والأنشطة المختلفة.

(ج) حرص الباحث على تبصير أعضاء الجماعة بأهمية المشاركة الاجنماعية في زيادة

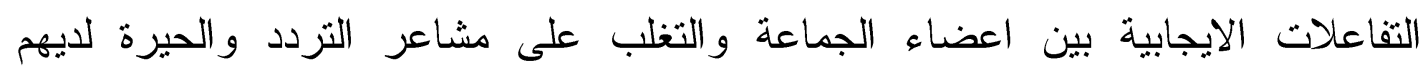
و الشعور بالمتعة و السعادة من خلال مشاركته للآخرين.

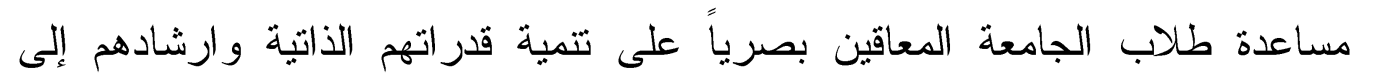
الاتجاهات التي تدعم المشاركة الاجتماعية.

خامساً: الإجراءات المنهجية للار اسة:

ا-نوع الدراسة: تتنمي الدراسة الحالية إلى الدراسات شبه التجريبية حيث تهدف إلى تحديد

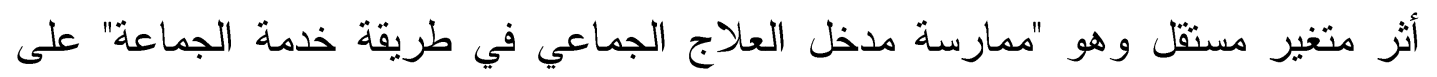
متغير تابع وهو "تنمية المهار ات الاجتماعية لدى ضحايا التتمر من طلاب الجامعة المعاقين بصرياً. 


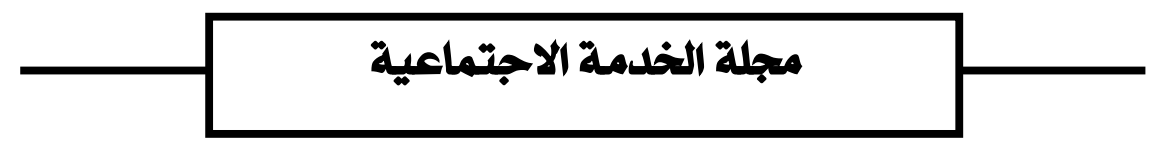

ץ- المنهج المستخدم: اعتمدت الدراسة على المنهج التجريبي الذي يعتمد على التصميم

$$
\text { التجريبي باستخدام مجمو عتين إحداهما تجريبية و الأخرى ضابطة. }
$$

ب- فروض الار اسة: تتطلق الدراسة من فرض رئيس مؤداه: توجد فروق معنوية ذات دلالة احصائية بين استخدام مدخل العلاج الجماعي في طريقة خدمة الجماعة لتتمية المهار ات الاجتماعية لدى ضحايا التتمر من طلاب الجامعة المعاقين بصرياً. وينبثق من هذا الفرض مجموعة من الفروض الفرعية مؤداها كالتالي: أ-توجد فروق معنوية ذات دلالة احصائية بين استخدام مدخل العلاج الجماعي في طريقة خدمة الجماعة لتتمية مهارة تكوين العلاقات الاجتماعية لدى ضحايا التتمر من طلاب الجامعة المعاقين بصرياً. ب-توجد فروق معنوية ذات دلالة احصائية بين استخدام مدخل العلاج الجماعي في طريقة خدمة الجماعة لتتمية مهارة التو اصل الاجتماعي لدى ضحايا التتمر من طلاب الجامعة المعاقين بصرياً.

ج- توجد فروق معنوية ذات دلالة احصائية بين استخدام مدخل العلاج الجماعي في طريقة خدمة الجماعة لتتمية مهارة المشاركة الاجتماعية لدى ضحايا التنمر من طلاب الجامعة المعاقين بصرياً.

$$
\text { ع - أدوات الار اسة: اعتمد الباحث على الادوات التالية: }
$$

أ- تحليل محتوى التقارير الدورية لاجتماعات الجماعة التجريبية وذلك لمعرفة تأثير برنامج التذخل المهني باستخدام مدخل العلاج الجماعي لتتمية المهار ات الاجنماعية لضحايا التتمر من المعاقين بصرياً.

ب- مقياس المهار ات الاجتماعية: وقد تم اتباع الخطوات التالية في اعداد المقياس: (1) قام الباحث بالاطلاع على العديد من الكتابات العلمية المتخصصة والبحوث العربية و الاجنبية و المقاييس التي تتاولت موضوع المهار ات الاجتماعية، و التي منها:

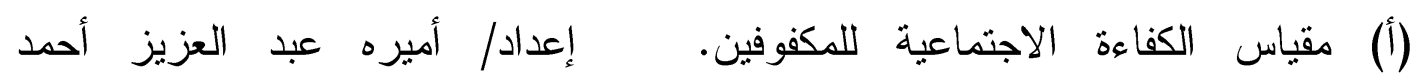

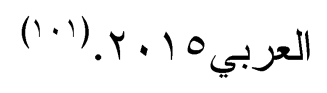

(ب) مقياس المهار ات الاجتماعية لدى الطلاب المكفوفين في مدارس الدمج بالمرحلة إعداد/ عباد بن عبيد بن منيع الله بل بله

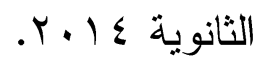
العتيبي. (1.) 


\section{مجلة الخدمة الاجتماعية}

(ج)مقياس تقدير المهارات الاجتماعية للأطفال. إعداد/ أماني عبد المقصود عبد

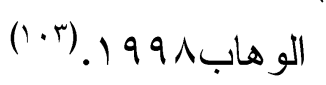

(r) تحديد أبعاد المقياس وفقاً لأهداف الدراسة وفروضها في ثلاثة أبعاد هي:

- البعد الأول: تتمية مهارة نكوين العلاقات الاجتماعية وتتضمن العبارات من (1)

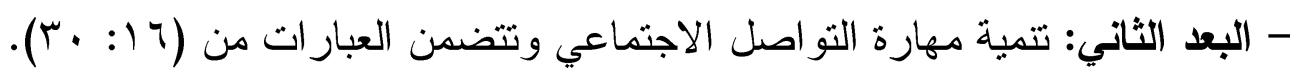

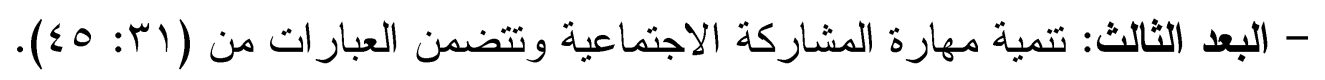
عرض أبعاد المقياس في صورته الأولية على مجموعة من المحكمين في الخدمة الاجتماعية وكلية التربية و الآداب وبلغ عددهم (V) سبعة محكمين.

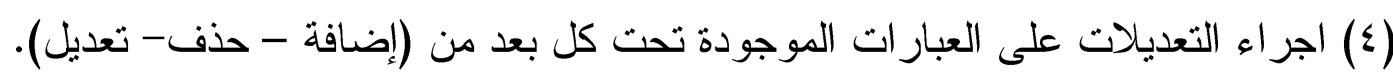

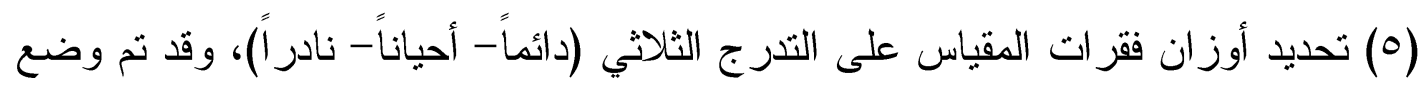

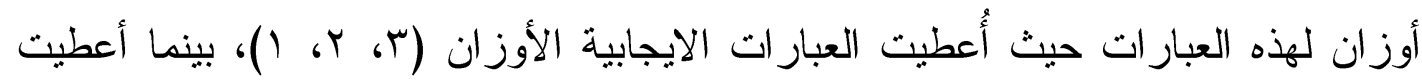

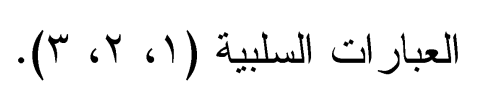

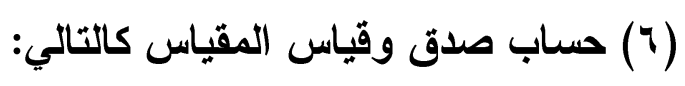

للتأكد من الخصائص السيكومترية (الثبات و الصدق) لمقياس المهارات الاجتماعية لضحايا

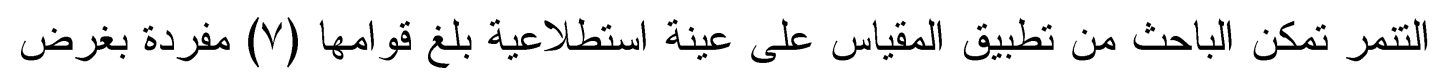

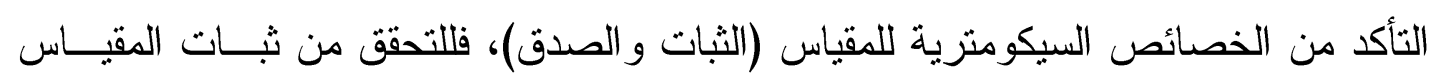

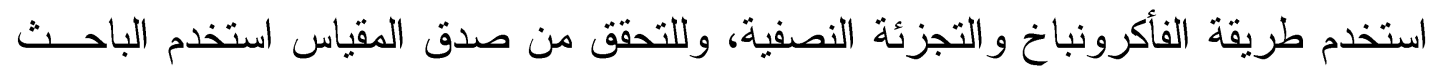
طريقة صدق المحكين والاتساق الداخلي ويمكن عرض الثبات و الصدق بالثكل التالي:-

(أ) صدق المقياس: - - صدق المحكمين (الصدق الظاهري):

أمكن للباحث من إعداد مقياس للمهارات الاجتماعية وتم إعـــاد الصـــورة الأوليــة

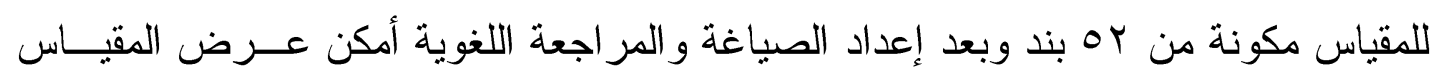

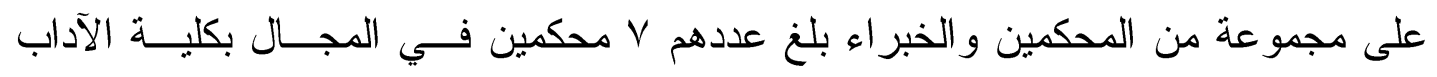

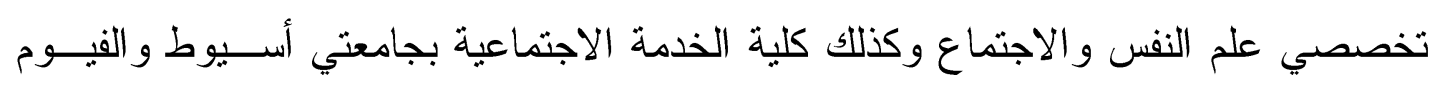

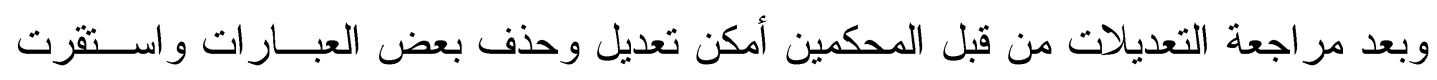

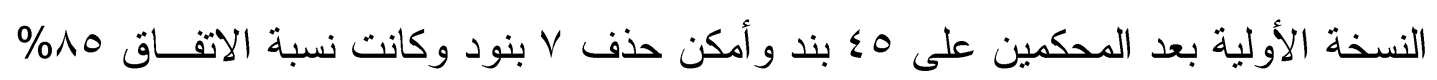




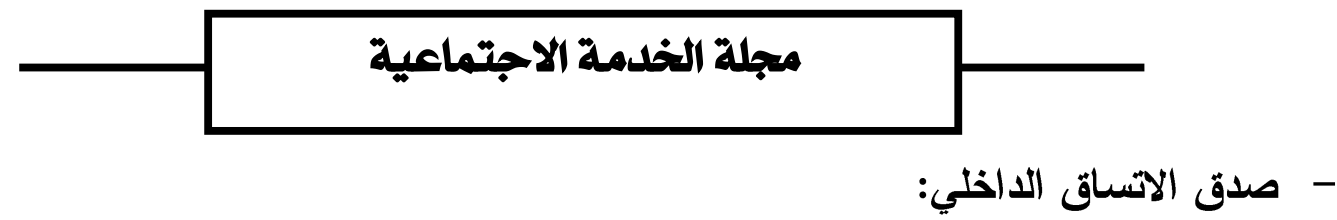

جدول (r) يوضح الاتساق الداخلي بين درجة كل بند بالدرجة الكلية للبعد على مقياس المهار ات الاجنماعية لدى عينة الدراسة

\begin{tabular}{|c|c|c|c|c|c|}
\hline \multicolumn{2}{|c|}{ المشاركة الاجتماعية } & \multicolumn{2}{|c|}{ التواصل الاجتماعي } & \multicolumn{2}{|c|}{ تكوين العلاقات الاجتماعية } \\
\hline الارتباط & البند & الارتباط & البند & الارتباط & البند \\
\hline$* * * T \leq r$ & 1 & **..TY人 & 1 & $* * . . T Y \leq$ & 1 \\
\hline$* * \ldots \leqslant Y q$ & r & $* * . . \vee 9 \leq$ & r & $* * . .0 \leq 0$ & r \\
\hline$* * .701$ & $r$ & $* * .70 \leqslant$ & r & ***. • . TY & $r$ \\
\hline$* * \ldots \leqslant \Lambda \leqslant$ & $\varepsilon$ & $* * . \vee V r o$ & $\varepsilon$ & ***. & $\varepsilon$ \\
\hline **..0T & 0 & ש** • & 0 & $* * . \wedge r V$ & 0 \\
\hline$* * .0 \vee 0$ & 7 & $* * . .7 \leq 0$ & 1 & $* * . . T \leq V$ & 7 \\
\hline$* * .0 \leqslant 0$ & v & ***. . & v & $* * .0 \mathrm{VV}$ & V \\
\hline ***.TrV & $\wedge$ & $* * . V \leq V$ & $\wedge$ & $* * . .011$ & $\wedge$ \\
\hline$* * .091$ & 9 & $* * . . \vee 90$ & 9 & $* * \cdot . \vee \cdot 1$ & 9 \\
\hline$* * .090$ & 1. & $* * . .0 Y \leq$ & 1. & $* * . . \vee 91$ & 1. \\
\hline$* * .00 r$ & 11 & $* * . .0 \leqslant 1$ & 11 & $* * . .090$ & 11 \\
\hline$* * . .7 .9$ & Ir & ** • . Vo & Ir & *** . . & ir \\
\hline$* . M 10$ & $\pi$ & *** • . & Ir & $* * . . \vee \wedge \leq$ & r \\
\hline$* * \ldots \leqslant$ & $1 \varepsilon$ & $* * .70 \leq$ & $1 \varepsilon$ & 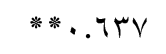 & $1 \varepsilon$ \\
\hline$* * . \wedge \ldots$ & 10 & $* * . \vee v q r$ & 10 & $* *, . V \leq 1$ & 10 \\
\hline
\end{tabular}

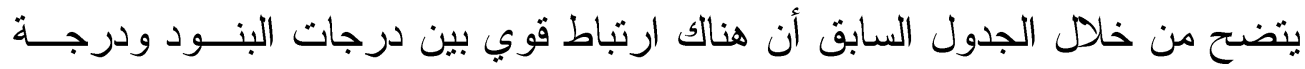
الأبعاد الثلاثة الخاصة بمقياس المهار ات الاجتماعية لاى ضحايا التتمر من الطلاب المعاقين

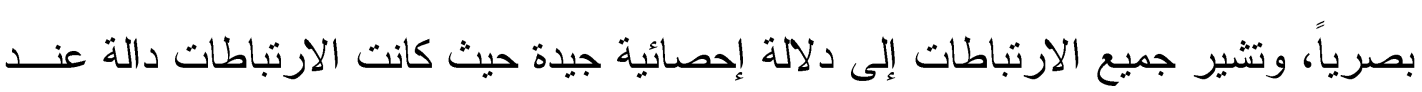

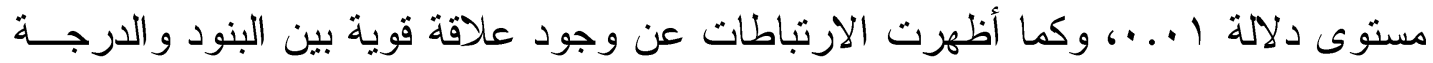

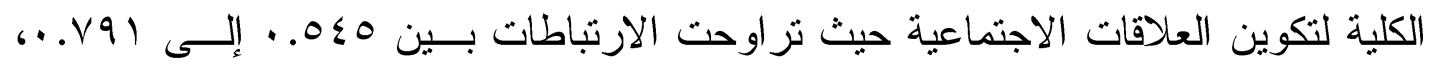
بينما تراوحت الارتباطات على البنود الخاصة بالدرجة الكلية للتو اصــل الاجتـــاعي بـين

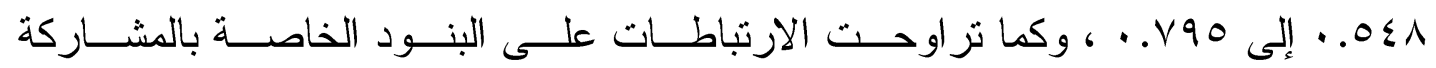

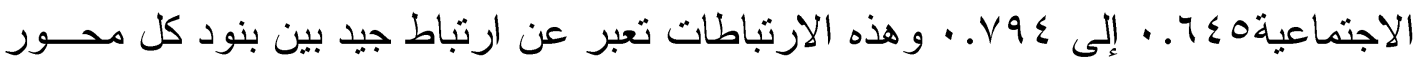

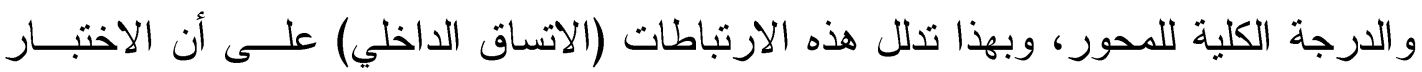

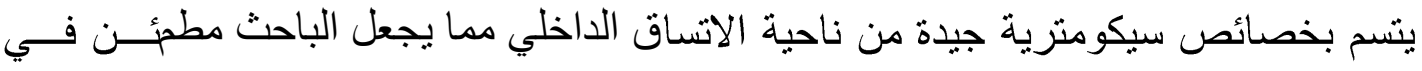

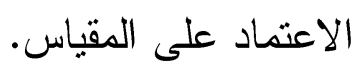




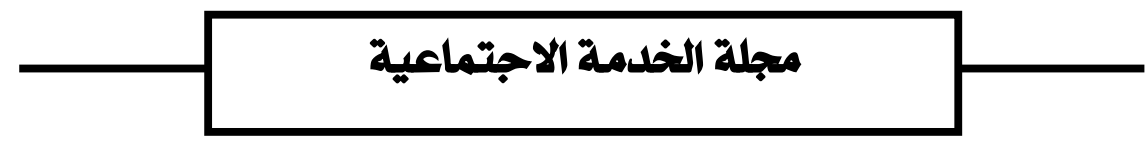

(ب) ثبات المقياس:

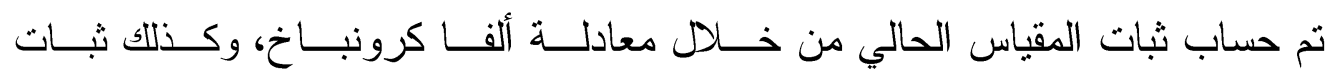
التجزئة (سبيرمان - براون، جتمان). و الجدول التالي يبين معاملات الثبات للمقاييس الفرعية و الدرجة الكلية للمقياس:

جدول (ء) يوضح ثبات ألفاكرونباخ و التجزئة النصفية لاختبار المهار ات الاجتماعية

\begin{tabular}{|c|c|c|c|c|}
\hline \multicolumn{2}{|c|}{ ثبات التجزئة بعد تصحيح أثر طول الاختبار } & \multirow{2}{*}{ الارتباط معامل } & \multirow{2}{*}{ 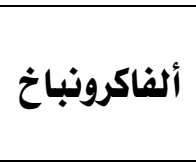 } & \multirow{2}{*}{ المتفيرات } \\
\hline 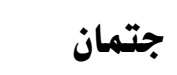 & سبيرمان - براون & & & \\
\hline.$\wedge 9$. & $\therefore \wedge 9$. & $\cdot . \wedge \cdot r$ & $\cdot v \leq r$ & مهارة تكوين العلاقات الاجتماعية \\
\hline.$\times 91$ & $\cdot . \wedge \cdot V$ &. $.7 V 7$ &.$V Y T$ & مهارة التواصل الاجتماعي \\
\hline. .101 &.$\wedge 4$ & $\because v 0 \leq$ & $\because \vee \wedge \circ$ & مهارة المشاركة الاجتماعية \\
\hline$. \vee \vee 9 \leq$ &.$v 90$ &. .77 &.$V O V$ & الدرجة الكلية \\
\hline
\end{tabular}

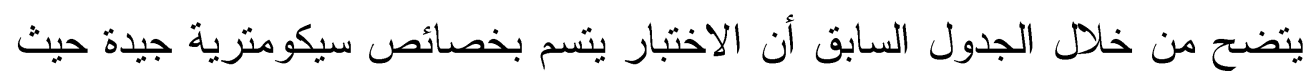

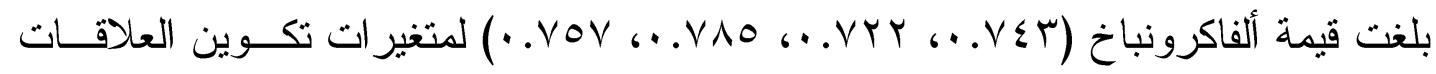

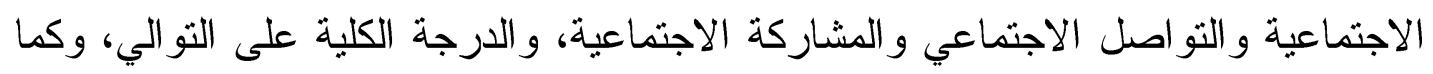

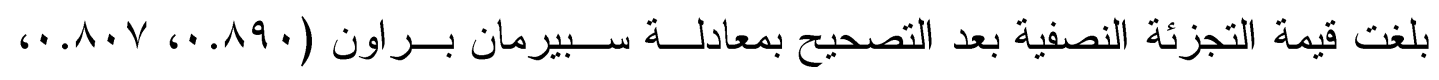

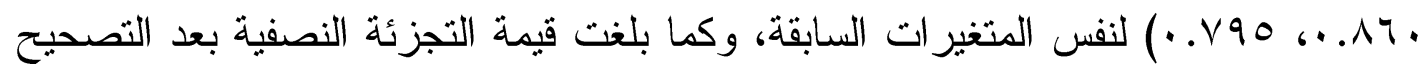

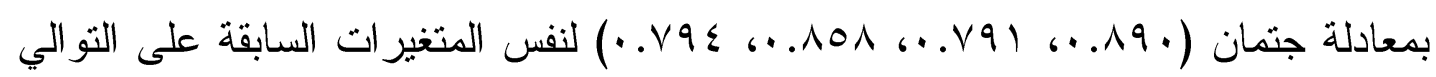

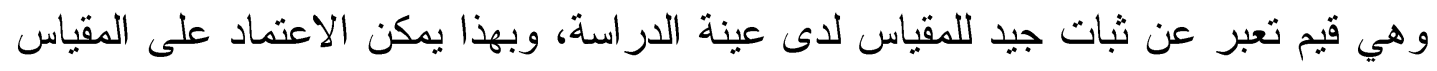
الحالي في قياس المهار ات الاجتماعية.

\section{( الصياغة النهائية للمقياس: (v)}

في هذه المرحلة وعقب الانتهاء من تعديل عبار ات المقياس وأبعاده الأساسية وفي ضوء

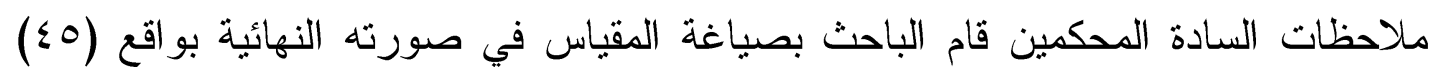

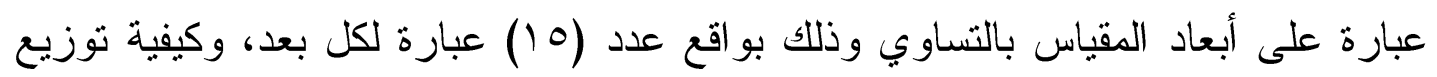

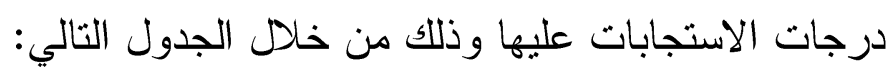




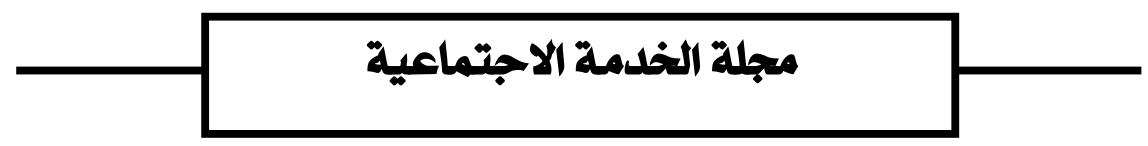

جدول رقم (0) يوضح عدد عبار ات كل بعد من أبعاد المقياس ووزنها النسبي

\begin{tabular}{|c|c|c|}
\hline الوزن النسبي & 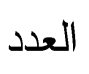 & أبعاد المقياس \\
\hline 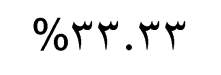 & 10 & البعد الأول: مهارة تكوين العلاقات الاجنماعية \\
\hline 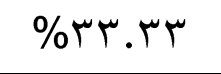 & 10 & البعد الثاني: مهارة التو اصل الاجنماعي \\
\hline سז. & 10 & البعد الثالث: مهارة المشاركة الاجتماعية \\
\hline$\% 1 \ldots$ & $\leqslant 0$ & المجموع \\
\hline
\end{tabular}

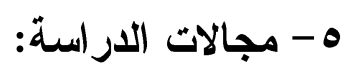

أ- المجال البشري: تكون إطار المعاينة من 70 طالب جامعي معاق بصرياً، ولكن ما تم

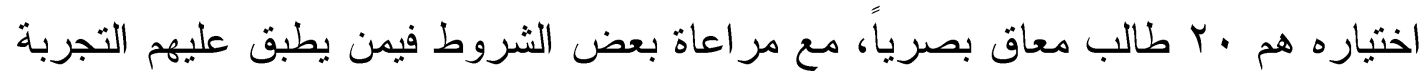
و هي كالتالي: - 20 - 20

(1) أن يكون من المترددين على المركز الثقافي للمكفوفين بجامعة أسيوط بصفة دائمة. (Y) أن يكون ليس لايه اعاقة أخرى مع الاعاقة البصرية.

(r) قد حصل على درجات منخفضة في مقياس المهار ات الاجتماعية لضحايا التتمر. (§) أن يكون لديه الرغبة في حضور أنشطة برنامج التدخل المهني. ب- المجال المكاني: ثم تطبيق البحث على المركز الثقافي للمكفوفين التابع للإدارة العامة لرعاية الشباب بجامعة أسيوط وسبب اختيار هذه المؤسسة: (1) أنها المؤسسة الوحيدة التابعة لمؤسسة حكومية (جامعة أسيوط) و التي تؤدي خدمات ثقافية و اجتماعية ورياضية للطلاب الجامعيين المعاقين بصرياً. (r) تزحيب القائمين على إدارة هذه المؤسسة و العاملين بها بالباحث. (r) وجود قاعات وحجرات لإجر اء أنشطة برنامج التذخل المهني فيها. ج- المجال الزمني للار اسة: ويتمنل في الفترة الزمنية التي استغرقها برنامج التدخل

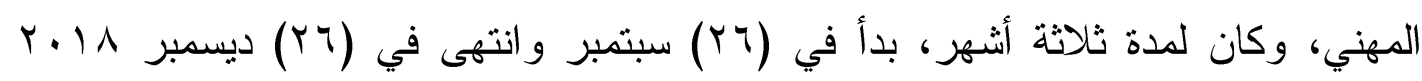
بو اقع TV اجتماع بمعدل اجتماعين أسبو عياً يومي الأثنين، الأربعاء. 


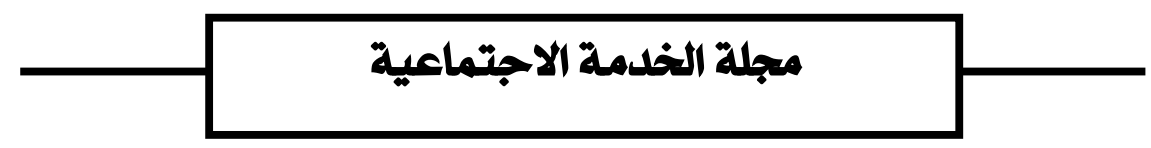

سادساً: برنامج التدخل المهني باستخدام العلاج الجماعي لتنمية المهارات الاجتماعية لضحايا التنمر من طلاب الجامعة المعاقين بصرياً:

1- الأسس العلمية التي يعتد عليها برنامج التلخل المهني:

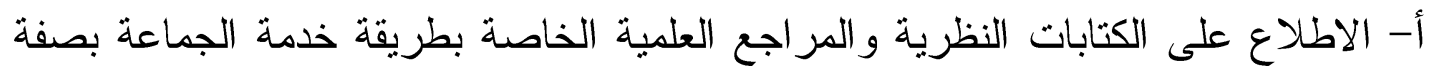

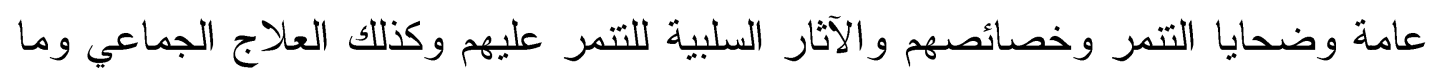

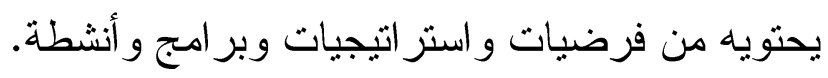
ب- الاستعانة بآراء الخبراء و العاملين مع المكفو فين. ج- اجات ورغبات وميول أعضاء الجماعة التجريبية، بحيث تثوافق أنشطة برنامج التدخل المهني معها.

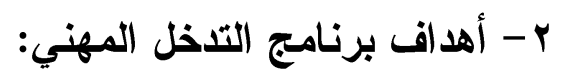

الهدف الرئيس لبرنامج التذلل المهني هو اختبار استخدام مدخل العلاج الجماعي في

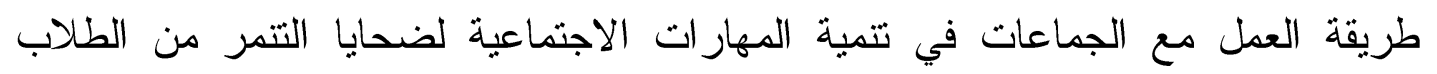
المكفوفين.

وينيثق من هذا الهدف مجموعة من الأهداف الفرعية تتمثل في:

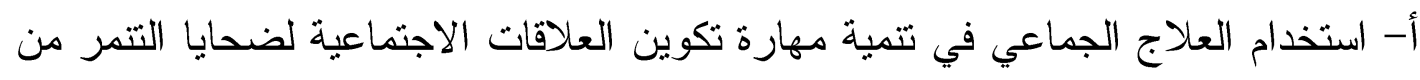
طلاب الجامعة المعاقين بصرياً. ب- استخام العلاج الجماعي في تتمية مهارة التواصل الاجتماعي لضدايا التتمر من

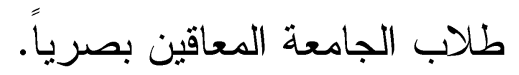
ج- استخدام العلاج الجماعي في تتمية مهارة الشاركة الاجتماعية لضحايا التتمر من

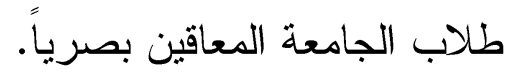

ب- ب- مراحل التخل المهني باستخام العلاج الجماعي:

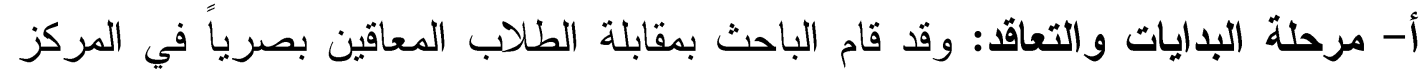

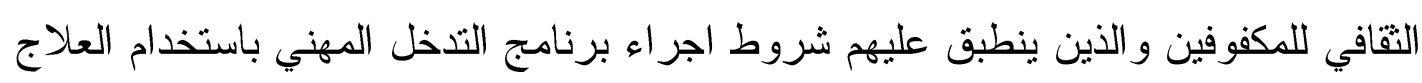

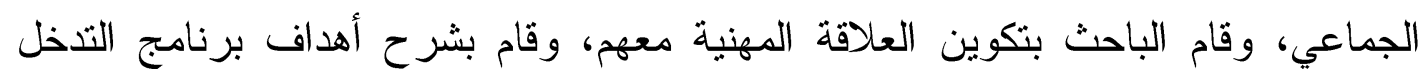

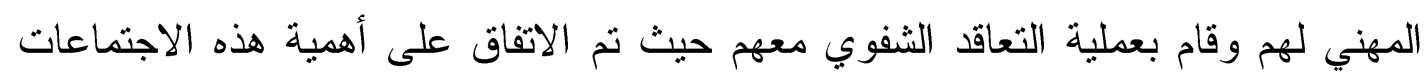

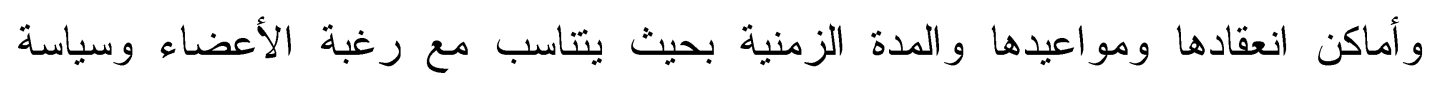
المؤسسة وعمل الباحث، وكذلك تم تطبيق مقياس المهار التهات الاجتماعية عليهم. 


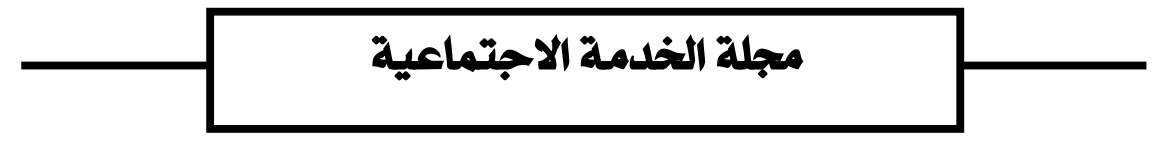

ب- مرحلة نضج الجماعة: وفي هذه المرحلة أصبحت الجماعة أكثر انتظاماً في حضور

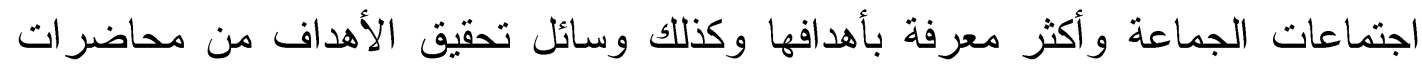

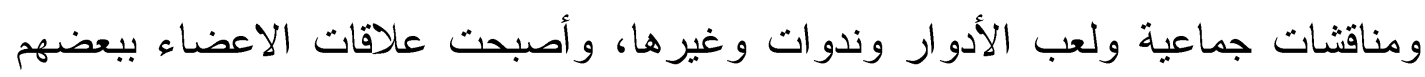
أكثر تماسكاً، وأصبحت استجاباتهم لأنشطة الجماعة كبيرة.

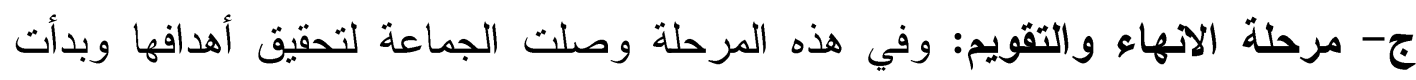
تطالب الباحث بالانضمام لجماعة أخرى لعمل أنشطة أخرى، وقد قام الخاء ولباحث بعملية الانهاء التدريجي لأنشطة الجماعة وقام بنطبيق القياس البعدي لمقياس المهار ات الاجتماعية عليهم. ع - أدوار الأخصائي الاجتماعي:

أ- دور المعلم: حيث حرص الأخصائي الاجتماعي بتعليم أعضاء الجماعة التجريبية

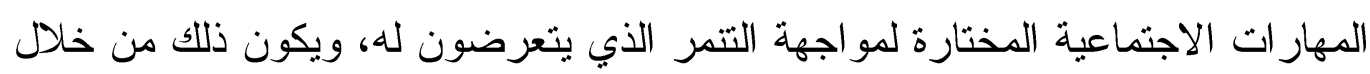

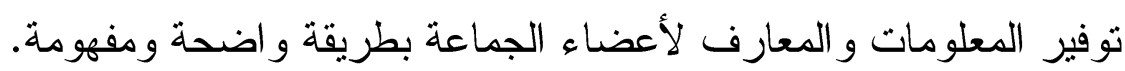
ب- دور الموجه: وفي هذا الدور قام بتوجيه التفاعلات لأعضاء الجماعة التجريبهاء وفيهة وفية أثناء

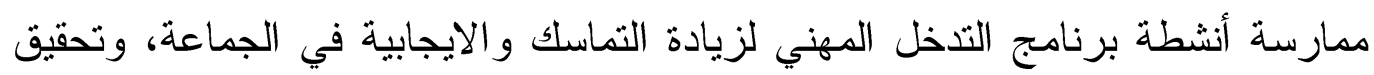
الأهداف التي تكونت الجماعة لتحقيقها ألا وهي (تتمية المهار ات الاجتماعية).

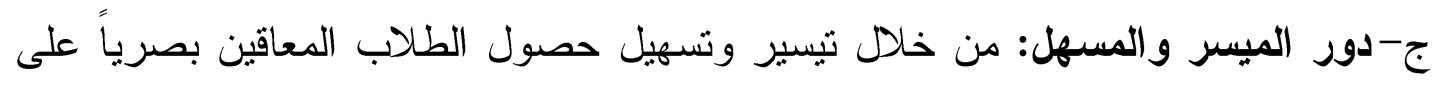

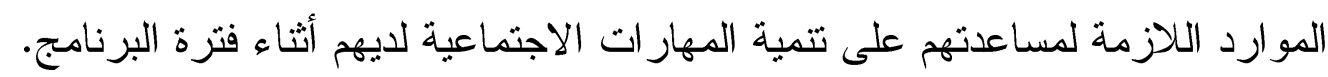

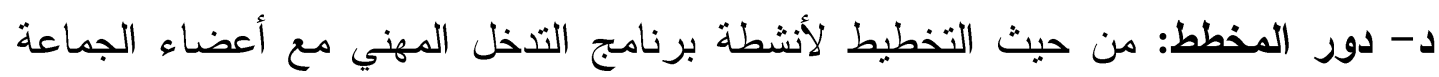

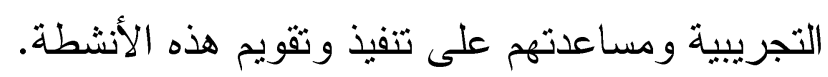
ه- دور المنسق: من خلال التتسيق مع الخبراء الذين يقومون بإمداد الطلاب بالمعارف

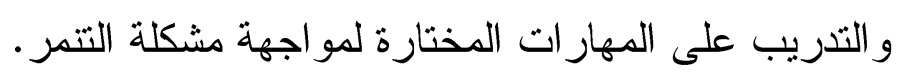
و - دور الخبير: حيث قام بتقيم النصح و الارشاد و المشورة النافعة للطالب المعاق بصرياً.

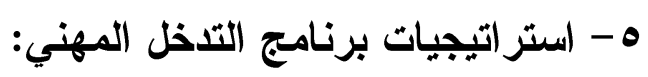
أ- استراتيجية العمل الجماعي: وتتضمن مشاركة الجماعة العلاجية في الحياة الجماعية،

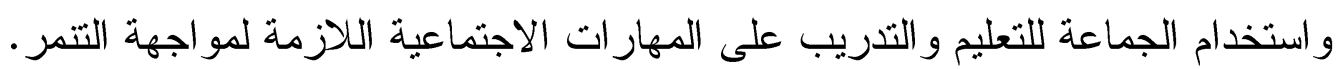

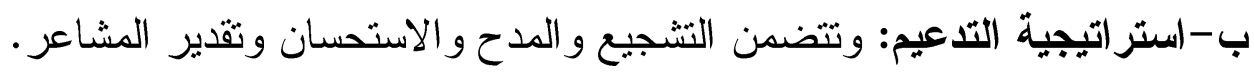
ج- استراتيجية المحادثة العلاجية: وتركز هذه الاستر اتيجية على الجلسات العلاجية

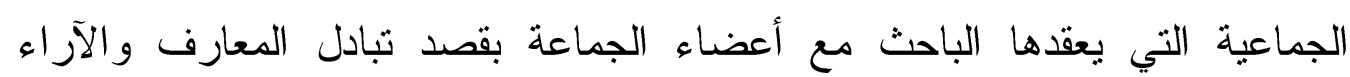
والأفكار بينه وبين أعضاء الجماعة التجرييية بغرض تنمية المهارات الاجنماعية 


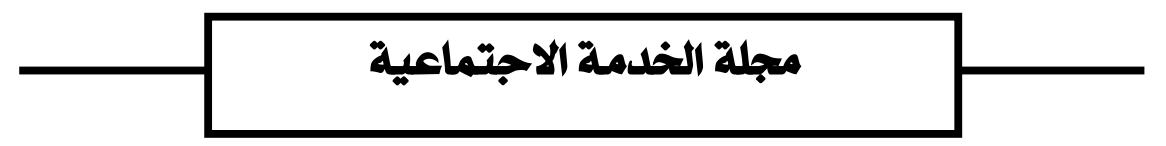

צ- التكنيكات المستخدمة:

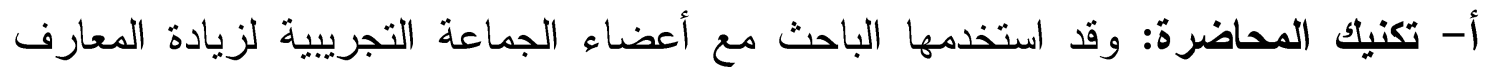

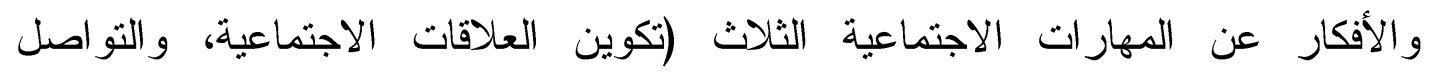

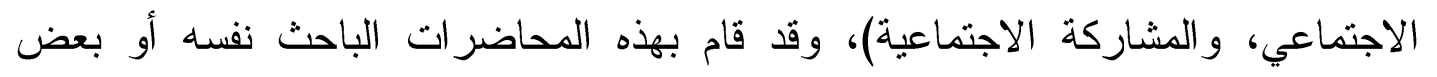

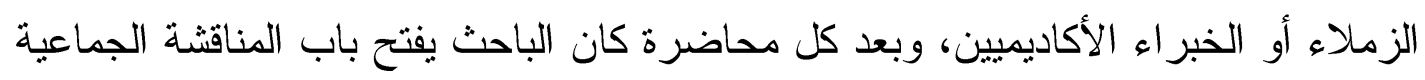

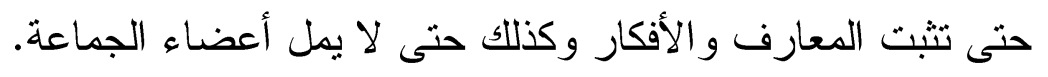

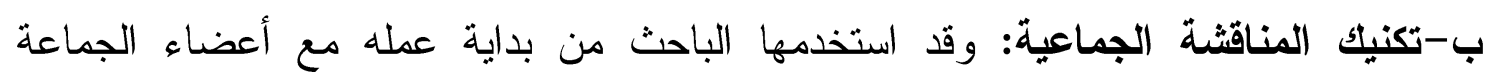

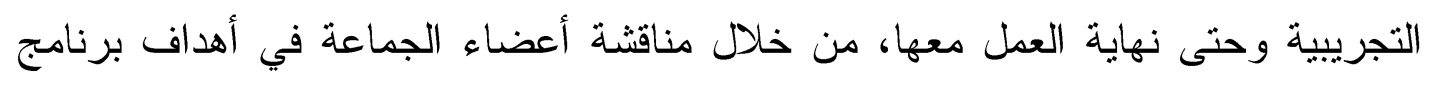
التدخل المهني واجراءات تحقيق هذه الأهداف و المو اعيد المناسبة لهم وللباحث ولاعنة اللعاملين بالمؤسسة وكذلك المناقثة و الحوار في كل الاجتماعات الخاصة بالتدريب على المهار الاهن الاجتماعية الثلاث.

ج-تكنيك لعب الدور: و هو تكنيك علاجي استخدمه الباحث مع أعضاء الجماعة التجريبية حتى يمكن توصيل المعارف و المعلومات اللازمة عن التتمر وعن كيفية التدريب على المهارات

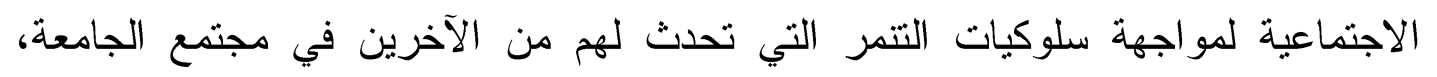

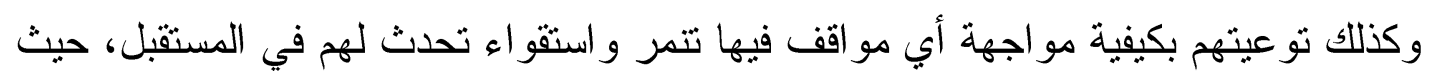
اتبع الباحث الخطوات التالية مع أعضاء الجماعة التجريبية:

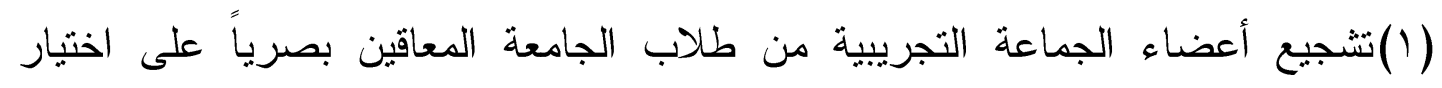

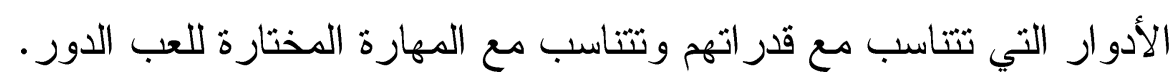

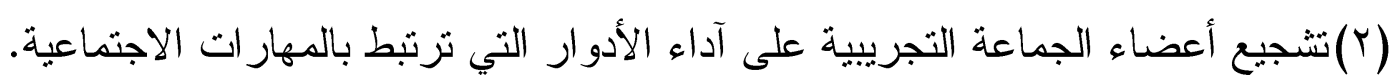

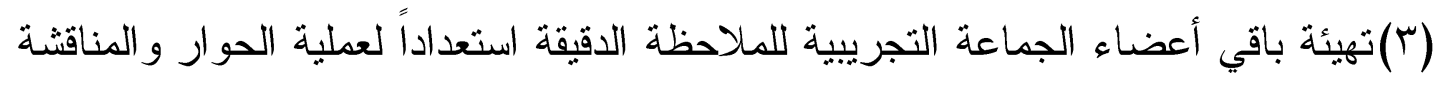

$$
\text { الخاصة بالأدو ار التي تم تمثنالها. }
$$

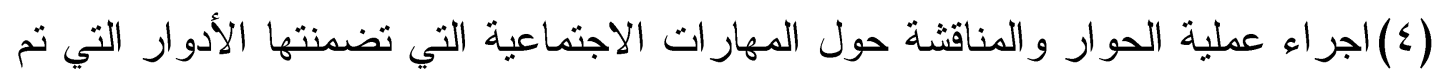

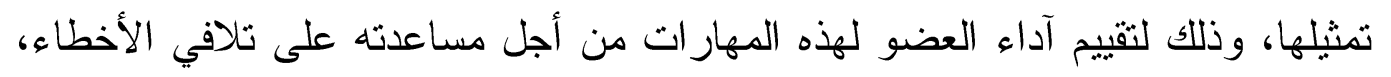

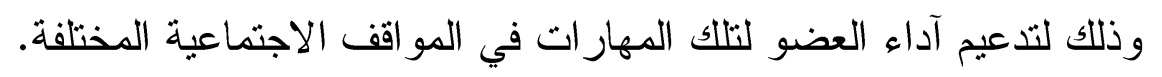

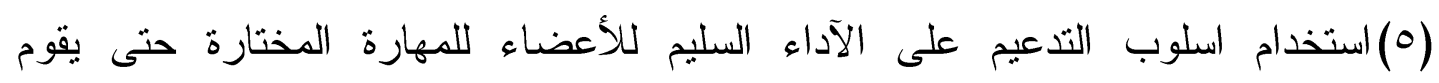
الأعضاء بتكرار هذا الآداء وبالتالي ثثبت المهارة ويتم تتمينها عندهم.

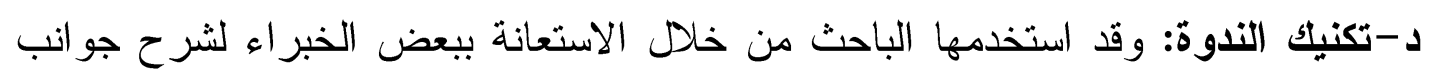

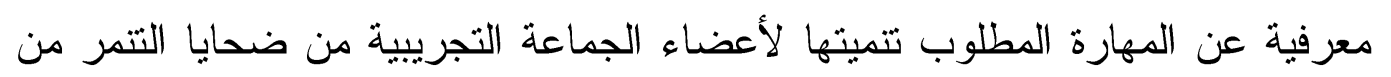




\section{مجلة الخدمة الاجتماعيةم}

طلاب الجامعة المعاقين بصرياً ثم بعد شرح المحاضرين لجو انب المهارة المختلفة يتم

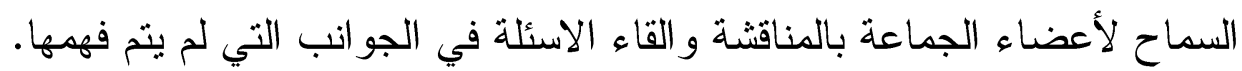

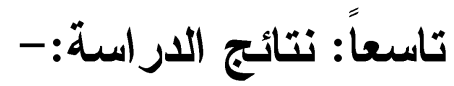

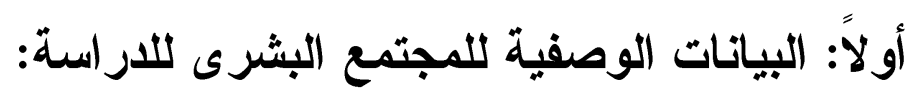

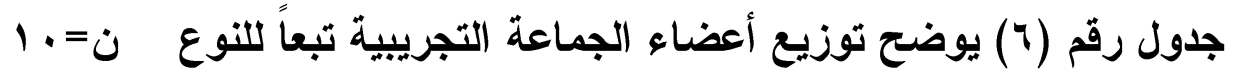

\begin{tabular}{|c|c|c|c|}
\hline النسبة المئوية & التكرار & النوع & م \\
\hline$\% \varepsilon$. & $\varepsilon$ & ذكـــــــ & 1 \\
\hline$\% \uparrow$. & T & أن & ب ب \\
\hline$\% 1 \ldots$ & 1. & المجموع & \\
\hline
\end{tabular}

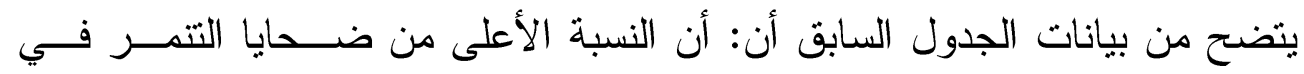

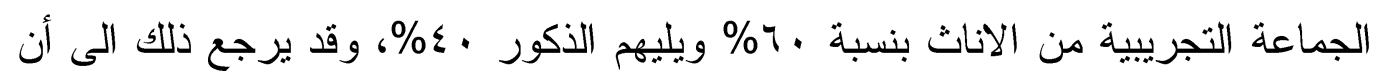

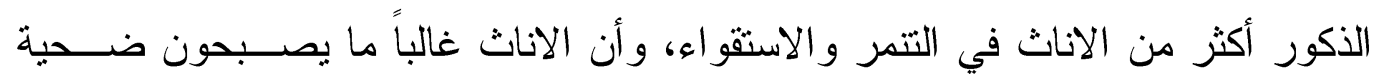

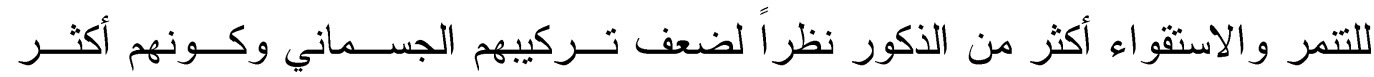
حساسية لأي مضايقات أكثر من الذكور.

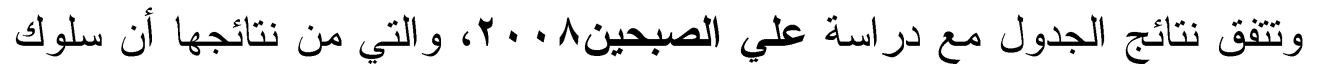

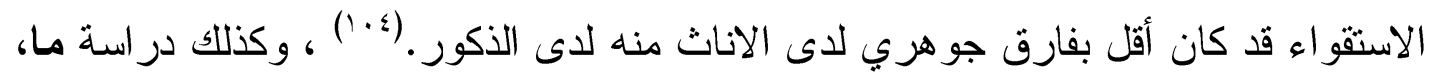
لينرMa \& Lener 2009 و التي أكدت أن الفتبات أكثر تأثراً بالتتمر من الذكور (1.0)،

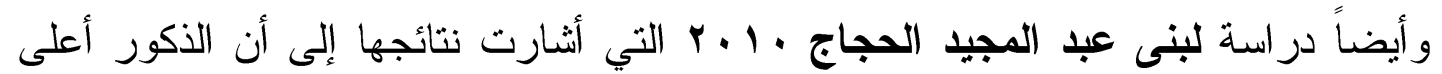

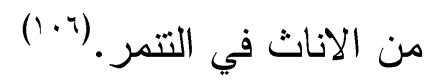

جدول رقم (V) يوضح توزيع أعضاء الجماعة التجريبية تبعاً للسن ن= . 1.

\begin{tabular}{|c|c|c|c|}
\hline$\%$ & s & السن & م \\
\hline$\% \circ$ & 0 & -19 & 1 \\
\hline$\% r$. & r & $-r$. & ب \\
\hline$\%)$. & 1 & $-r_{1}$ & $\rightarrow$ \\
\hline$\%$ \%. & $r$ & من ب r إلى أقل من بr & $د$ \\
\hline$\% 1 \ldots$ & 1. & \multicolumn{2}{|l|}{ المجموع } \\
\hline \multicolumn{2}{|c|}{ r } & \multicolumn{2}{|l|}{ المتوسط الحسابي } \\
\hline
\end{tabular}

يتضح من بيانات الجدول السابق أن: المتوسط الحسابي لسن أعضاء الجماعة التجريبية

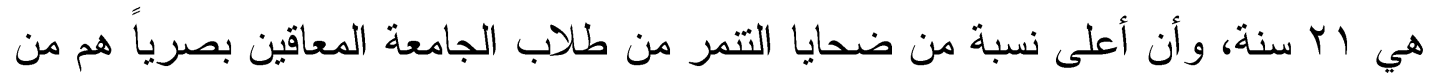




\section{مجلة الخدمة الاجتماعية}

تتز اوح أعمار هم من بين (9 1: أقل من · ب) سنة بنسبة •0\%، وقد يرجع ذلك إلى بداية

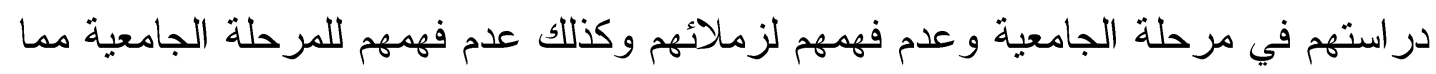

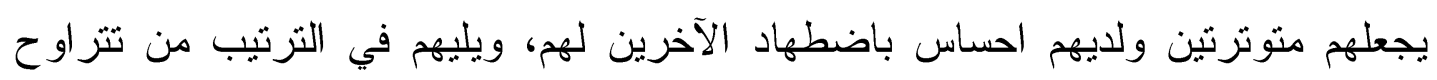

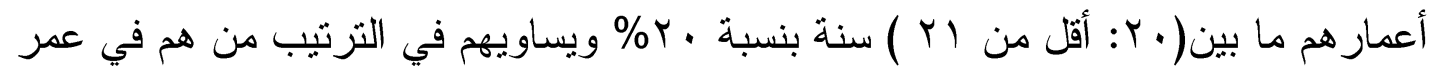

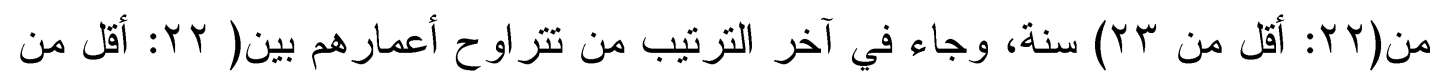

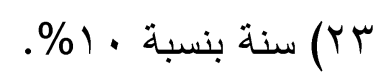

ويتفق نتائج الجدول السابق مع ما جاء في نتائج در اسة يســري ســعيد حســانين

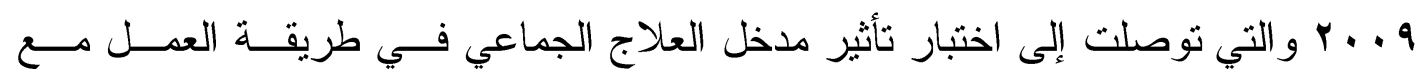

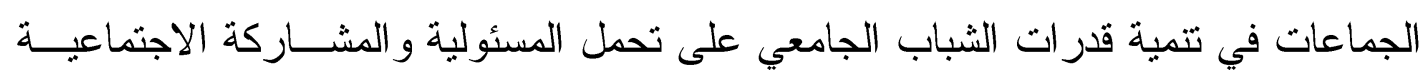

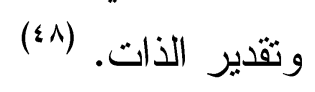

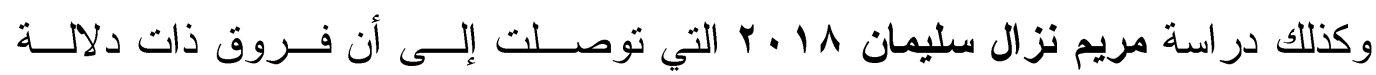

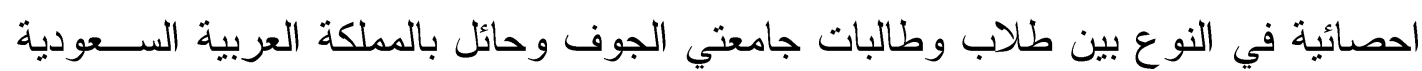

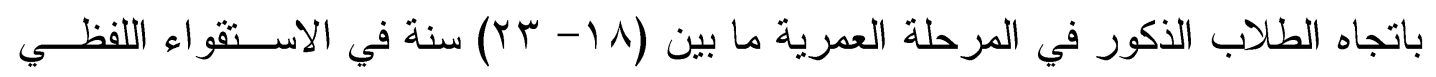

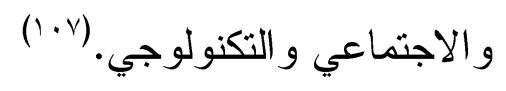

جدول رقم (^) يوضح توزيع أعضاء الجماعة التجريبية تبعاً للقسم العلمي ن=. 1.

\begin{tabular}{|c|c|c|c|}
\hline$\%$ & ك & القسم العلمي & r \\
\hline$\% \varepsilon$. & $\varepsilon$ & اللغة العربية & 1 \\
\hline$\%$ \%. & $r$ & الدراسات الإسلامية & ب \\
\hline$\% 1$. & 1 & الفلسفة & $\rightarrow$ \\
\hline$\%$ \%. & $r$ & التاريخ & $د$ \\
\hline$\% 1 \ldots$ & 1. & المجموع & \\
\hline
\end{tabular}

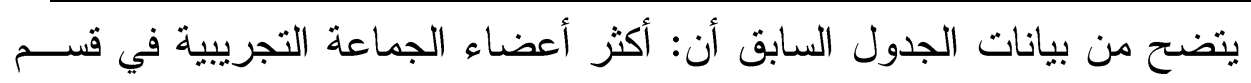

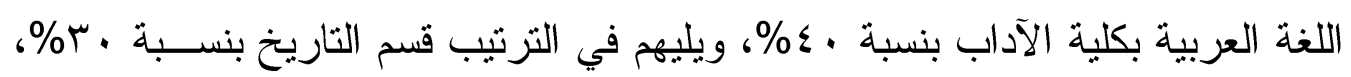

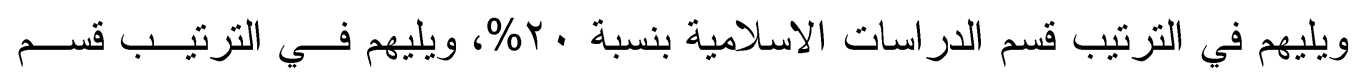

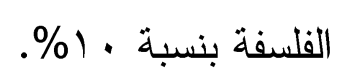

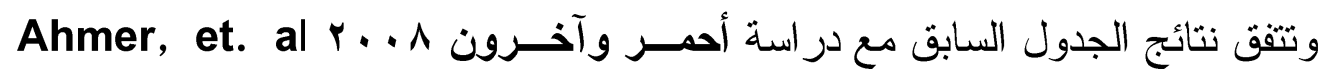

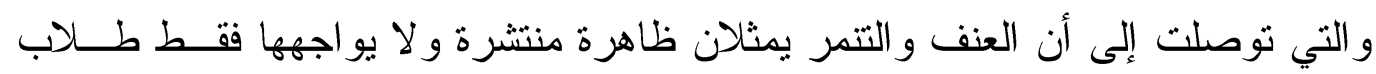

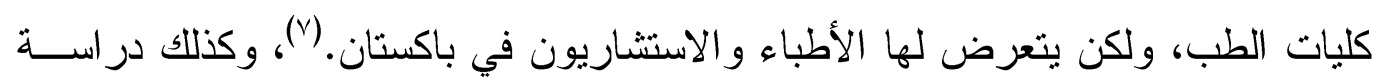


حسن الزهر اني Hasan Alzahrani و التي أثشارت إلى انتشار ظاهرة التتمر

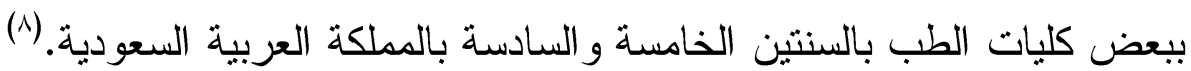

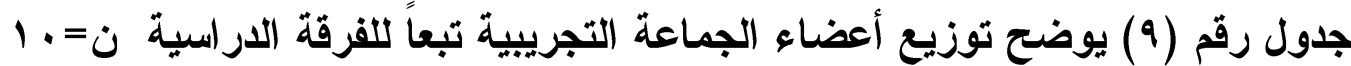

\begin{tabular}{|c|c|c|c|}
\hline$\%$ & كs & الفرقة الدراسية & م \\
\hline$\%$. & 0 & الأولى & 1 \\
\hline$\%$ \%. & $r$ & الثانية & ب \\
\hline$\%$ \%. & $r$ & الثالثة & $\rightarrow$ \\
\hline$\% 1$. & 1 & الر ابعة & $د$ \\
\hline$\% 1 \ldots$ & 1. & المجموع & \\
\hline
\end{tabular}

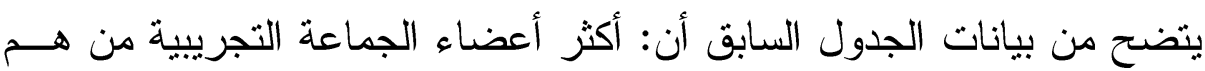

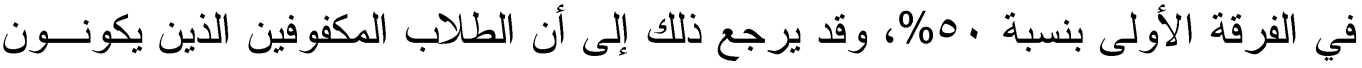

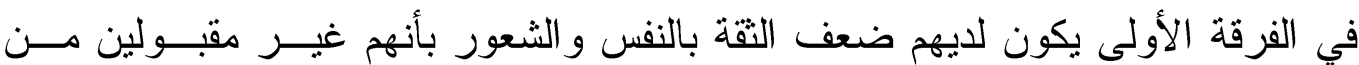

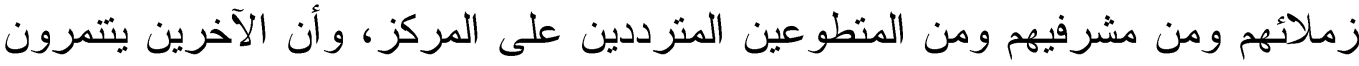

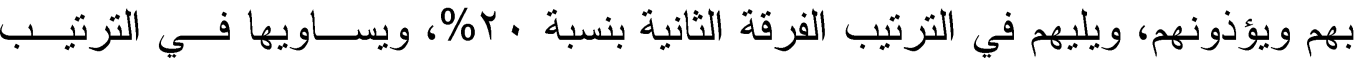

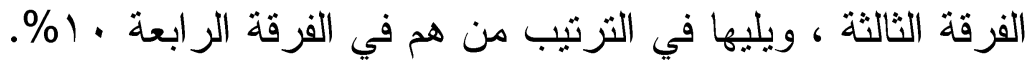

$$
\text { جدول رقم (1. (1) }
$$

يوضح توزيع أعضاء الجماعة التجريبية تبعاً لنوع التنمر الذي يتعرضون له ن=. 1.

\begin{tabular}{|c|c|c|c|}
\hline$\%$ & s & الفرقة الار اسية & م \\
\hline$\%$. & $v$ & لفظي & 1 \\
\hline$\%$. & . & بذني & ب \\
\hline$\% 1$. & 1 & جنسي & $\rightarrow$ \\
\hline$\% 1 \ldots$ & 1. & المجموع & \\
\hline
\end{tabular}

يتضح من بيانات الجدول السابق أن: أكثر أعضاء الجماعة التجريبية بنسبة .9\% أقروا

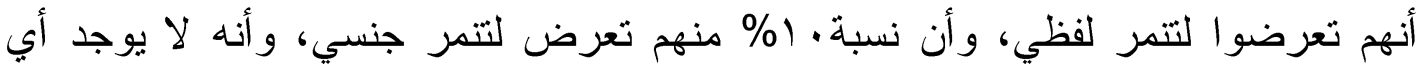
منهم تعرض لتتمر بدني بنسبة ،\%، وتتفق نتائج الجدول السابق مع ما جاء في دراسة حسن الزهراني Hasan Alzahrani و والتي أشارت إلى انتشار ظاهرة التتمر ببعض كليات الطب بالمملكة العربية السعودية، جاء ترتيبه تتمر لفظي بنسبة ، 9\%، تتمر

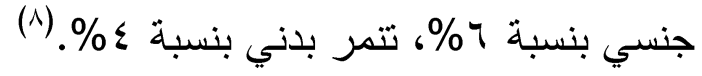




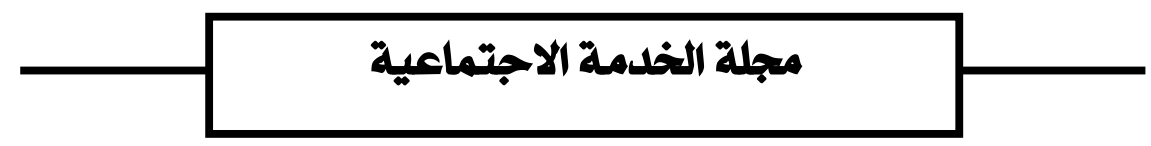

r-النتائج الخاصة بفروض الار اسة:

أ- النتائج الخاصة باختبار الفرض الرئيس للار اسة:

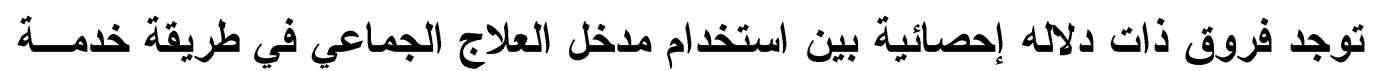
الجماعة لتنمية المهارات الاجتماعية لضحايا التنمر من طلاب الجامعة المعاقين بصرياً.

جدول (11)

يوضح الفروق بين المتوسطات للقياسين القبلي والبعدي للمجموعة التجريبية على مقياس تنميـة المهارات

الاجتماعية لضحايا التنمر منطلاب الجامعة المعاقين بصرياً.(ن = •1)

\begin{tabular}{|c|c|c|c|c|c|c|c|c|c|}
\hline \multirow{2}{*}{ مستوى } & \multirow{2}{*}{ قلمة } & \multirow{2}{*}{ الفروق } & \multirow{2}{*}{ مستوى الدلالة } & \multirow[b]{2}{*}{ قيمة ت } & \multicolumn{2}{|c|}{ القياس البعدي } & \multicolumn{2}{|c|}{ القياس القبلي } & \multirow[b]{2}{*}{ المتغير ات } \\
\hline & & & & & $\varepsilon$ & s & $\varepsilon$ & s & \\
\hline كبير & .911 & القياس البعدي & $\ldots$. & $r \cdot . r \leqslant \varepsilon$ & t.ro & rᄉ.r. & r.IT & $1 v .9$. & تكوين العلاقات \\
\hline كبير & $-.9 V$ & القياس البعدي & $\ldots$ & $11 . V 4 \varepsilon$ & $r .1 r$ & 14.1. & 1.99 & $1 \wedge . \wedge$. & التو اصل الاجتماعي \\
\hline كبير & $.9 \mathrm{~V}$ & القياس البعدي & $\ldots$ & IV.IYq & 1.9 & rV.o. & T.7T & 19.1. & المشاركة الاجتماعية \\
\hline كبير & .99 & القياس البعدي & $\ldots$. & $\mathrm{r} 1.0 \mathrm{Vr}$ & r.or & 111.1. & $\varepsilon . Y \wedge$ & 07.0. & الدرجة الكلية \\
\hline
\end{tabular}

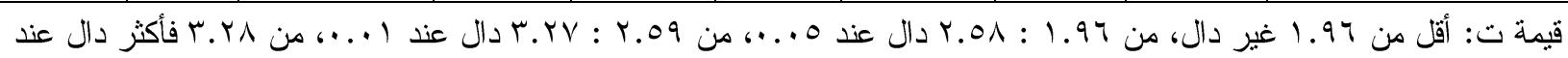
....

حجم الثأثير : أقل من ه. • تأثير ضعيف، من ه. • إلى أقل من ^. . تأثير متوسط، من ^. . فأكثر تأثير كبير

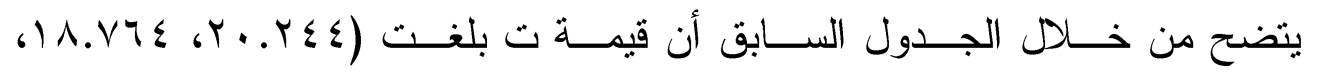

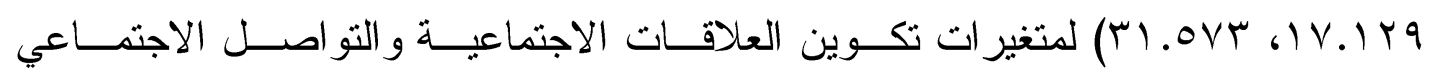

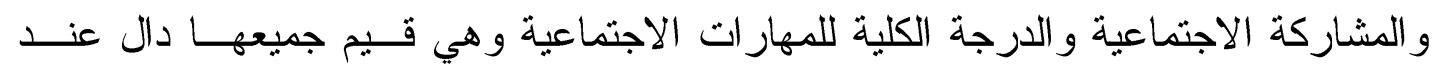

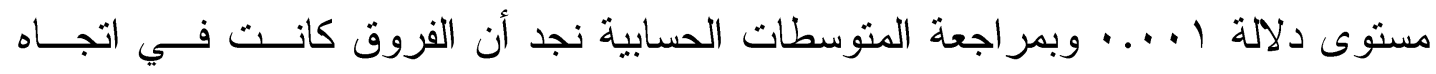

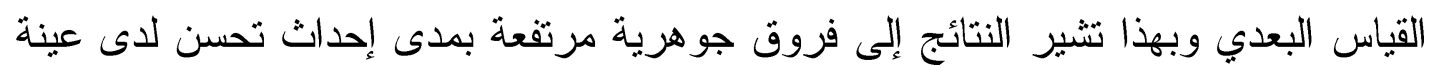

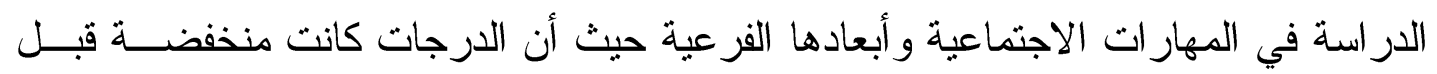

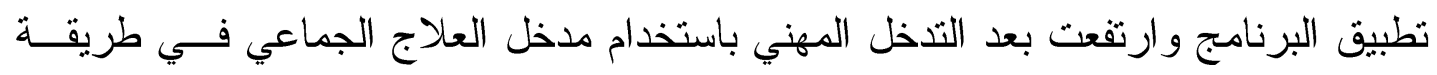

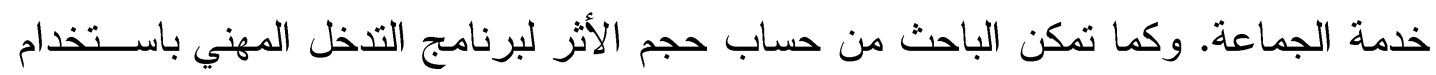

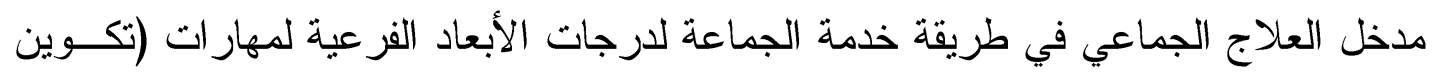

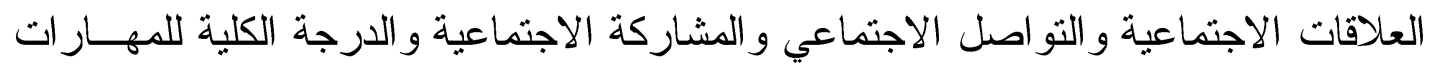

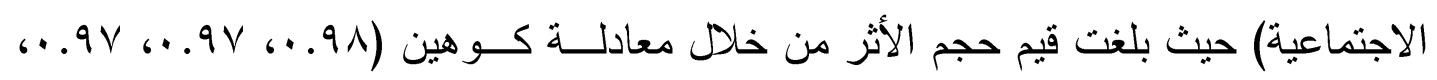

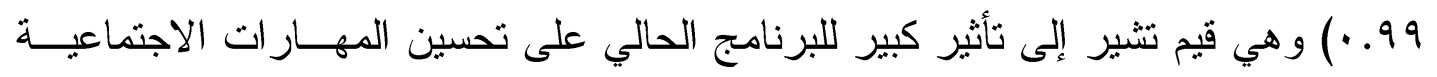




\section{مجلة الخدمة الاجتماعيةً}

و أبعادها الفرعية، وبهذا تشير النتائج إلى ارتفاع المهارات الاجتماعية بعد تطبيق البرنــامج مقارنة بقبل تطبيق البرنامج. وادها وبهان وتتفق نتائج الجدول السابق مع ما جاء في دراسة إليوت Elliott, 1991 و التي توصلت

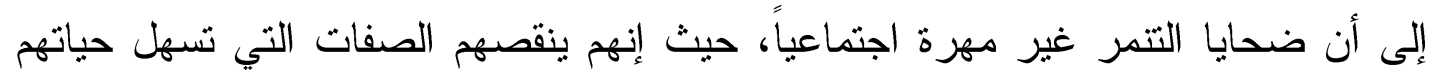

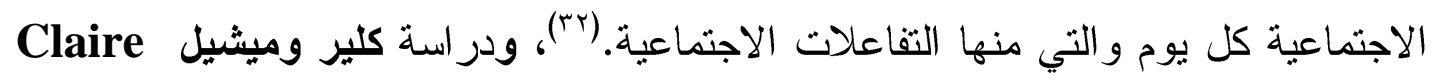
L. and Michael J. 2005

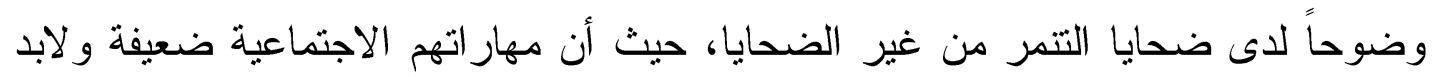

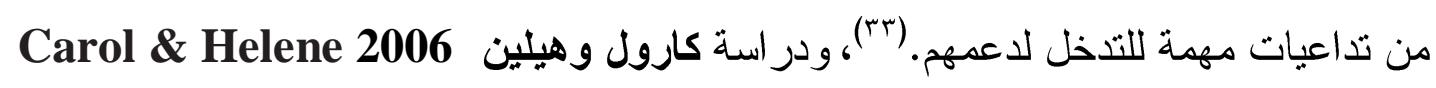
التي أشارت إلى أن ضحايا التنمر يعانون من سوء النوافق التهات النفسي والاجتماعي وندرة

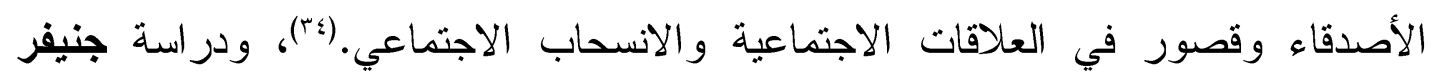

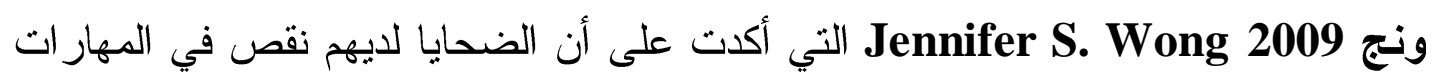

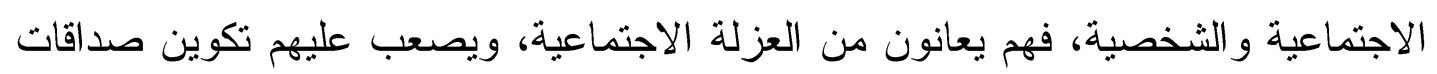

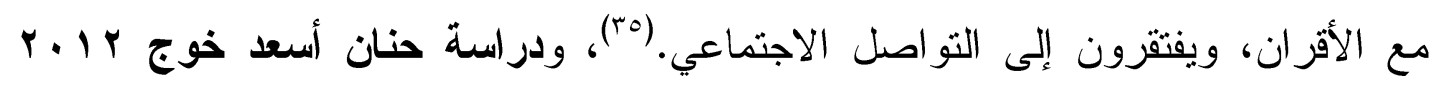

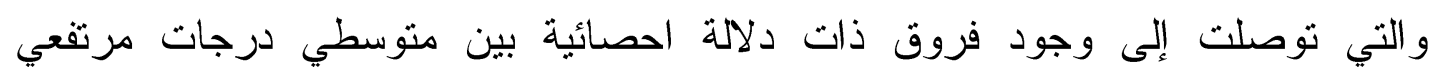

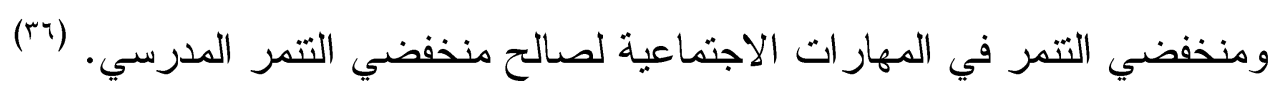
وتتفق نتائج الجدول السابق أيضاً مع ما جاء في دراسة عادل محمود مصطفى ؟ ... و التي أكدت على أن استخدام مدخل العلاج الجماعي في برنامج التدخل المهني لطريقة

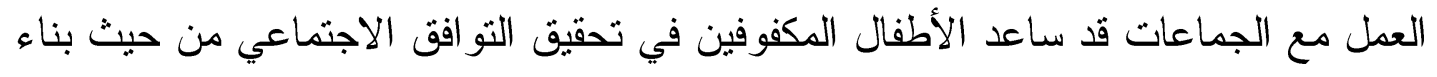

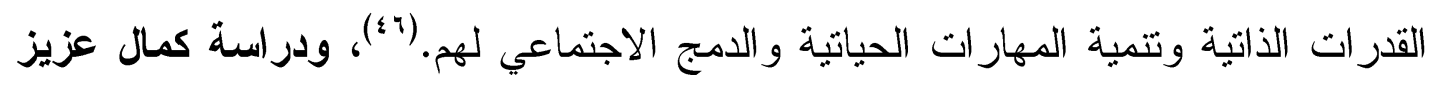

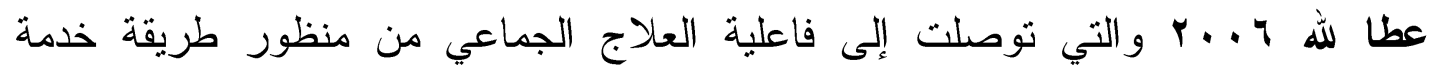

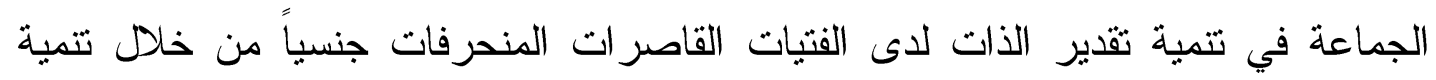

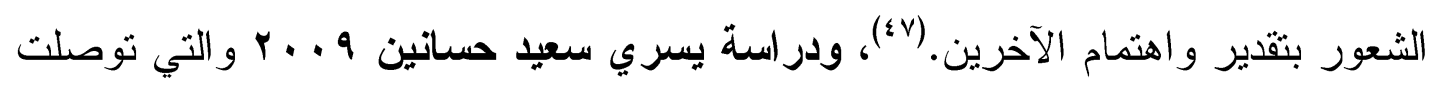

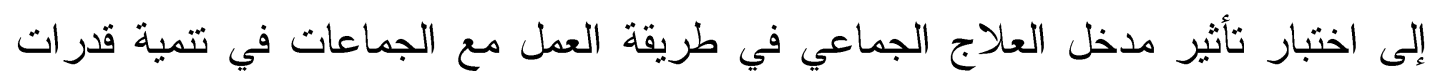

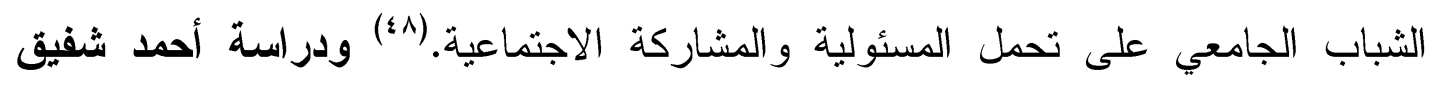

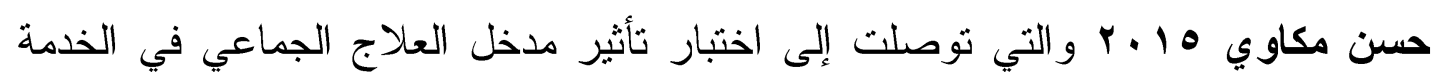

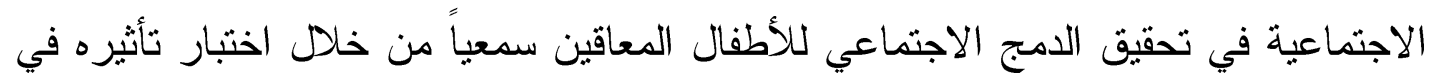

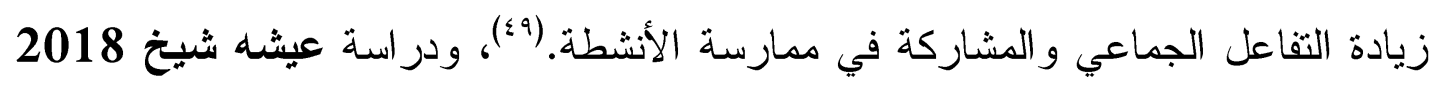
Ayesha Shaikh والاجنماعية. (0.) () 


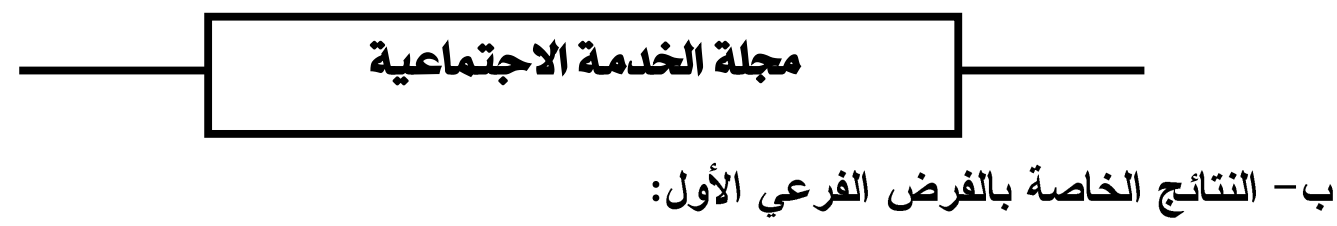

توجد فروق معنوية ذات دلالة احصائية بين استخدام مدخل العلاج الجماعي في

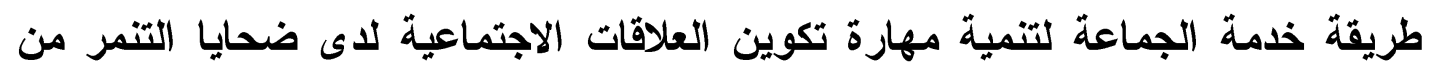
طلاب الجامعة المعاقين بصرياً.

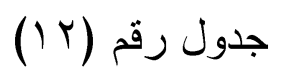

يوضح الفروق بين المتوسطات للقياسين القبلي والبعدي للمجموعة التجريبية على مقياس تنمية المهارات الاجتماعية لهارة تكوين العلاقات الايجابية لضحايا التنمر منطلاب الجامعة المعاقين بصرياً

$(1 \cdot=\dot{j})$

\begin{tabular}{|c|c|c|c|c|c|c|c|c|c|}
\hline \multirow{2}{*}{ مستوى } & \multirow{2}{*}{ قاليمة } & \multirow{2}{*}{ الفروق } & \multirow[b]{2}{*}{ مستوى الدلالة } & \multirow[b]{2}{*}{ ق ق قيمة ت ت } & \multicolumn{2}{|c|}{ القياس البعدي } & \multicolumn{2}{|c|}{ القباس القبلي } & \multirow[b]{2}{*}{ المتغير ات } \\
\hline & & & & & $\varepsilon$ & 5 & $\varepsilon$ & s & \\
\hline كبير ك &. .91 & البعدي & $\ldots .1$ & T., T $\leq \varepsilon$ & T.ro & YN.Y. & $r .1 r$ & IV.q. & تكوين العلاقات الاجتماعية \\
\hline
\end{tabular}

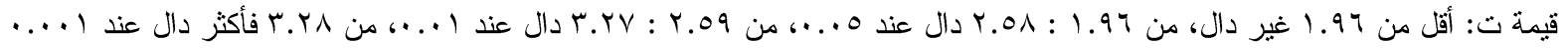

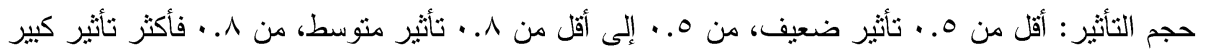

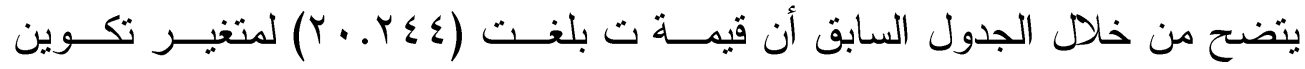

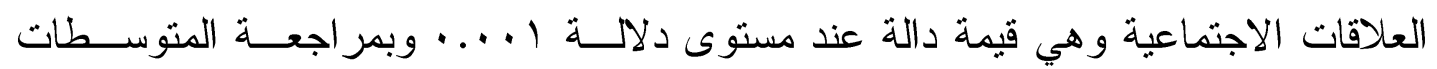

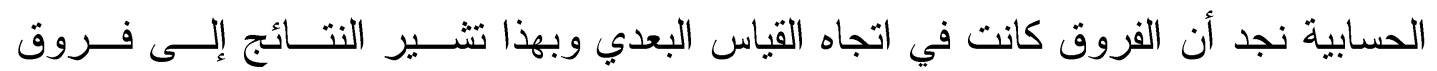

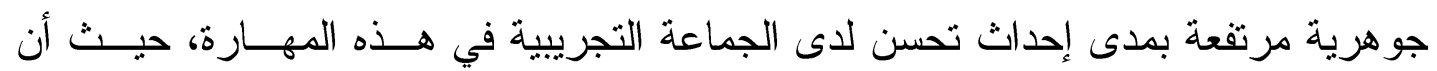

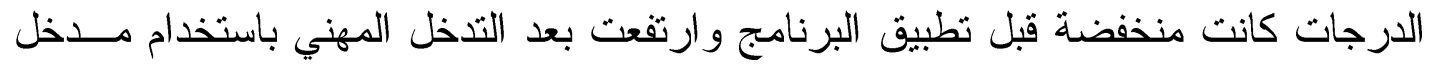

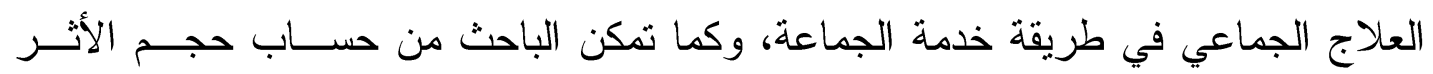

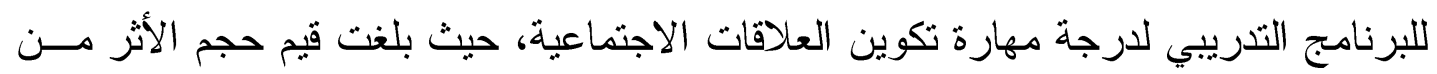

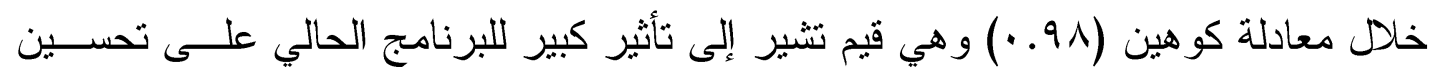

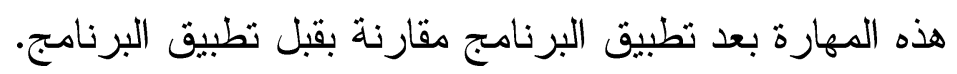

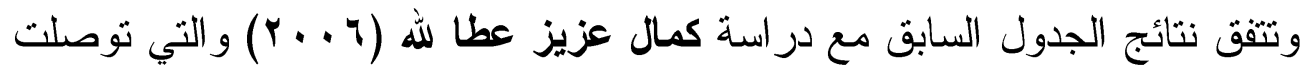

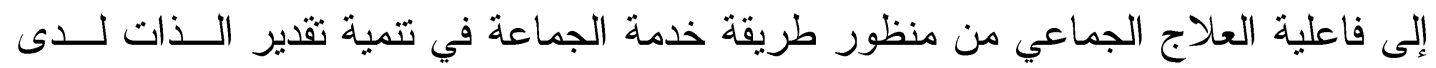

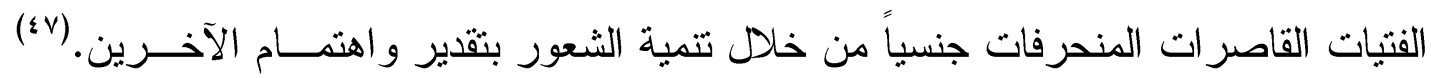

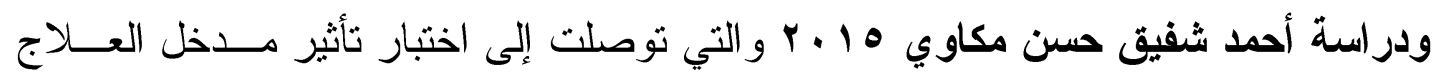




\section{مجلة الخدمة الاجتماعية}

الجماعي في الخدمة الاجتماعية في تحقيق الدمج الاجتماعي للأطفال المعاقين سـمعياً مــن

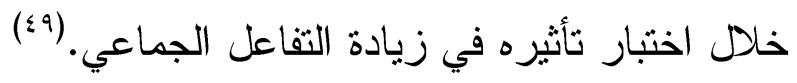
ج. النتائج الخاصة بالفرض الفرعي الثاني: توجد فروق معنوية ذات دلالة احصائية بين استخدام مدخل العلاج الجماعي في التئي

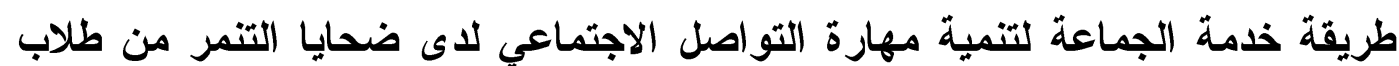
الجامعة المعاقين بصرياً.

$$
\text { جدول رقم (r) (1) - (1) }
$$

يوضح الفروق بين المتوسطات للقياسيز القبلي والبعدي للمجموعة التجريبية على مقياس تنمية المهارات

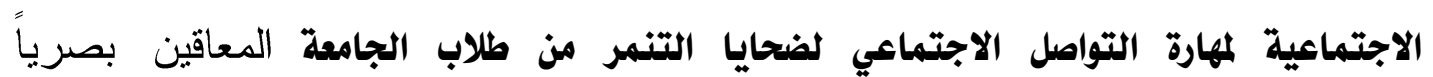
$(1 \cdot=\dot{0})$

\begin{tabular}{|c|c|c|c|c|c|c|c|c|c|}
\hline \multirow{2}{*}{ مستوى } & \multirow{2}{*}{ قليمة } & \multirow{2}{*}{ الفروق } & \multirow{2}{*}{ الدلالة } & \multirow[b]{2}{*}{ 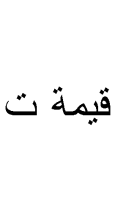 } & \multicolumn{2}{|c|}{ القياس البعدي } & \multicolumn{2}{|c|}{ القياس القبلي } & \multirow[b]{2}{*}{ المتغير ات } \\
\hline & & & & & $\varepsilon$ & 5 & $\varepsilon$ & r & \\
\hline كبير &. $.9 \mathrm{~V}$ & البعدي & $\ldots$. & $10 . V 7 \varepsilon$ & $r .14$ & r... & 1.99 & 1ᄉ... & التو اصل مع الآخرين \\
\hline
\end{tabular}

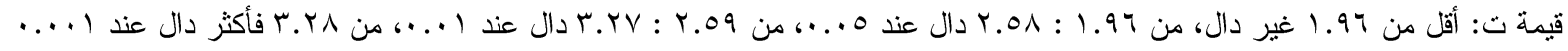

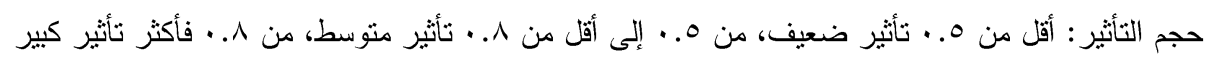

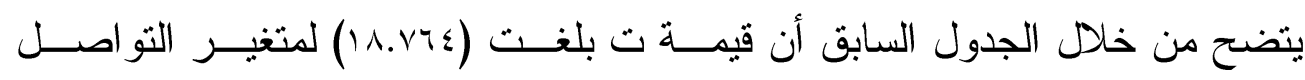

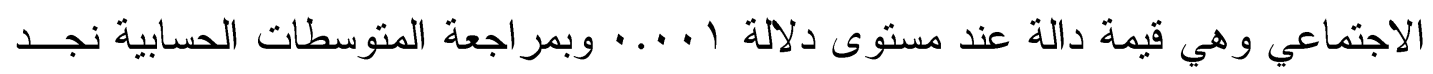

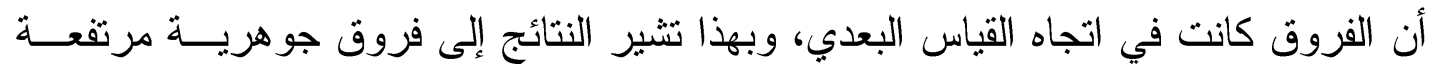

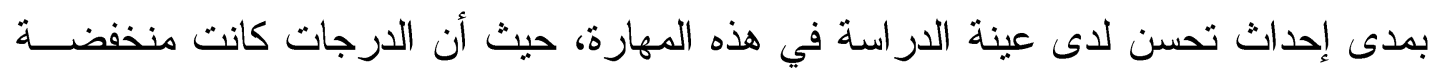

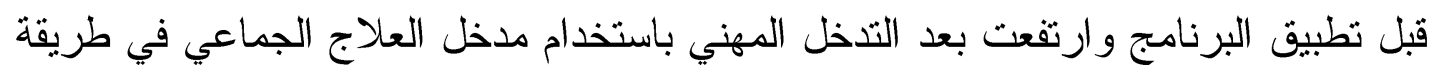

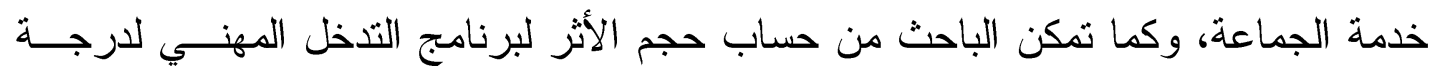

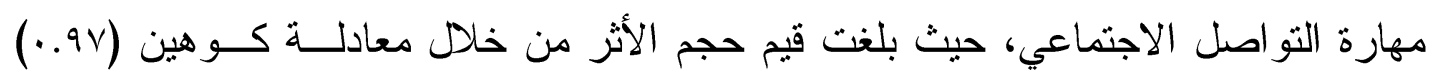

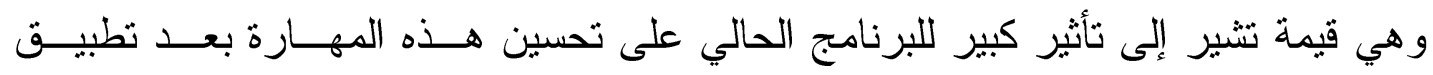
البرنامج مقارنة بقبل تطبيق البرنامج.

وتتفق نتائج الجدول السابق مع دراسة أحمد شفيق حسن مكــاوي 10 ـ ب و التــي

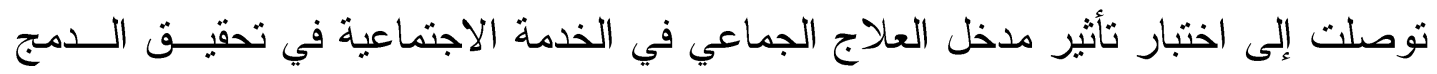




\section{مجلة الخدمة الاجتماعيةً}

الاجتماعي للأطفال المعاقين سمعياً من خلال اختبار تأثيره في زيــادة التفاعـل الجمــاعي

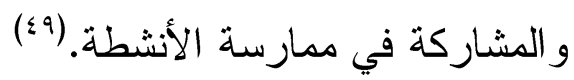

د- النتائج الخاصة بالفرض الفرعي الثالث.

توجد فروق معنوية ذات دلالة احصائية بين استخدام مدخل العلاج الجماعي في

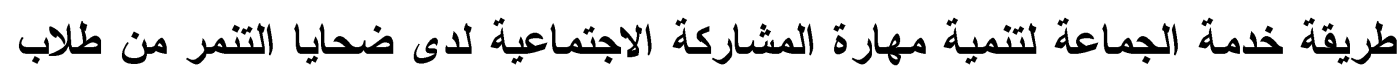
الجامعة المعاقين بصرياً.

$$
\text { جدول رقم (ع () }
$$

يوضح الفروق بيز المتوسطات للقياسين القبلي والبعدي للمجموعة التجريبية على مقياس تنمية المهارات

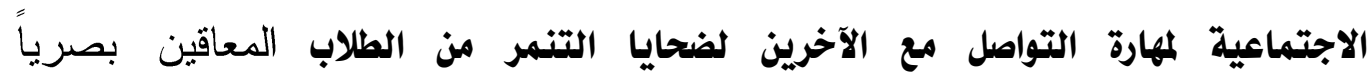

\begin{tabular}{|c|c|c|c|c|c|c|c|c|c|}
\hline \multirow{3}{*}{ مستوى } & & & & & & & & & $(1 \cdot=\dot{j})$ \\
\hline & \multirow{2}{*}{ قجمة } & \multirow{2}{*}{ الفروق } & \multirow{2}{*}{ مستوى الدلالة } & \multirow{2}{*}{ قيمة } & \multicolumn{2}{|c|}{ القياس البعدي } & \multicolumn{2}{|c|}{ القياس القبلي } & \multirow[b]{2}{*}{ المتغير ات } \\
\hline & & & & & $\varepsilon$ & 5 & $\varepsilon$ & s & \\
\hline كبير &. $.9 V$ & البعدي & $\ldots .1$ & IV.IYq & 1.9 & rV.O. & r.T4 & 19.1. & المشاركة الاجتماعية \\
\hline
\end{tabular}

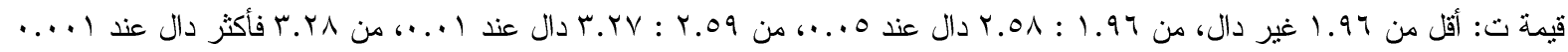

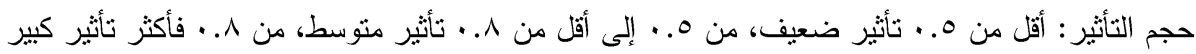

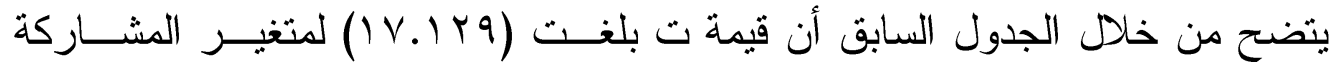

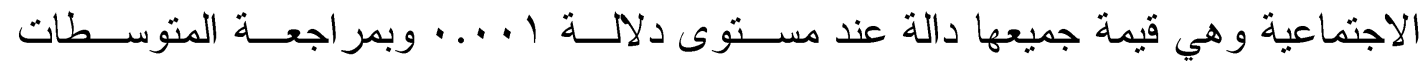

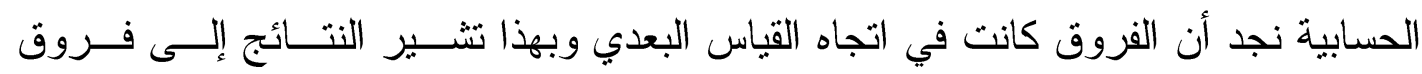

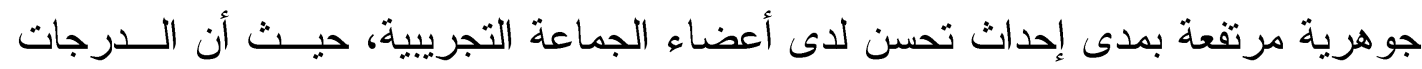

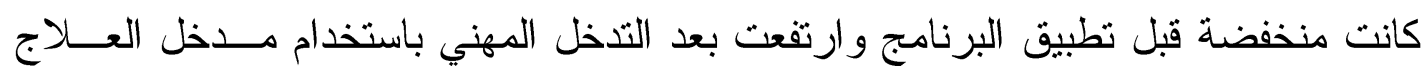

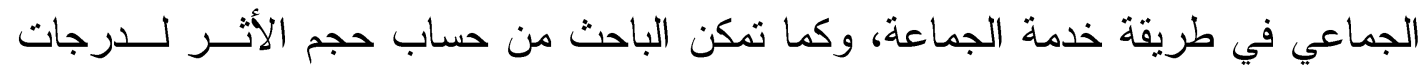

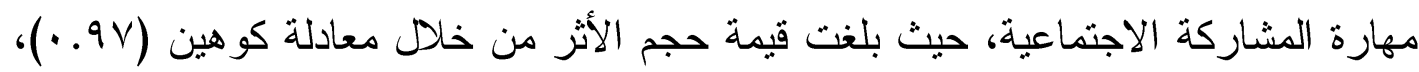

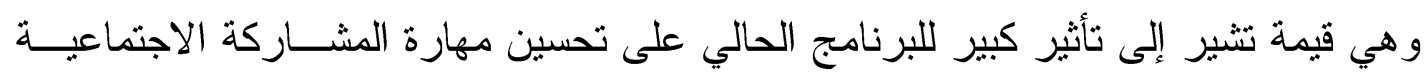
بعد تطبيق البرنامج مقارنة بقبل تطبيق البرنامج.

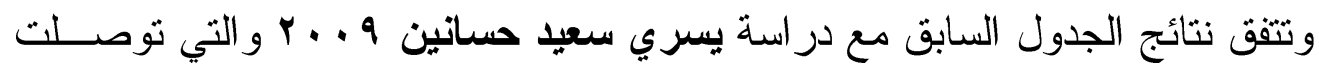

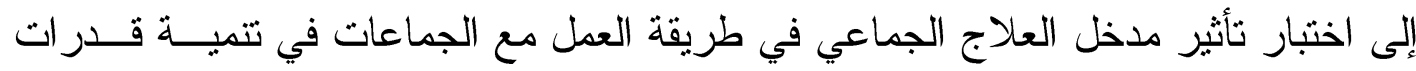

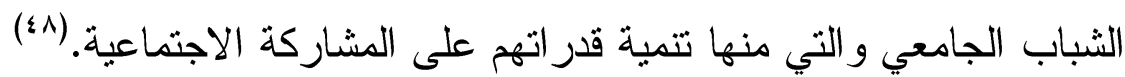




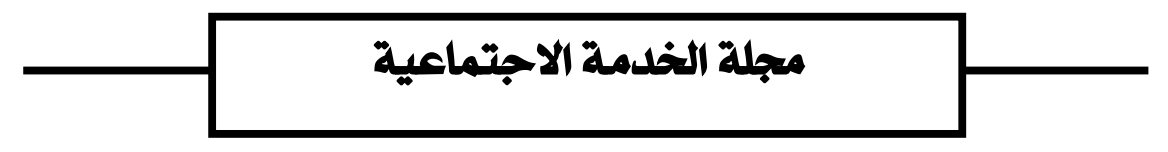

ه- النتائج الخاصة بإجمالي الفرض الأول للار اسة:

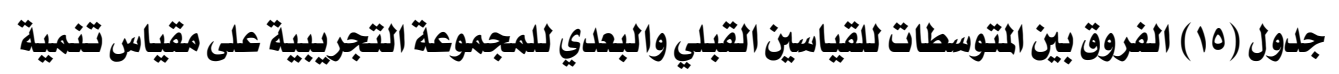

المهارات الاجتماعية لضحايا التنمر من طلاب الجامعة المكفوفين. (ن =.1)

\begin{tabular}{|c|c|c|c|c|c|c|c|c|c|}
\hline \multirow{2}{*}{ مستوى } & \multirow{2}{*}{ قائمة } & \multirow{2}{*}{ الفروق } & \multirow{2}{*}{ مستوى الدلالة } & \multirow[b]{2}{*}{ قيمة ت } & \multicolumn{2}{|c|}{ القياس البعدي } & \multicolumn{2}{|c|}{ القياس القبلي } & \multirow[b]{2}{*}{ المتغير ات } \\
\hline & & & & & $\varepsilon$ & s & $\varepsilon$ & 5 & \\
\hline كبير &. .99 & القياس البعدي & $\ldots .1$ & ri.ovr & r.or & 111.1. & E.YA & 07.0. & الدرجة الكلية \\
\hline
\end{tabular}

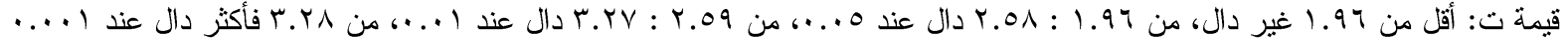

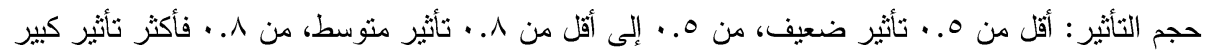

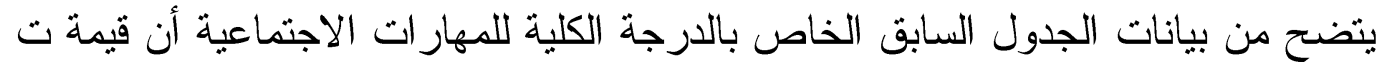

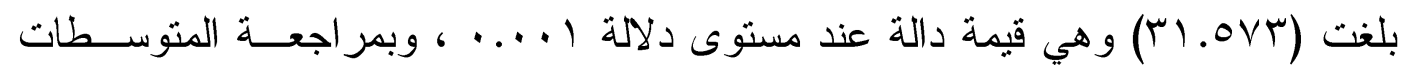

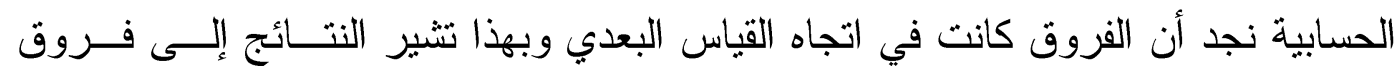
جوهرية مرتفعة بمدى إحداث تحسن لدى عينة الدراسة في المهار ات الاجتماعية و أبعادها

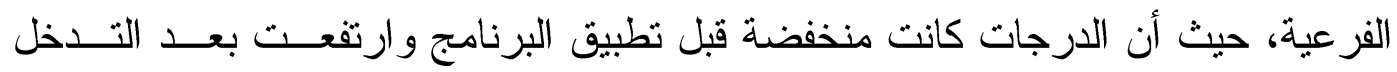
المهني باستخدام مدخل العلاج الجماعي في طريقة خدمة الجماعة، وكما تمكن الباحث من البرنات

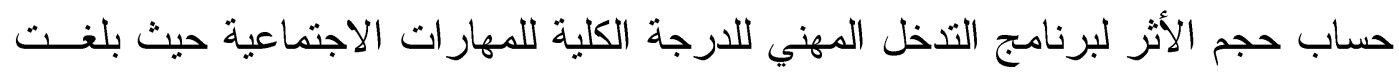

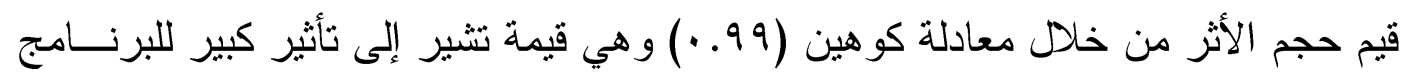

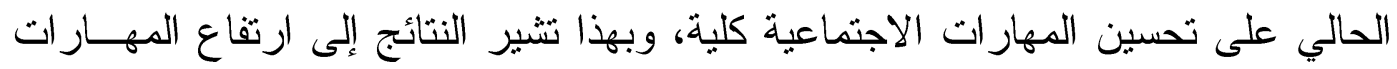
الاجتماعية بعد تطبيق البرنامج مقارنة بقبل تطبيق البرنامج. تحليل ومناقثة نتائج الارسة: سوف ينم تحليل ومناقثة نتائج الدر اسة وفقاً لتطبيق مقياس المهار ات الاجتماعية لطلاب

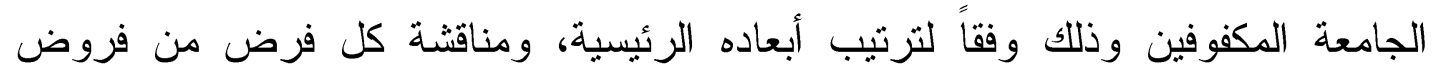
الدر اسة على حدة وذلك في ضوء الدر اسات السابقة.

اثتبت نتائج الدراسة أن استخدام مدخل العلاج الجماعي في طريقة خدمة الجماعة في تتمية المهار ات الاجتماعية لضحايا التتمر من طلاب الجامعة الدكفوفين.

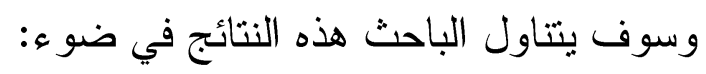

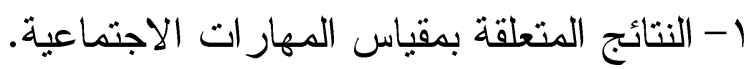
r-تحليل محتوى التقارير الدورية لاجتماعات الباحث مع الجماعة التجريبية. 


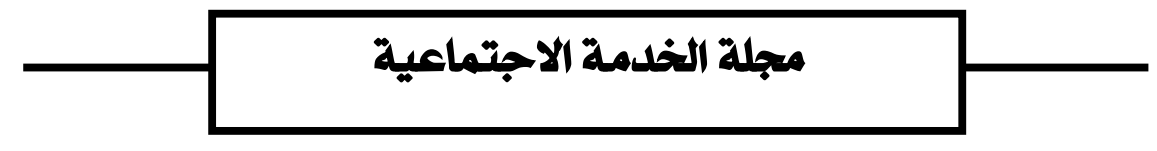

الجانب الأول: مناقثة النتائج المتعلقة بتطبيق مقياس المهارات الاجتماعية:

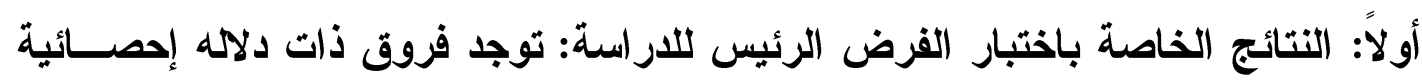

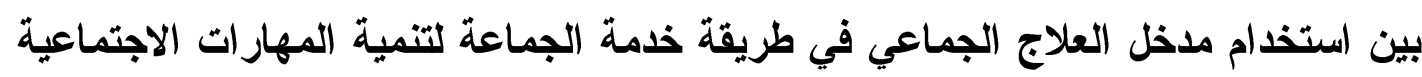
لضحايا التنمر من طلاب الجامعة المعاقين بصرياً.

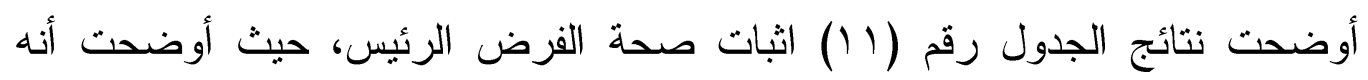

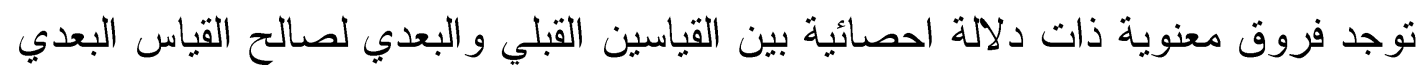

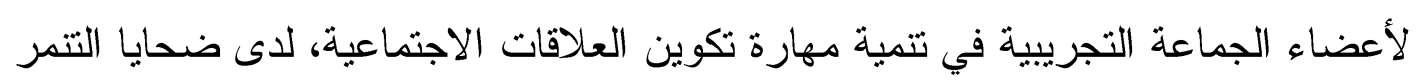

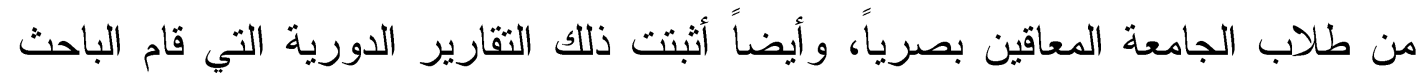
بتسجيلها عقب الاجنماعات التي أجر اها مع أعضاء الجماعة التجريبية.

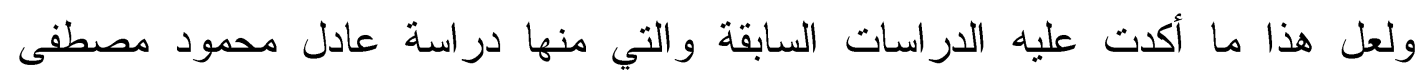

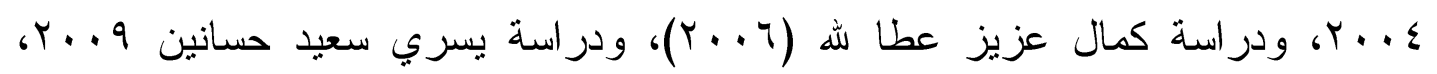

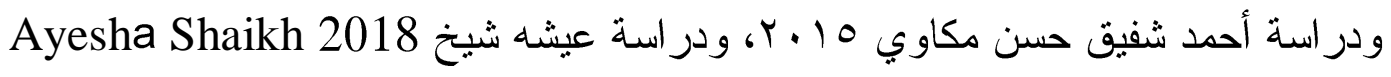

ويتضح ذلك من خلال التحقق من صحة الفروض الفرعية الآتية:

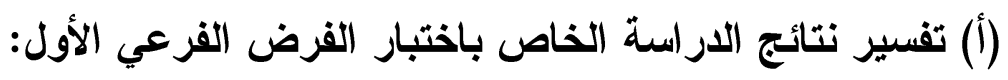

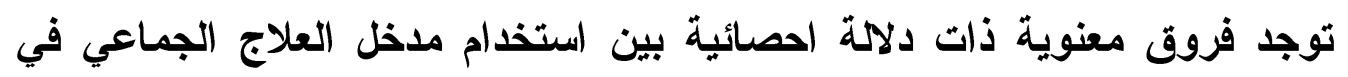

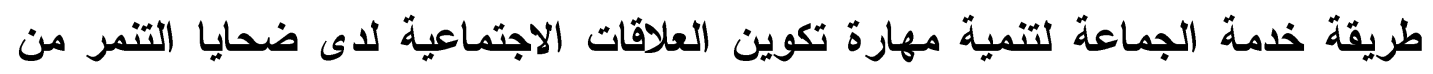
طلاب الجامعة المعاقين بصرياً.

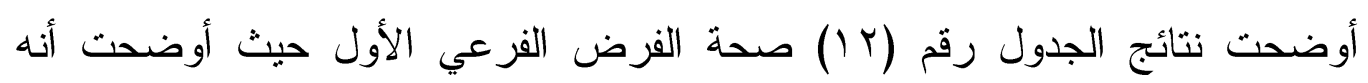

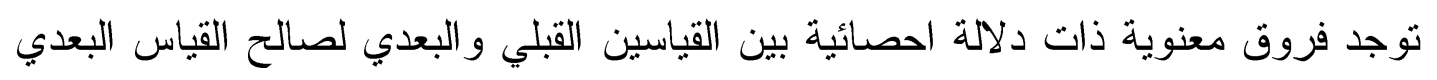

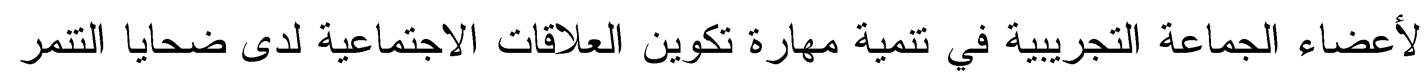

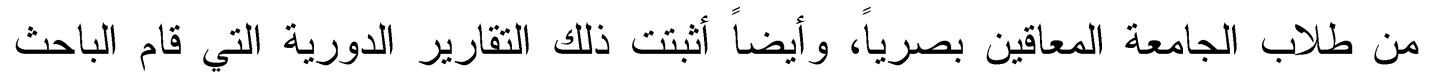
بتسجيلها عقب الاجتماعات التي أجر اها مع أعضاء الجماعة التجريبية.

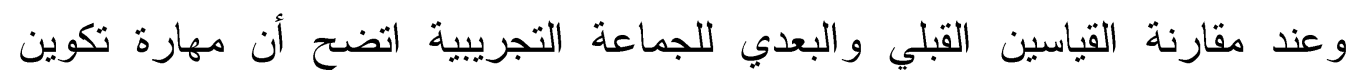
العلاقات الاجتماعية كانت ضعيفة في القياس القبلي والمتمثل في (علاقاني الاجتماعية

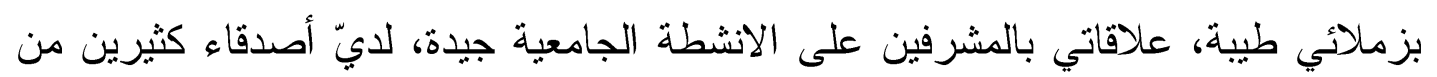

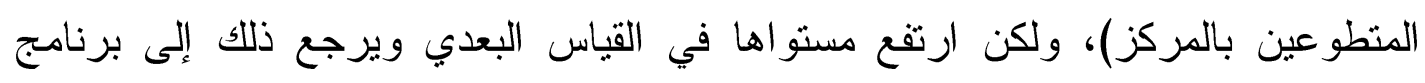
التدخل المهني الذي قام به الباحث باستخدام مدخل العلاج الجماعي باستر اتيجياته (التدعيم،

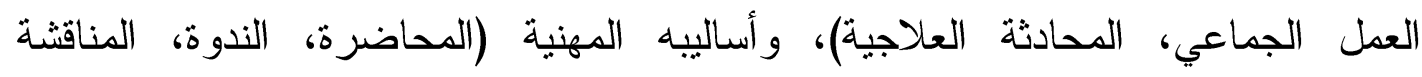
(الجماعية). 


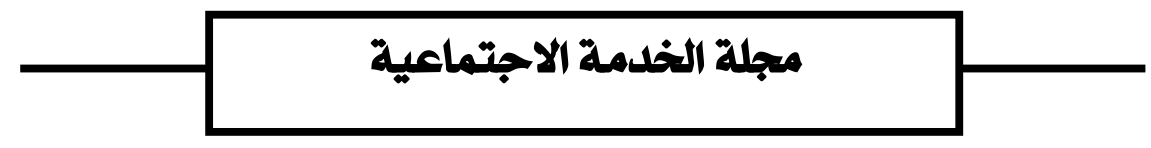

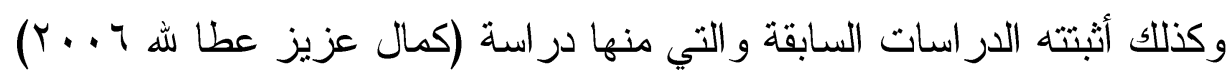
(ب) تفسير نتائج الاراسة الخاص باختبار الفرض الفرعي الثاني: توجد فروق معنوية ذات دلالة احصائية بين استخدام مدخل العلاج الجماعي في طريقة

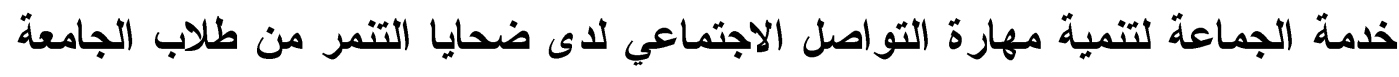
المعاقين بصرياً. أوضحت نتائج الجدول رقم (T M) اثبات صحة الفرض الفرعي الثاني حيث أوضحت أنه

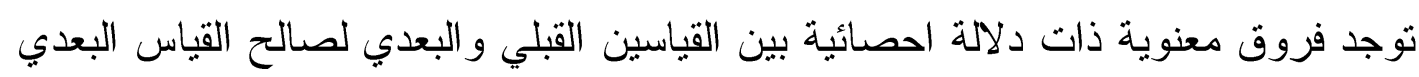

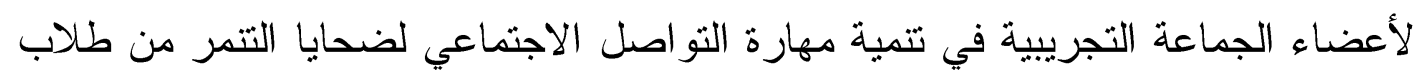

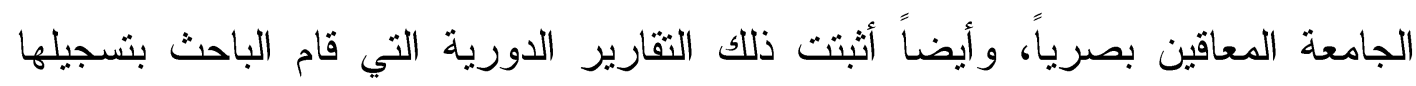
عقب الاجتماعات التي أجر اها مع أعضاء الجماعة التجريبية.

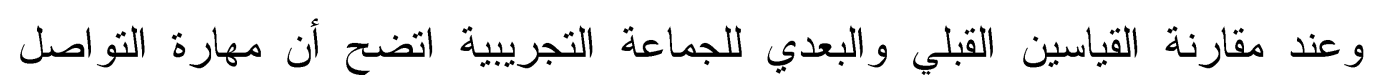
الاجتماعي كان مستو اها منخفض في القياس القبلي و المتمنل في (القدرة على التعبير عن المشاعر الايجابية والسلبية، القدرة على الحوار مع الآخرين، القدرة على فئل اقناع الآخرين)

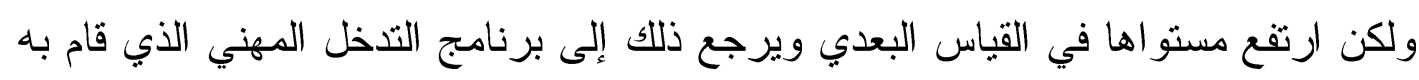
الباحث باستخدام مدخل العلاج الجماعي في طريقة خدمة الجماعة باستر اتيجياته (العمل الجماعي، التدعيم)، وأساليبه المهنية (المحاضرة، المناقشة الجماعية، لعب الأدوار).

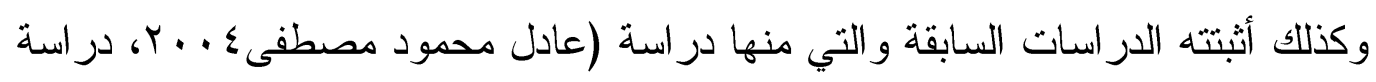

(Ayesha Shaikh عيشه شيخ 2018 وكني

(ج) تفسير نتائج الدراسة الخاص باختبار الفرض الفرعي الثالث: توجد فروق معنويــة

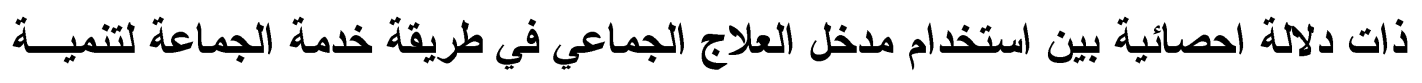
مهارة المشاركة الاجتماعية لدى ضحايا التنمر من طلاب الجامعة المعاقين بصرياً.

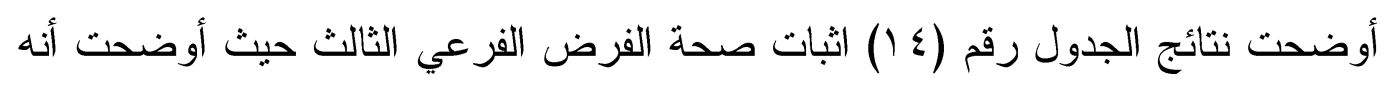
توجد فروق معنوية ذات دلالة احصائية بين القياسين القبلي و البعدي لصاكي لأح القياس البعدي

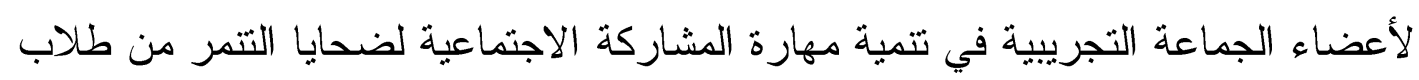

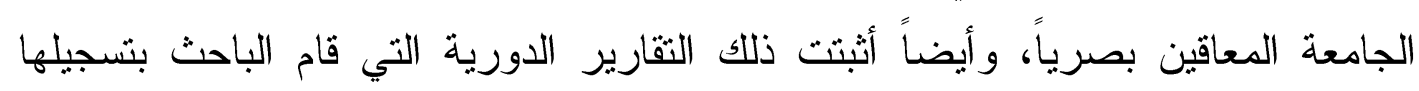
عقب الاجتماعات التي أجر اها مع أعضاء الجماعة التجريبية. وعند مقارنة القياسين القبلي و البعدي للجماعة التجريبية اتضح أنساء الجياعة مهارة المشاركة

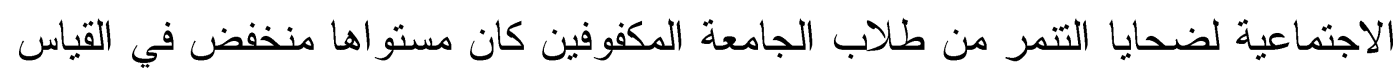

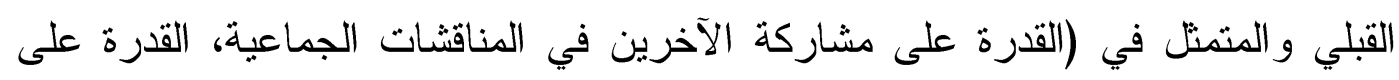




\section{مجلة الخدمة الاجتماعية]}

القدرة على مشاركة الزملاء في الأنشطة الجامعية مشاركة في المناقشات، القدرة على مشاركة الزملاء في المو اقف الحياتية) ولكن ارتفع مستو اها في القياس البعدي ويرجع ذلك الك إلى برنامج التذخل المهني الذي قام به الباحث باستخدام مدخل العلاج الجماعي في طريقة خدمة الجماعة باستر اتيجياته (التدعيم، المحادثة العلاجية، العمل الجماعي) و أساليبه المهنية (المحاضرة، لعب الأدوار، الندوة، المناقشة الجماعية). وكذلك أثثتته الدر اسات السابقة والتي منها در اسة يسري سعيد حسانين 9 ـ . ب، در اسة أحمد شفيق مكاوي 10 . أ.

الجانب الثاني: نتائج الدراسة على الجانب الكيفي (تحليل محتوى التقاريز الاورية): قام الباحث بتسجيل الاجتماعات عقب الاجتماع مع اجتماعات الجماعة التجريبية أثناء تتفيذ برنامج التذخل المهني باستخدام مدخل العلاج الجماعي في طريقة خدمة الجماعة و الذي يهذف إلى (تنمية المهار ات الاجتماعية لضحايا التنمر من طلاب الجامعة المعاقين بصرياً)، حيث أثارت نتائج التقارير الدورية إلى تتمية المهار ات الاجنماعية الثلاث (تكوين العلاقات الايجابية، التواصل الاجنماعي، المشاركة الاجنماعية) وذلك من خلال تفاعل أعضاء الجماعة التجريبية مع بعضهم البعض ومشاركتهم في الأنشطة المختلفة للجماعة.

\section{توصيات الار اسة:}

بناء على ما أسفرت عنه نتائج الدراسة يمكن عرض التوصيات التالية: ا- إجر اء العديد من الدراسات عن التتمر والآثار السلبية له على المتتمرين وضحايا التتمـر

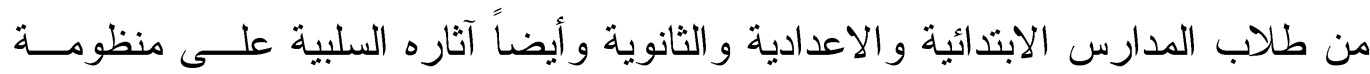
القيم و الأخلاقيات في المجتمع الذي يعيشون فيه. ץ- إجر اء المزيد من الدراسات حول استخدام النماذج الحديثة في طريقة خدمــة الجماعــة لمواجهة التتمر سواء كان للمتتمرين أو ضحايا التتمر . ب- أهمية استخدام فنيات العلاج الجماعي في طريقة خدمة الجماعة مثـلـل السوشـيودر اما لتتمية وعي طلاب الجامعة المعاقين بصرياً بحقوقهم الاجتماعية، وكذلك تتميــة وعـــهرم بأهمية مشاركتهم في التتمية المجتمعية. ع- استخدام العلاج الجماعي في تتمية المهار ات الحياتيــة لفئـات الأطفــال و المـــر اهقين و الشباب المعاقين بصرياً.

ه- استخدام العلاج الجماعي في طريقة خدمة الجماعة في تتميــة المهـــار ات الشخصــية

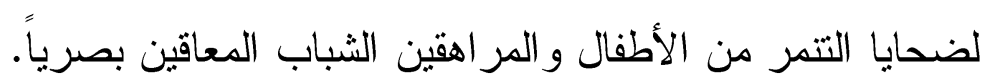




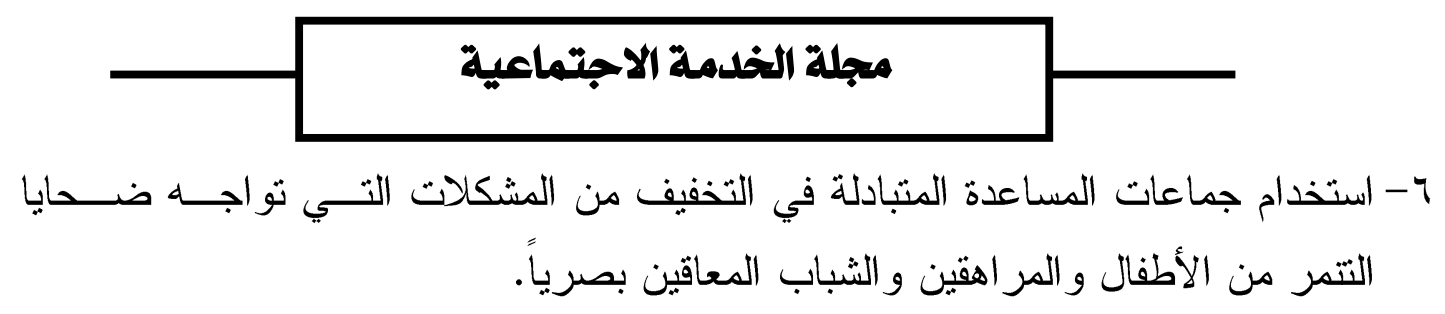




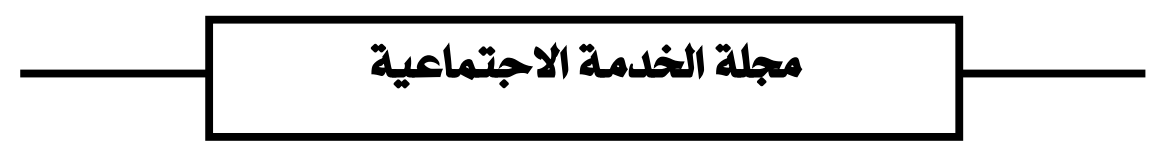

$$
\text { مراجع الدر اسة }
$$

' ' تهاني محمد عثمان منيب، عزه محمد سليمان: العنف لاى الثباب الجامعي، جامعة

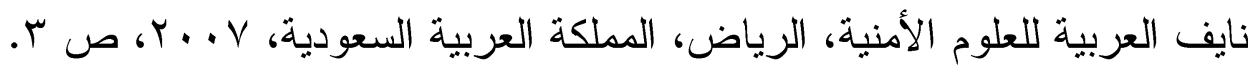

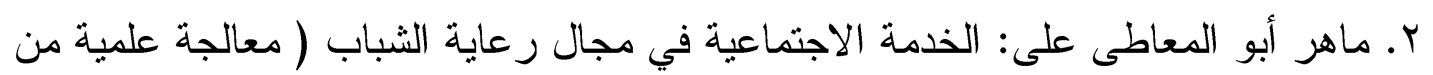

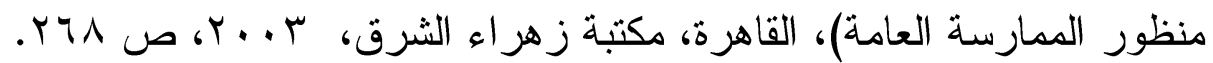

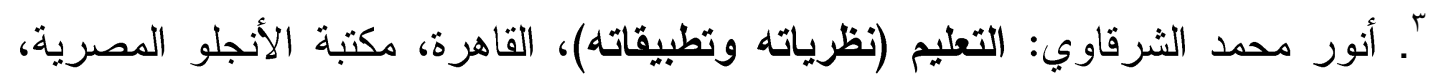

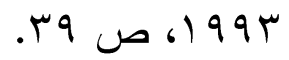

ع. محمد سيد فهمي: واقع رعاية المعاقين في الوطن العربي، الاسكندرية، المكتب الجامعي

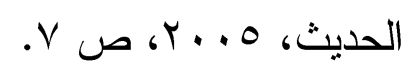
ه. الجريدة الرسمية: نص قرار اللائحة التنفيذية لقانون حقوق الأثخاص ذوي الاعاقة،

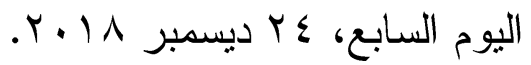

6. Kean Poon: Understanding Risk- taking Behavior in Bully Victims Using Cognitive- and Emotion- Focused Approaches, Frontiers in Psychology, Vol (7), 2016. 7. Sayed Ahmer et. al: bullying of medical students in Pakistan: A cross- sectional questionnaire survey, PLOS ONE, No 3, Vol (12), 2008.

8. Hasan Ali Alzahrani, H. : Bullying among medical students in a Saudi medical school. BMC Research Notes, No (5), 2012.

9. عبد الكريم الدويري، وفاء جرادات: البيئة الأسرية والاستقواء: دراسة لأثر البيئة

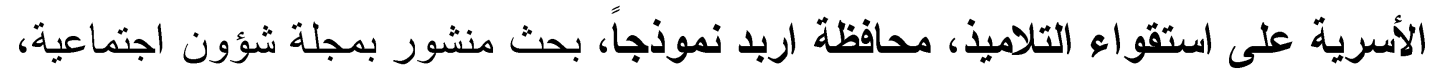

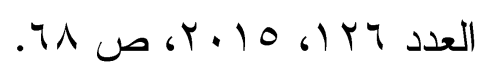

• . . . عدنان السبيعي: معاقون وليسوا عاجزين، بيروت- لبنان، دار الفكر المعاصر، . . . . I... L 11. عمر مصطفى الثوانرة وآخرون: الاستقواء والوقوع ضحية لدى طلبة ذوي

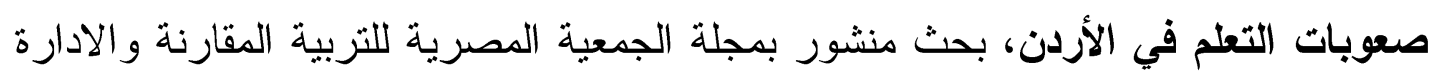

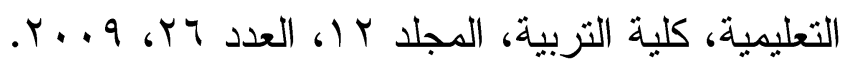
12. Rose Green et. al: Characteristics of Bullying Victims in School, Gov. Uk, National Center for Social Research, 2010. 13. Holomquist, Julie: Use Positive Strategies to Protect Your Child with a disability from bullying " Exceptional Parent, Vol 41, N 12, 2011. 
14. Pacers National Bulling center: Bullying and Harassment of students with disabilities, top 10 facts parents, educators and. students need to know", Paceer center, Inc, 2012.

10 - منى حسين محمد الدهان: سلوك التنمر لاى الطقل المعاق عقلياً، سمعياً وعلاقته

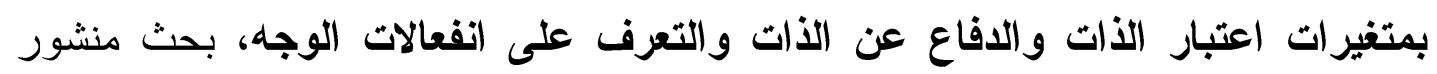
بمجلة دراسات الطفولة، جامعة عين شمس، معهد الدراسات العليا للطفولة، المجلد (1) (1)،

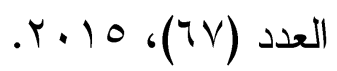

17

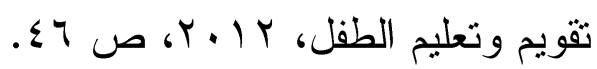

17. National Children Resource Center: Information pack bullying , Brend Every childhood Lasts a Lifetime, 2002.

18. Cranham. 1. \& carroll. A : Dynamics within the bullyL victim paradigm: A qualitative analysis, Educational Psychology in Practice, 19 (2), 2003.

19. Motoko Akiba,: Nature and Correlates of Ljime- Bullying in Japanese middle school, International Journal of Education Research, No 41, Vol 3, 2004.

20. Eric Storch, Carrie Masia: The relationship of peer victimization to social anxiety and loneliness in adolescent Females, USA, Journal of adolescent, 27(3), 2004

21. Delfabro, P., et. Al: Peer and teacher bullying, victimization of South Australian secondary school students: prevalence and psychosocial profiles, British Journal of Educational Psychology, 76 (1), 2006.

22. McKenny, S., et. al: Peer victimization and psychological adjustment, the experiences of Canadian immigrant youth, electronic Journal of Research in Educational psychology, 4(9), 2006.

بr - معاوية أبو غزال: الاستقواء وعلاقته بالثعور بالوحدة والدعم الاجتماعي، بحث

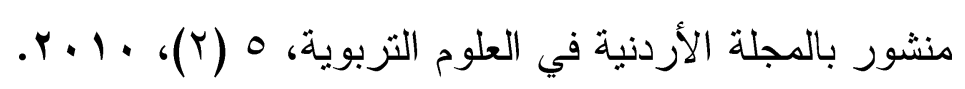

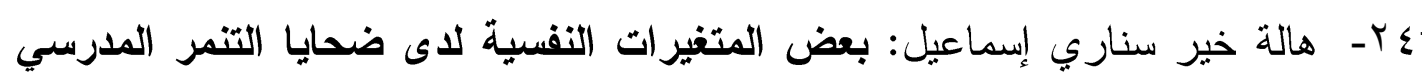

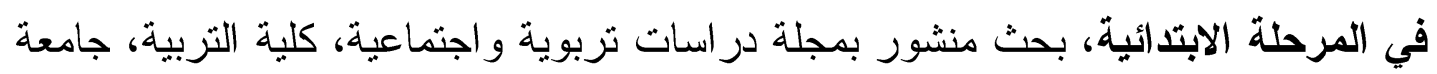

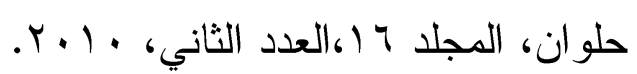

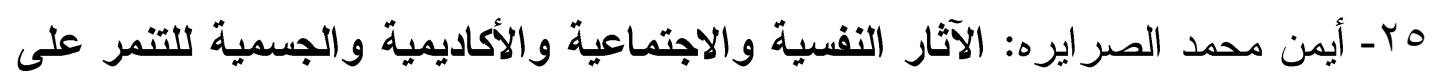

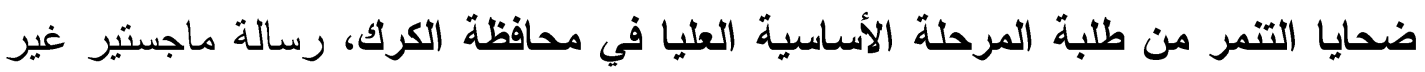

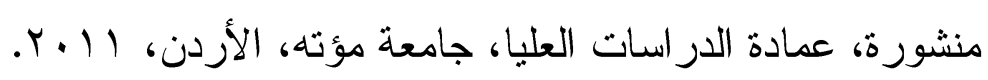




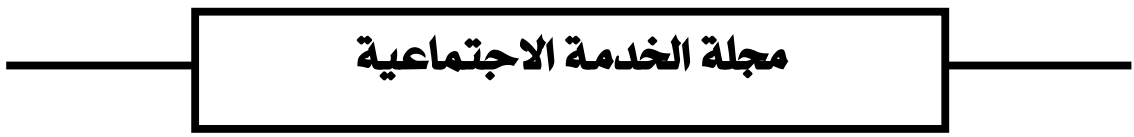

צr- سيد أحمد أحمد محمد البهاص: الأمن النفسي لاى التلاميذ المتنمرين وأقرانهم

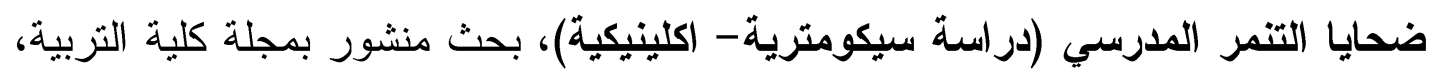

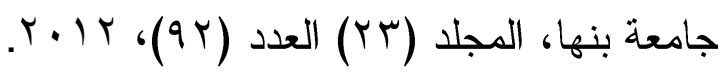

27. Brank, E. M., Hoetger, L.,\& Hazen, K. P.: Bullying, the Annual

Review of Law and Social Science, US, Annual Reviews, Vol 8, 2012. 28. Tritt, c., Duncan: The relationship between childhood bullying and young adult self- esteem and loneliness, Journal of Humanistic Education and Development, Vol 36, 2015.

29. Nana Sekol and David P. Farrington: Personal Characteristics of bullying victims in residential care for youth, Journal of Aggression and Peace Research, Vol 8, N2, 2016.

30. Demaray, M., Malecki, C: Perceptions of the frequency and importance of social by students classified as victims, bullies and bully victims, School Psychology Review, 32,2017.

31. Hana Khaled Al-Raqqad et. al: The Impact of School Bullying On Students Academic Achievement from Teachers Point of View, International Education Studies, Canadian Center of Science and Education, Vol 10, No 6, 2017.

32. Michele Elliott: Bullying: A practical guide to coping for schools, Exeter, Longman, Pearson Education; $3{ }^{\text {rd }}$ ed ,1991.

33. Claire L. Fox and Michael J. Boulton: the Social Skills Problems of Victims of bullying: Self, Peer and Teacher Perceptions, British Journal of Educational of Educational Psychology, (35), 2005. 34. Carol Hillsberg \& Helene Spak: youth adult literature as the centerpiece of an anti- bullying program in middle School, Middle School Journal, N (38), Vol 2,2006.

35. Jennifer S. Wong: No bullies Allowed, understanding peer victimization, the impacts on delinquency, and effectiveness of prevention programs, PHD in Public policy analysis at the Pardee RAND Graduate School, 2009.

بس. حنان أسعد خوج: التنمر المدرسي وعلاقته بالمهارات الاجتماعية لاى تلاميذ المرحلة الابتدائية بمدينة جده بالمملكة العربية السعودية، بحث منشور بمجلة العلوم التربوية

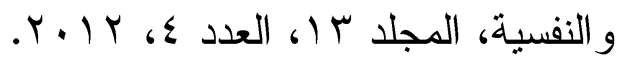

rV . . عبد الحليم محمود السيد و آخرون: علم النفس الاجنماعي المعاصر، القاهرة، إيتز الك

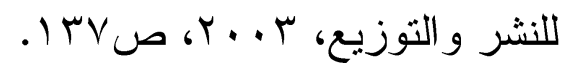




\section{مجلة الخدمة الاجتماعيةة}

مَ. ايمان فؤاد الكاشف، هشام ابر اهيم عبد اله: تنمية المهارات الاجتماعية للأطفال ذوي

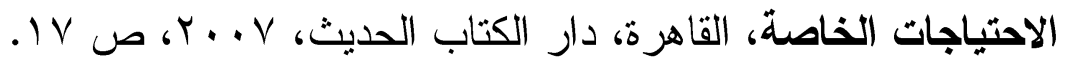
وس. طريف شوقي: المهارات الاجتماعية والاتصالية، دراسات وبحوث نفسية، القاهرة،

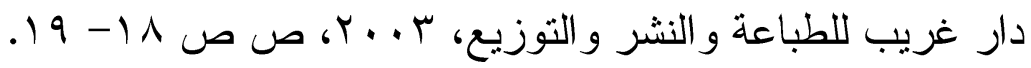
•ــ. ماهر أبو المعاطى على: مقدمة في الخدمة الاجتماعية مع نماذج تعليم وممارسة

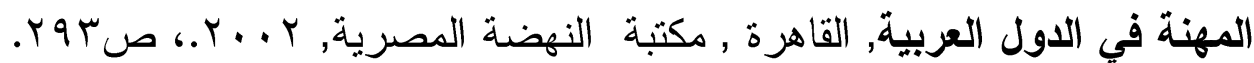
41. Kenneth, E. Ried: Social Work Practice with groups, A clinical perspective, USA, An international Thomson publishing company, inc, 1997, p 17.

42. Subtypes of victims and aggressors in children's peer groups Schwartz, D. :, Journal of Abnormal Child Psychology, (28), 2000. 43. Wong. D S.: School Bullying and Tackling Strategies in Hong Kong International, Journal of Offender Therapy and Comparative Criminology, 48 (5), 2004.

44. Kraiser, Sherry: the Safe Child Program, Retrieved October, 5, 2006 from . httpll : www.safechild. Org. bullies

○؛ ـ حسين حسن سليمان وآخرون: الممارسة العامة في الخدمة الاجتماعية مع الجماعة والمؤسسة والمجتمع، بيروت، مجد المؤسسة الجامعية للدر اسات و النشر و التوزيع، طاه

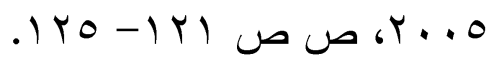

૫؟ . عادل محمود مصطفى: استخدام مدخل العلاج الجماعي في طريقة العمل مع الجماعات وتحقيق التوافق الاجتماعي للطقل الكفيف، بحث منشور بالمؤتمر العلمي السابع

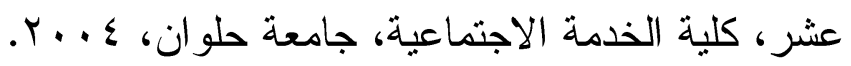
EV

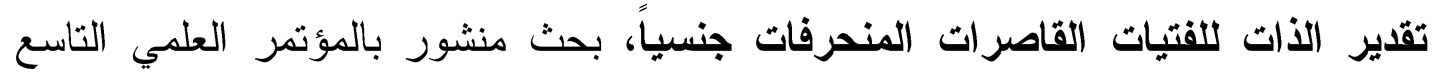

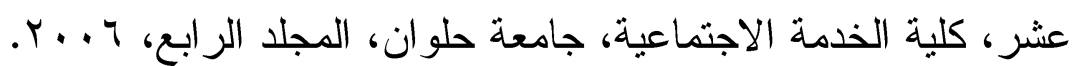
^؛ . . يسري بن سعيد حسانين: استخدام مدخل العلاج الجماعي في طريقة العمل مع الجماعات وتتمية قدرات الشباب الجامعي، بحث منشور بمجلة بحوث الشرق الأوسط في العلوم الانسانية و الدراسات الأدبية، جامعة عين شمس، مركز بحوث الشرق الأوسط، العدد .$r \cdot q \cdot(r 0)$

9ء. أحمد شفيق حسن مكاوي: استخدام مدخل العلاج الجماعي في الخدمة الاجتماعية وتحقيق الامج الاجتماعي للأطفال المعاقين بصرياً- دراسة تجريبية مطبقة على إحدى 
مدارس الامج بمحافظة الثرقية، بحث منشور بمجلة دراسات في الخدمة الاجتماعية

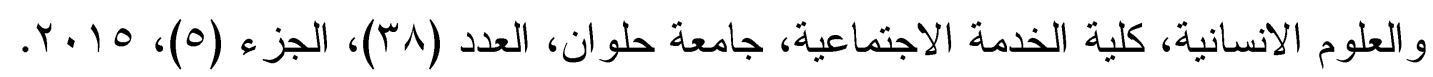
50. Ayesha Shaikh: Group Therapy for Improving Self-Esteem and Social Functioning of College Students with ADHD, Journal of College Student Psychotherapy, v32, n3 , 2018.

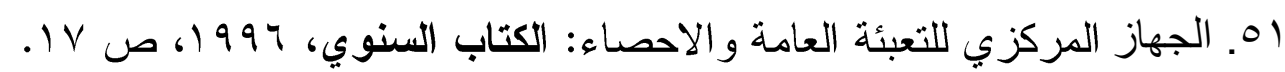
ror. عبد المنعم الحنفي: موسوعة علم النفس والتحليل النفسي، الطبعة الخامسة، القاهرة،

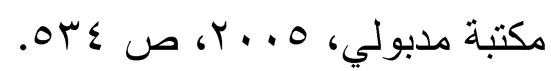
ro. حامد عبد السلام زهران: الصحة النفسية والعلاج النفسي، الطبعة الثالثة، القاهرة،

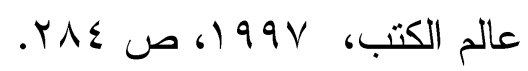
عه. أحمد شفيق السكري: قاموس الخدمة الاجتماعية والخدمات الاجتماعية، الاسكندرية،

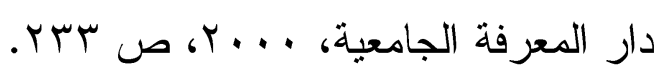

55. Harold Bernard et. al: Clinical Practice Guidelines for Group Psychotherapy, International Journal of group psychotherapy, 58 (4), 2008, p 456.

هo ـ رأفت عبد الرحمن محمد: رعاية الأسرة والطفولة من منظور الخدمة الاجتماعية،

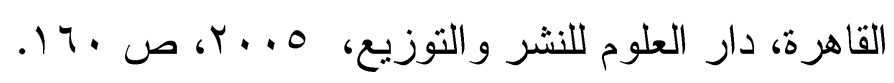
OV

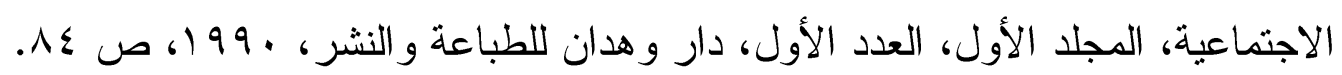

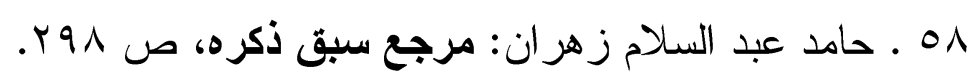
59. Gelard Corey: Theory and Practice of Counseling and Psychotherapy ,Australia, $9^{\text {th }}$ Ed, Brooks 1 Cole Cengage earning, , 2011, p p 273- 274.

60. Margarita Tartakovsky, M.S. : 5 Benefits of Group Therapy, Psych Central, 2018, in ttps://psychcentral.com/lib/5-benefits-of-grouptherapy

آT. كاميليا عبد الفتاح: سيكولوجية العلاج الجماعي للأطفال، القاهرة، دار قباء للطباعة

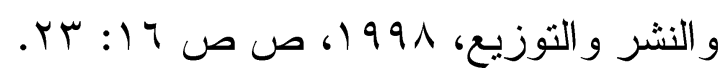

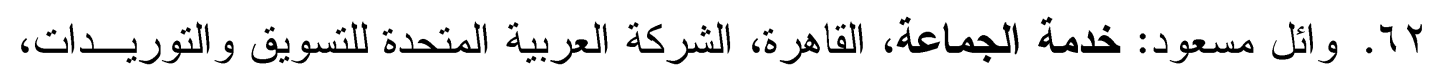

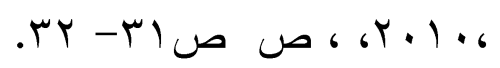

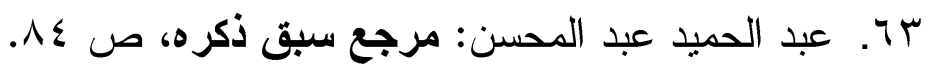




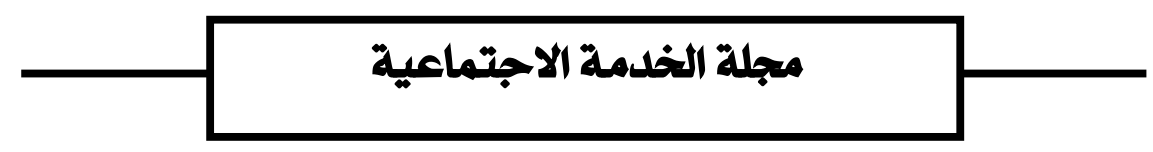

ع ا. مجمع اللغة العربية: المعجم الوجيز، القاهرة، الهيئة العامة لشئون المطابع الأميرية، ( D...

07 . . عادل محمد زيدان: السلوك التنظيمي للفرد والجماعة والمنظمة، القاهرة، مطابع

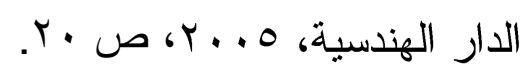

ד

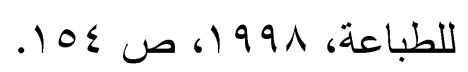
VI. أمل حسونه، منى أبو ناشي: الأكاء الوجداني، القاهرة، الدار العالمية للنشر و التوزيع،

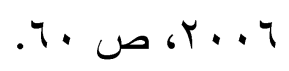

^1 ا. محمد بن أبى بكر بن عبد القادر الرازى: معجم مختار الصحاح، بيروت، مكتبة لبنان، .11990 .1990 9 7. إبر اهيم مدكور و آخرون: معجم العلوم الاجتمـاعية، القاهرة، الهيئة العامــة المصــرية

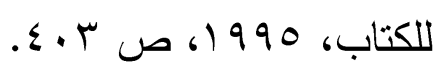

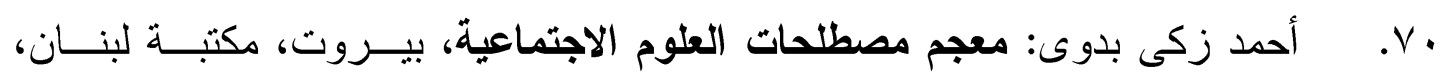
. (19

ال V ابر عوض سيد: التكنولوجيا والعلاقات الاجتماعية، الإســندرية، دار المعرفــة

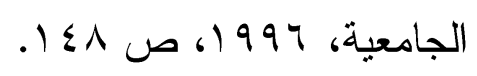

72.Don w stacks et. al: introduction to communication theory, New York, Harcourt, brace dovanovich publishers, 1993 p.10

73. Pamela trevithick: Social Work Skills, A practice Handbook, $2^{\text {nd }}$ ed, .London, open university press, 2005,p 116

ع V. جوده بن عبد العزيز البدر: أسس العلاقات العامة وتطبيقاتها، الرياض، دار العلوم

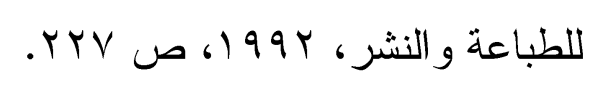

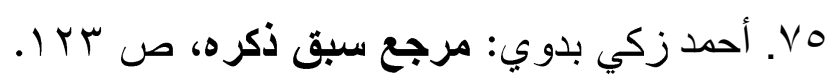
\V. أحمد محمد السنهوري: نحو نموذج للخدمة الاجتماعية لتنمية الوعي الاجتماعي في المجتمعات المحلية، بحث منشور بالمؤتمر العلمي العاشر، كلية الخدمة الاجتماعية، جامعة

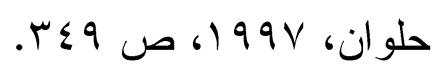
VV غريب للطباعة و النشر و التوزيع، . . . r، ص ص ب ror-ror.

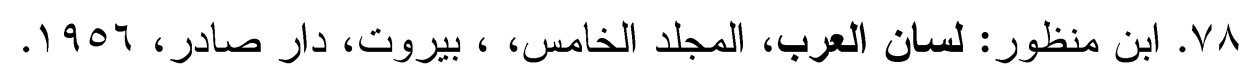

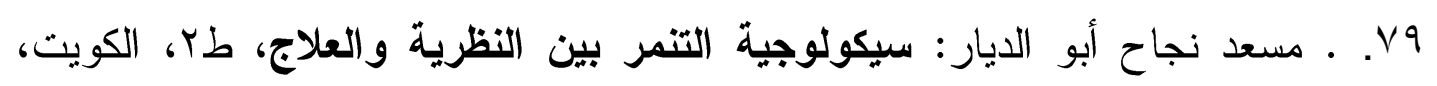

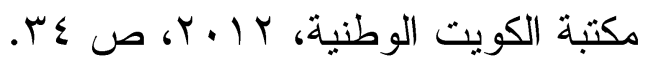




\section{مجلة الخدمة الاجتماعية}

80.. Frieden, T., et. al: Bullying- Victim Scale (BVS), National center for Injury Prevention and control, Atlanta, Georgia, 2010.

1 1 ـ طه عبد العظيم حسين، سلامه عبد العظيم حسين: استراتيجيات وبرامج مواجهة

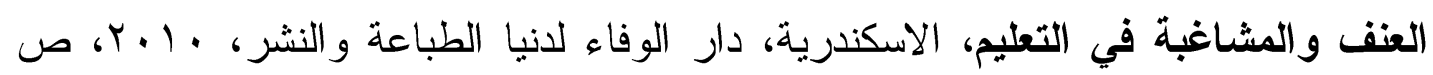
$r \cdot v$

82.. Allan L. Beane: Protect Your child from Bullying Expert advice to help you Recognize prevent, and stop Bullying Before your child Gets Hurt, $7^{\text {th }}$, Jossey Bass, 2008.

83. Ballard E. : Addressing the problem of Juvenile bullying, Office of Juvenile Justice and Delinquency Prevention, June Washington: the US Department of Justice, Office of Juvenile Justice, 1999, p 42. 84.Cambridge shire county council: Children who are bulling or being bullied, Cambridge shire county council: children and families, 2013.

1 ـ محمد حامد إمبابي: مدخل إلى الاعاقات البصرية، الرياض، مكتبة الرشد، ع ..ب، ص V

ד1. منى صبحي الحديدي: مقدمة في الاعاقة البصرية، عمان، الأردن، دار الفكر للطباعة

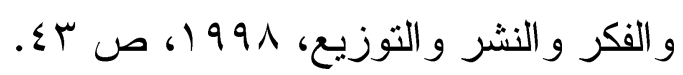

AV

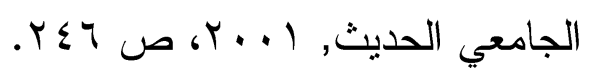

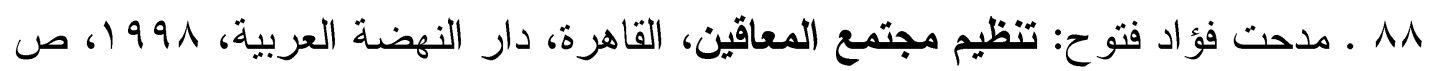
.$\leqslant 0$

19. عبد الرحمن سيد سليمان: سيكولوجية ذوى الحاجات الخاصة، ذوو الحاجات الخاصة

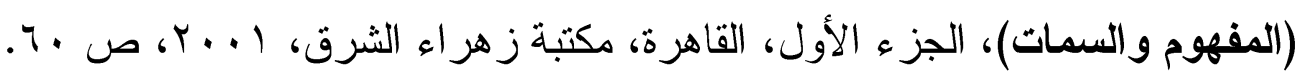
9. . زينب محمود شقير : سيكولوجية الفئات الخاصة والمعوقين (الخصائص - صعوبات

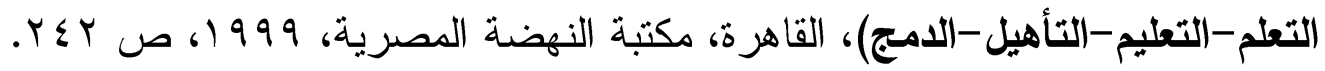
" خالد عبد الرازف السيد: سيكولوجية الأطفال ذوى الاحتياجات الخاصة، الإسكندرية،

$$
\begin{aligned}
& \text { مركز الإسكندرية للكتاب، r ...T، ص } 00 .
\end{aligned}
$$

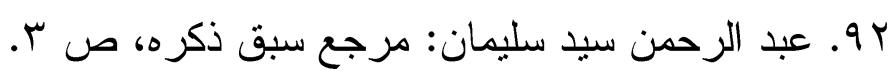

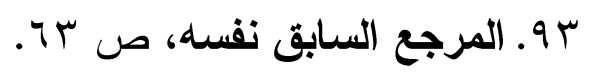

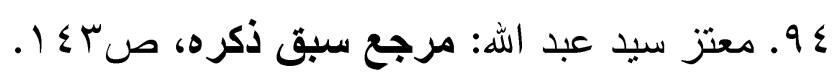

95. Carbone Vincent: Group Therapy, Theory and Practice for Children and Adults during multidisciplinary team, case reviews, Florida, Nova University, 2007. 


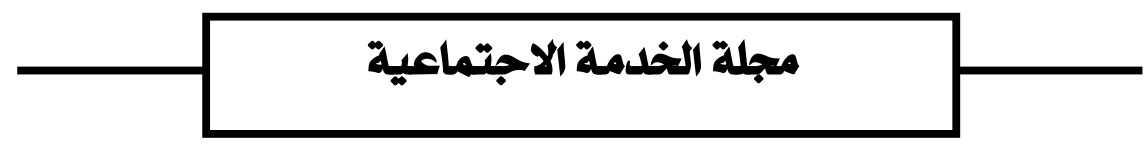

49. سلمى محمود جمعة: ديناميكية طريقة العمل مع الجماعات، الاسكندرية، دار المعرفة

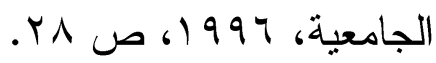

9V Vحمد حسن الثناوي وآخرون: التنشئة الاجتماعية للطفل، عمان، دار صفاء للنشر

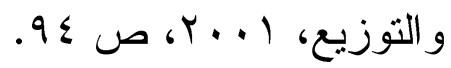

91. محمد بلال الجيوسي: أنت وأنا: مقدمة في مهارات التواصل الاساني، المملكة

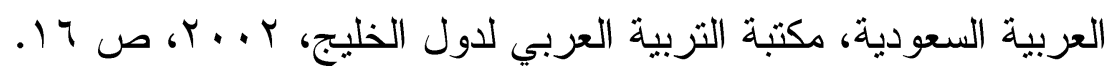

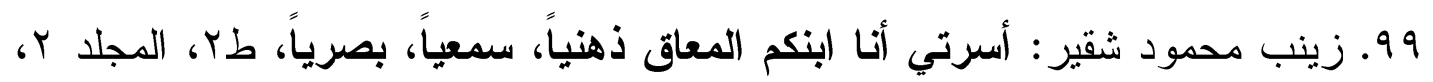

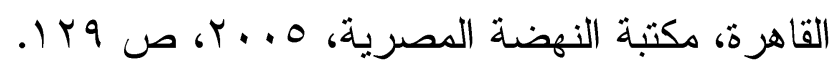

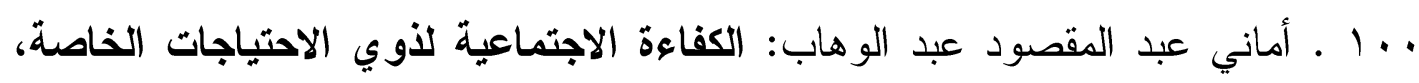

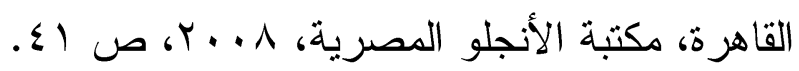

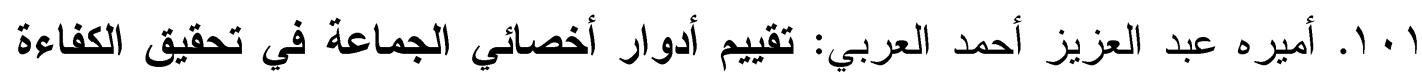
الاجتماعية للمكفوفين، بحث منشور بمجلة الخدمة الاجتماعية (الجمعية المصرية

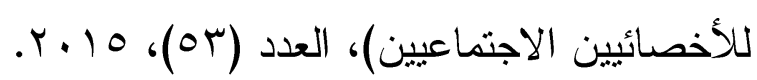
r.1

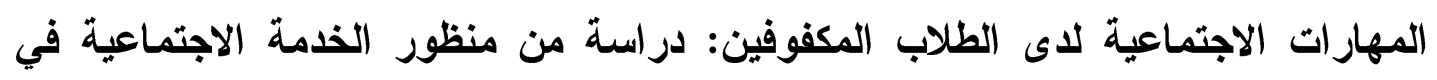

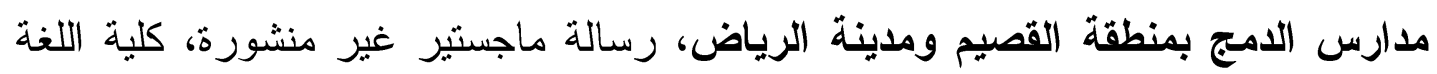

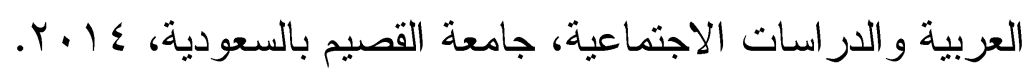

r.1. أماني عبد المقصود عبد الوهاب: مقياس تقدير المهارات الاجتماعية للأطفال،

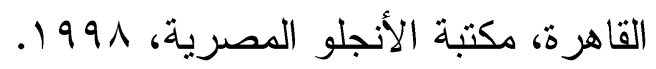

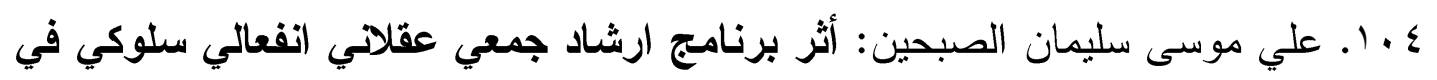

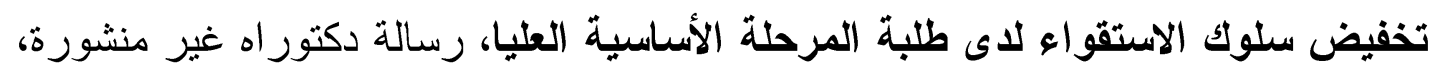

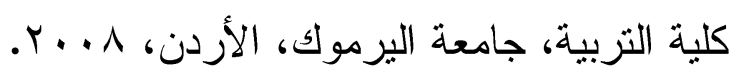
105. Ma, L, pheleps, E, Lener, J\& Lener, R: the development of academic competence among adolescents who bally and who are bullied, Journal of applied developmental psychology, No (30), Vol (5), pp 638- 649.

4.ا. لبنى عبد المجيد الحجاج، حسين الشرعة: علاقة التنمر بتمثل القيم الاجتماعية ويقظة

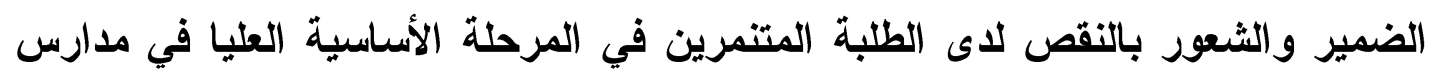

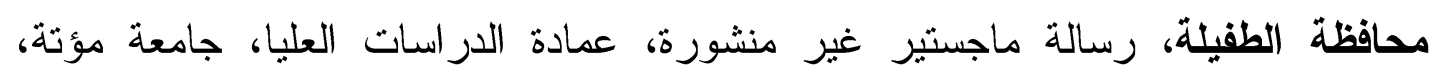

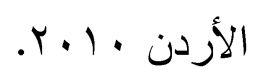




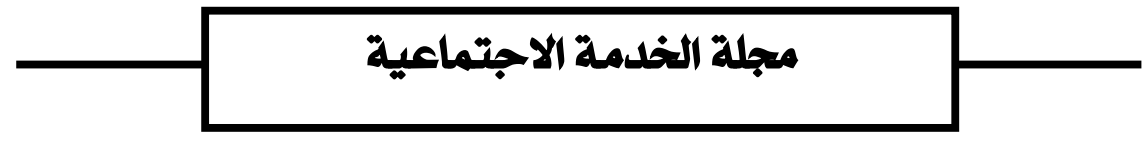

V • ا. مريم نز ال سليمان: السلوك الاستقو ائي لدى طلاب وطالبات جامعتي الجوف وحائل:

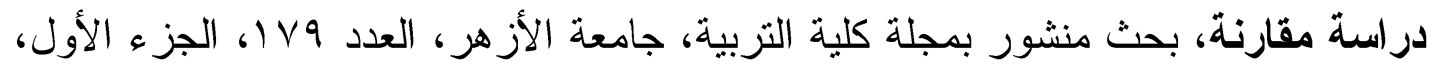
r. 11 


\section{مجلة الخدمة الاجتماعية]}

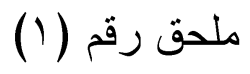

مقياس المهارات الاجتماعية لضحايا التنمر (الصورة النهائية)

أولاً: البيانات الأولية:

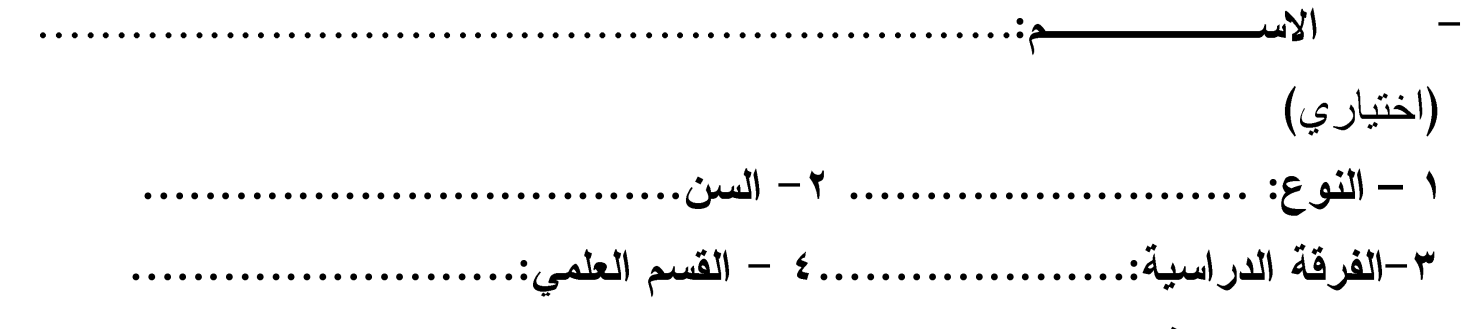

1-نوع التنمر الذي تتعرض له:.

\begin{tabular}{|c|c|c|c|c|}
\hline نادراً & أحيانًا & دائماً & الفقر ات & م \\
\hline & & & علاقاتي الاجتماعية بزملائي طيبة. & 1 \\
\hline & & & أستعين بزملائي في حالة مضايقتي من قبل البعض. & r \\
\hline & & & أهتم بر أي زملائي في التصرف الذي اتخذه مع أي متتمر . & r \\
\hline & & & اسأل زملائي عن أحو الهم وماذا يفعلون. & $\varepsilon$ \\
\hline & & & أقول "شكر ا للك" و أكون سعيداً عندما يفعل أحد زملائي شئ من أجلي. & 0 \\
\hline & & & ألجأ إلى المشرف الاجتماعي بالمركز اذا تعرضت للتنمر . & 7 \\
\hline & & & علاقاتي بالمشرفين داخل المركز جيدة. & v \\
\hline & & & علاقاتي بالمشرفين على الانشطة الجامعية جيدة. & $\wedge$ \\
\hline & & & أشعر بالقلق من الدخول في علاقات اجتماعية مع المشرفين. & 9 \\
\hline & & & أفقد قدرتي على التركيز عندما يناقشني أي مشرف. & 1. \\
\hline & & & أشعر بالخجل عند التعامل مع أي أحد غير زملائي. & 11 \\
\hline & & & أسعى دائماً إلى تكوين علاقات اجتماعية مع المتطو عين بالمركز . & ir \\
\hline & & & | أجد صعوبة في تكوين علاقات مع المتطو عين بالمركز . & r \\
\hline & & & لديّ أصدقاء كثيرين من المتطوعين بالمركز . & $1 \leqslant$ \\
\hline & & & أغضب بسر عة عندما يتحدث المنطو عين معي. & 10 \\
\hline & & & أستطيع التعبير عن مشاعري الايجابية للآخرين. & 17 \\
\hline & & & أستطيع التعبير عن مشاعري السلبية للآخرين. & iv \\
\hline & & & أنحدث مع زملائي اذا تعرضت للتتمر . & 11 \\
\hline & & & أتحدث مع الآخرين عما أُعانيه. & 19 \\
\hline & & & أرى أن الثكوى للمشرفين دليل على ضعف الشخصية. & r. \\
\hline
\end{tabular}




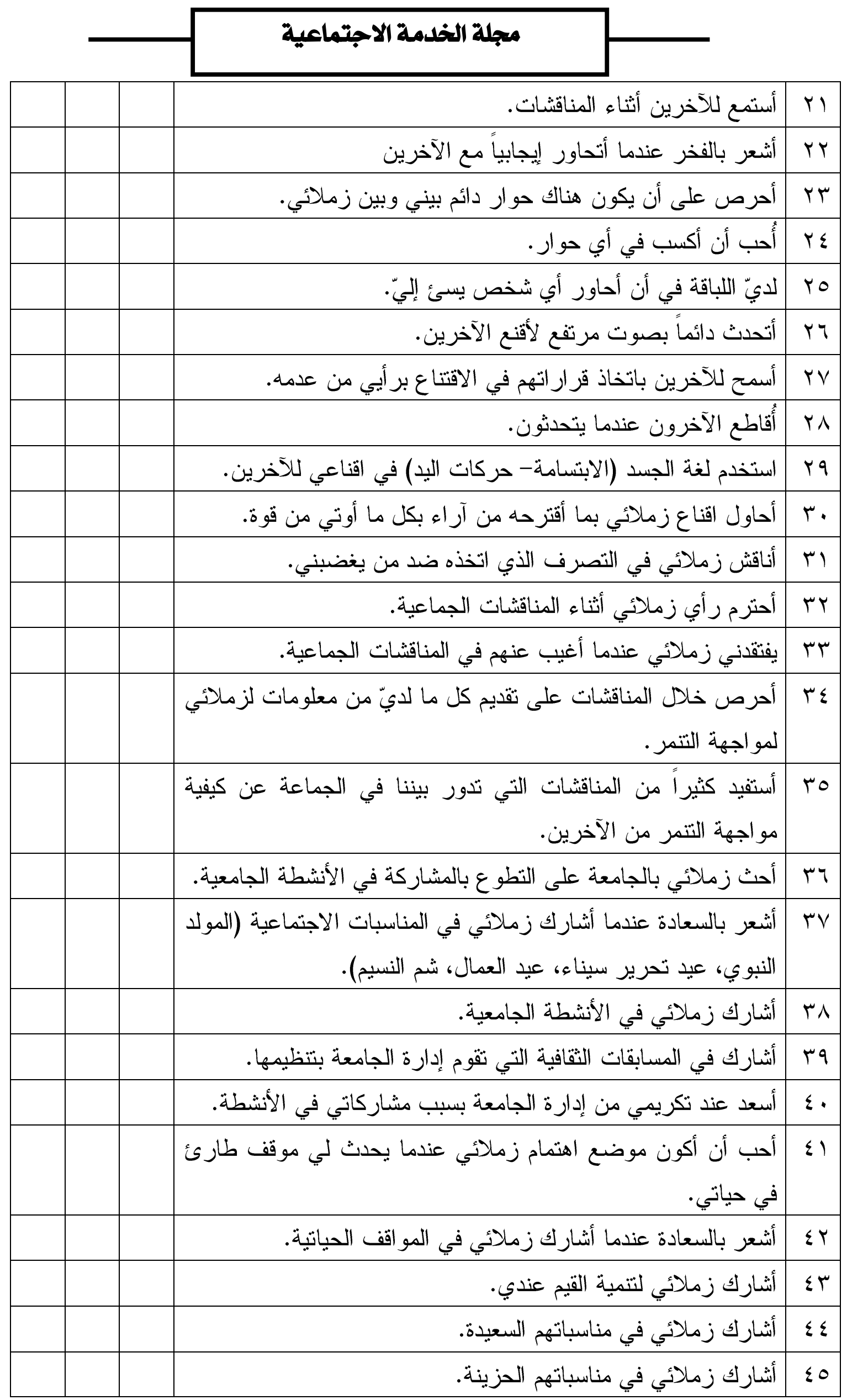




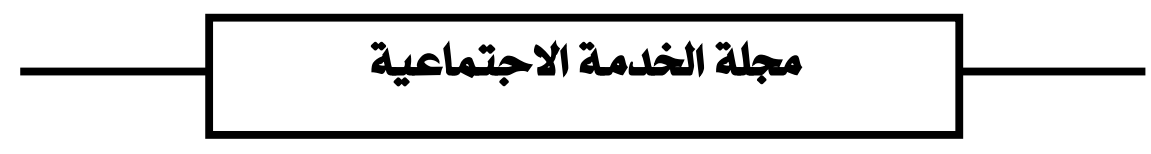

ملحق رقم (r)

مقتطفات من التقرير الدوري رقم (0) لاجتماع التجريبية وموضو عابه (مهارة تكوين

العلاقات الاجتماعية لضحايا التتمر )

أولاً: بيانات أولية عن الاجتماع: أولاع

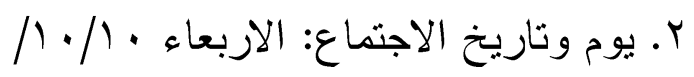

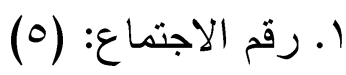

$. r+11$

r. مكان الاجتماع: قاعة الاجتماعات بالمركز الثقافي للمكفوفين بجامعة أسيوط.

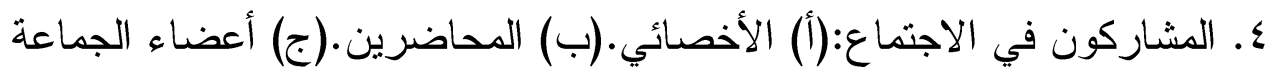

التجريبية.

4. العدد الكلي لأعضاء الجماعة: (·)

0. مدة الاجتماع: ساعة ونصف.

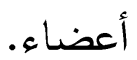

1. عدد الأعضاء الغائبين: لا

V. أل عدد الأعضاء الحاضرين: (• (1) أعضاء.

يوجد.

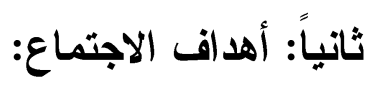

1. التصديق على محضر الجلسة السابقة.

r. تتفيذ ندوة بعنوان:" مهارة نكوين العلاقات الاجتماعية (المفهوم- الأهميةالأنو اع- خصائص العلاقات الاجتماعية الايجابية- دو افع العلاقات الاجتماعية).

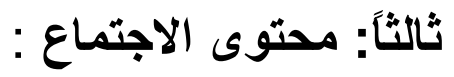

انه في تمام الساعة الثانية عشر ونصف مساءاً، حضر الأخصائي الاجتماعي ومعه

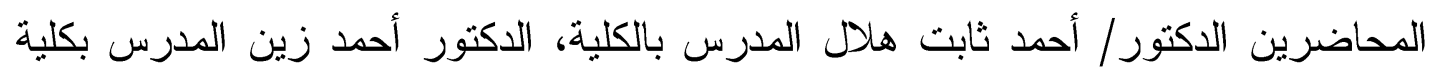

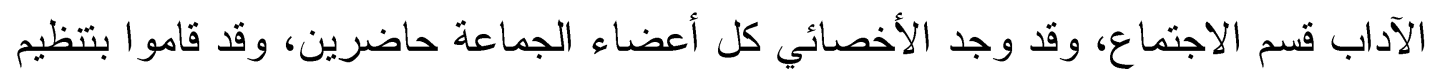

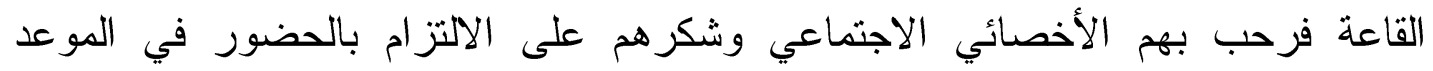

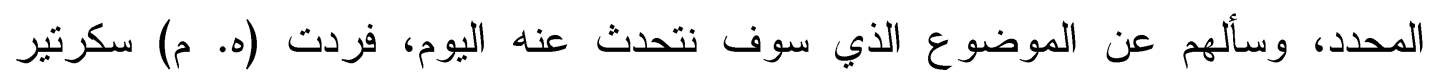

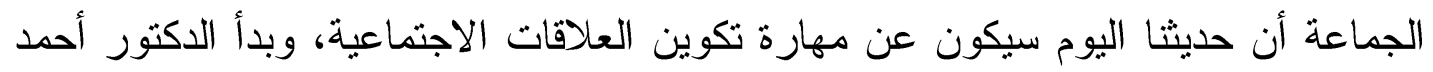

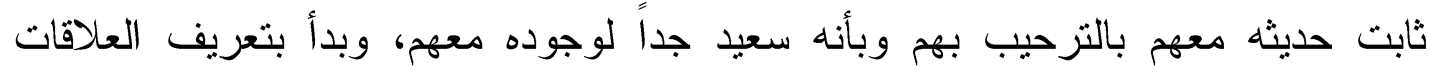

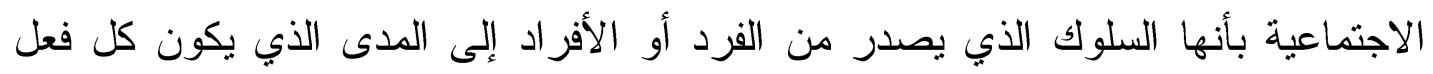

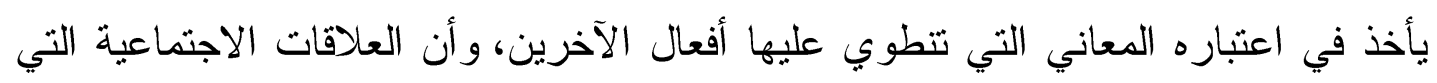

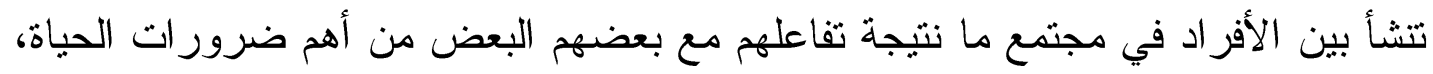

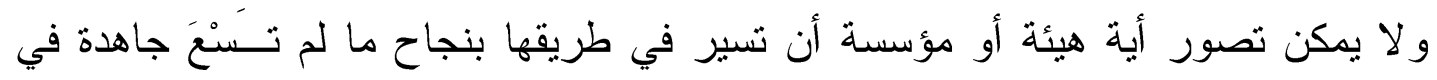

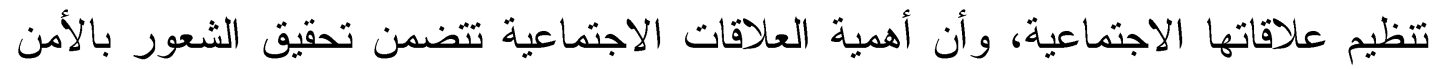




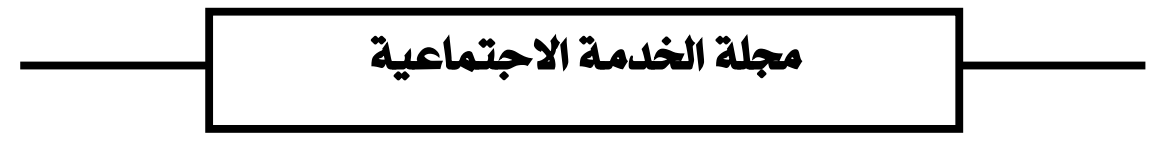

و الارتباط بالآخرين، وتوفر للإنسان الشعور بالسعادة والاطمئنان والأمان و الراحة النفسية،

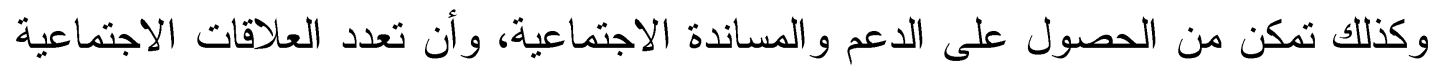

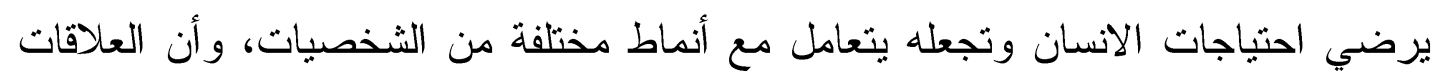
الاجتماعية لها نوعين وهي العلاقات الايجابية والسلبية، والعلاقات الايجابية تؤدي إلى التى

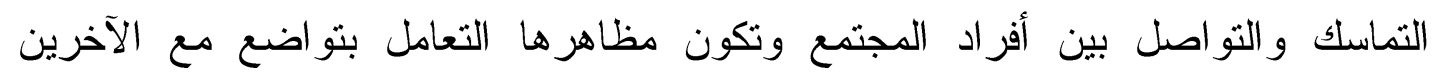

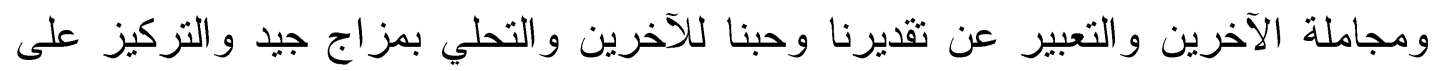

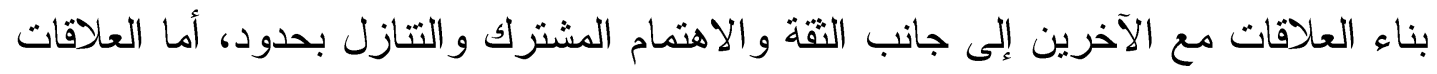

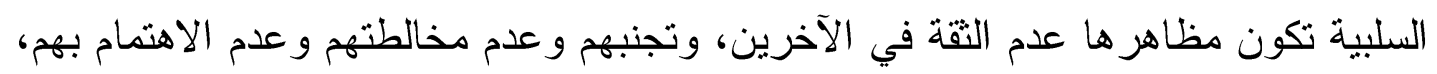

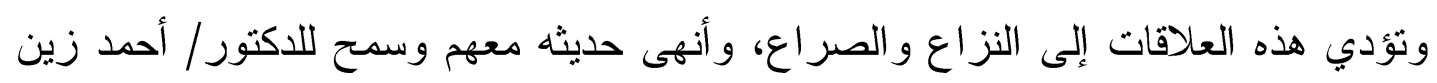

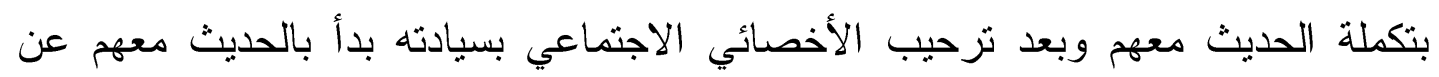

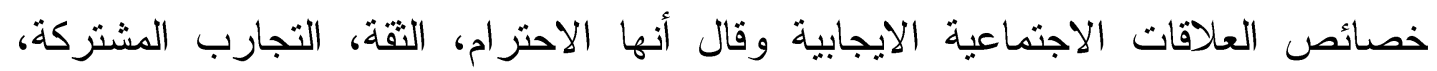

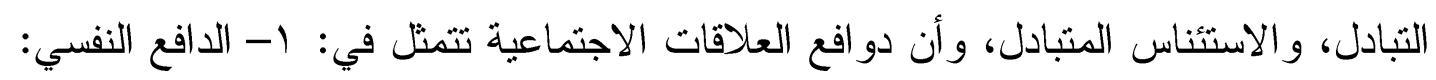
حيث إن العلاقات الاجتماعية تثبع مجموعة من الحاجات النفسية الهامة لدى الفرد مثل

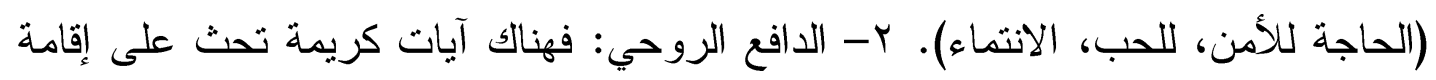

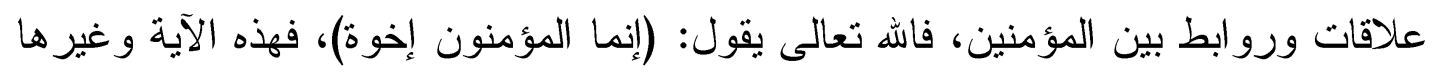

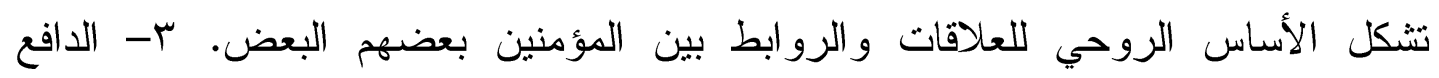

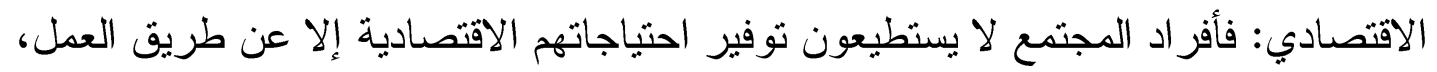

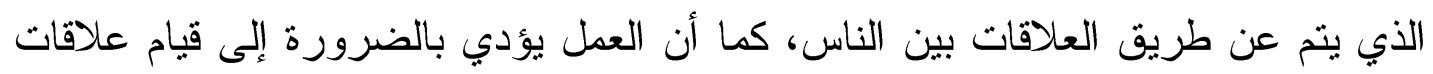

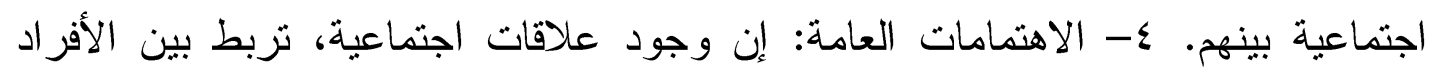

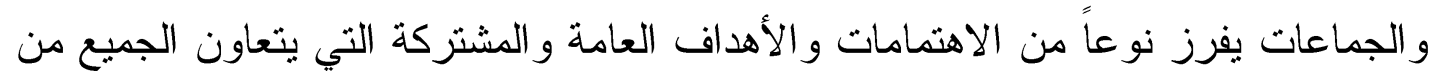

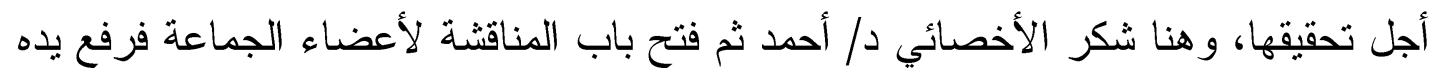
العضو (ح. ب) وقال ما أهمية مهارة تكوين العلاقات الاجتماعية في مو اجهة مشكلة التنمر ،

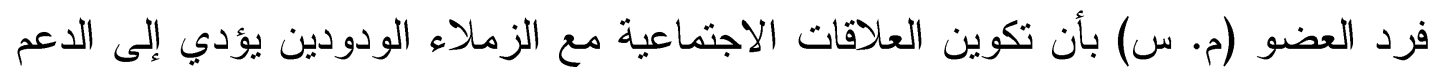

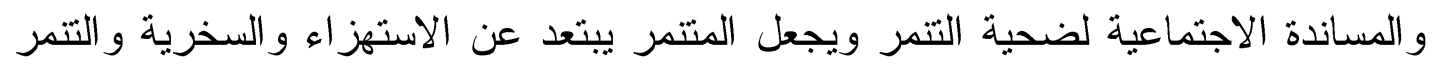

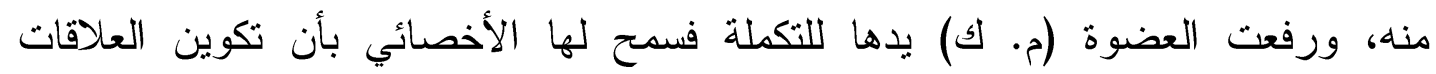
الاجتماعية مع المشرفين و المتطوعين بالمركز يفيد في التحدث معهم ومشاورتهم في أشكال

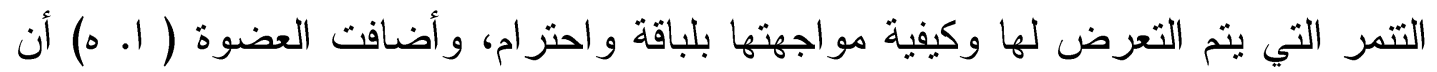

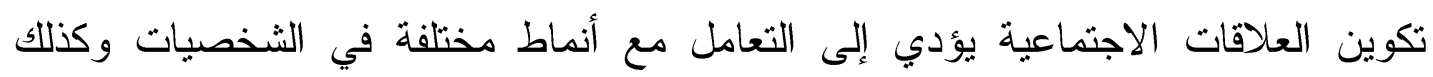




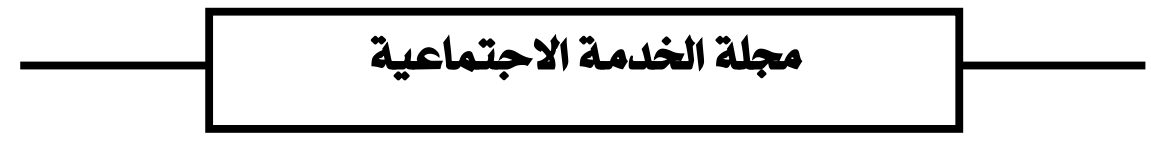

الثعور بالأمان و الراحة النفسية والتي تؤدي الى التقليل من حساسية الفرد لبعض الكلمات و الألفاظ من الآخرين

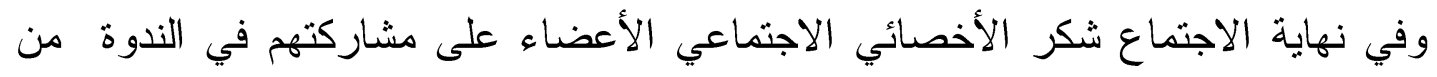

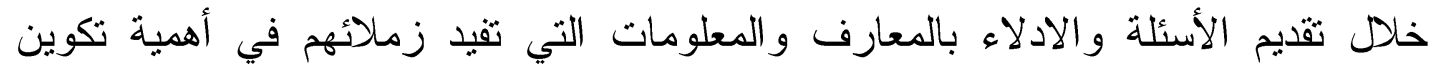
العلاقات الاجتماعية في مواجهة التتمر، ثم انتهى الاجتماع في تمام الساعة الثانية مساءاً، حيث قام الأخصائي بتحية أعضاء الجماعة على أمل اللقاء معهم في الاجتماع القادم.

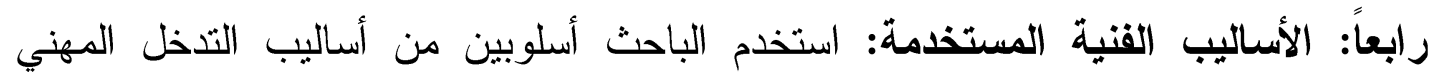
باستخدام مدخل العلاج الجماعي في طريقة خدمة الجماعة، ومنها أنه استخدم الندوة

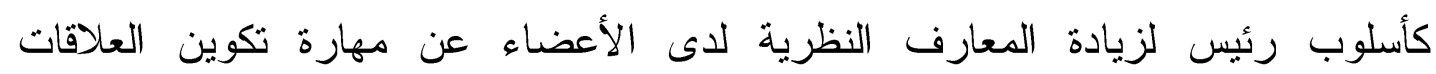

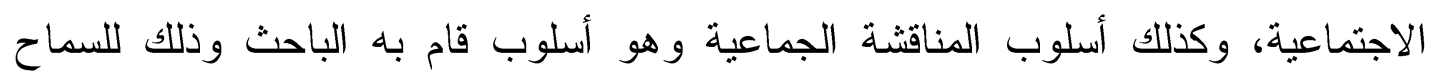
للأعضاء بإبداء آرائهم حول أهمية مهارة تكوين العلاقات الاجتماعية في مواجهة تتمر الآخرين ضدهم.

خامساً: دور الأخصائي الاجتماعي: اتضح من التقرير أن الأخصائي الاجتماعي قام بأدوار

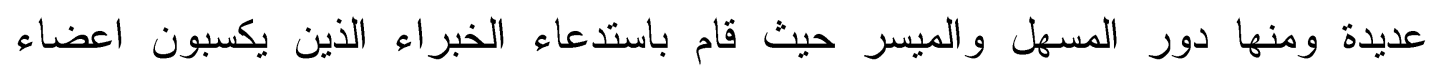
الجماعة المعارف و المعلومات عن مهارة تكوين العلاقات الاجتماعية، كما قام الأخصائي

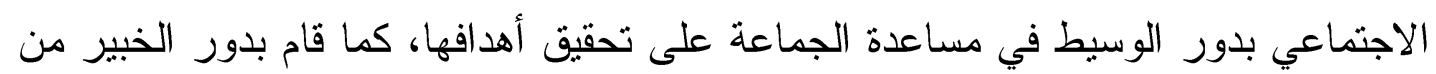

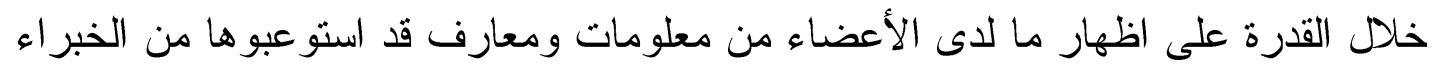

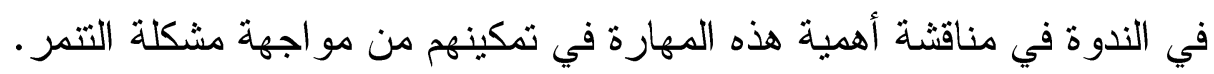

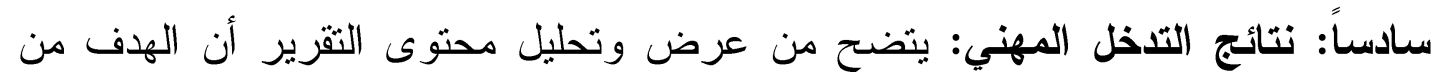

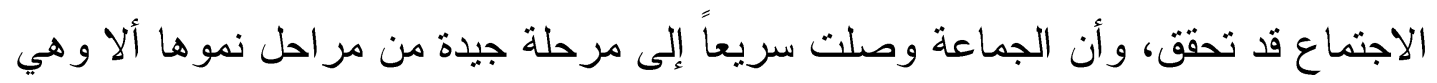

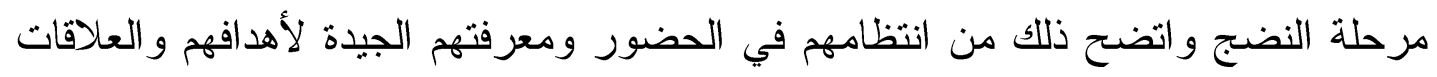

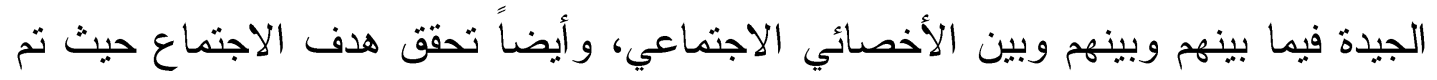

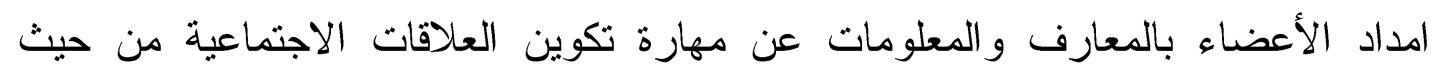

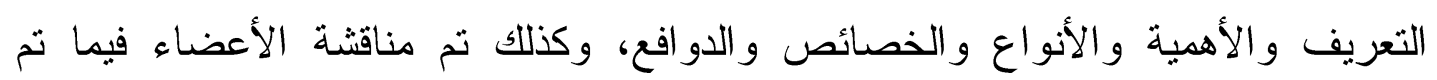

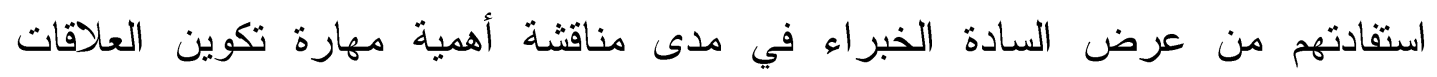

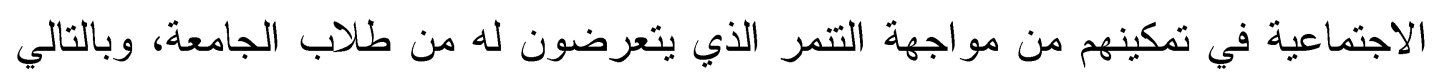
اتضح لنا أهمية استخدام مدخل العلاج الجماعي في تتمية مهارة تكوين العلاقات الاجتماعية

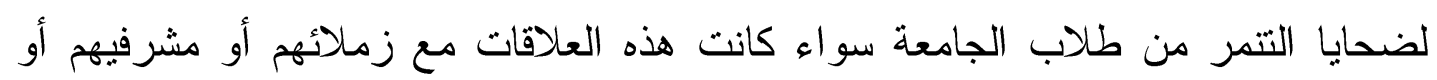

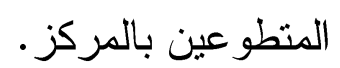

